$A K 0$
500
1122
1534

357
7551

De gevere Neteropeteryge

- Niedenzu - 


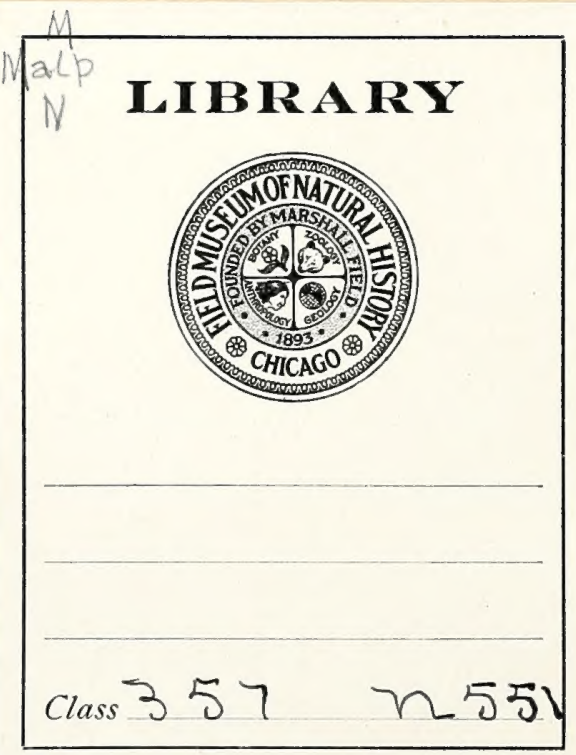




\section{Arbeiten}

ans

\section{dem botanischen Institut}

des

Kgl. Lyceum Hosianum

in

Braunsberg, Ostpreussen.

II.

De genere Heteropteryse.

Autore Franc. Niedenzu.

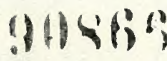

Braunsberg, 20 Juni 1903.

Heyne's Buchdruckerei (G. Riebensahm). 


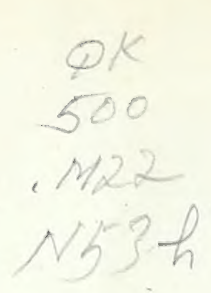

\section{Digitized by the Internet Archive in 2012 with funding from}

Field Museum of Natural History Library 


\title{
De genere Heteropteryge.
}

\author{
Autore F. Niedenzu.
}

Specimina perscrutatus herbariorum Berolinensis, Indiae occidentalis (olim $x$ Krug et Urban possessa), Bruxellensis, Candolleani, Christianiensis, Gottingensis, Grisebachiani, Hauniensis, Vindobonensis, Vratislaviensis necnon quaedam (et quidem pleraque indeterminata) Monacensis, denique a „Comm geogr. e geol, de S. Paulo" in illa civitate et a Dr. E. Hassler in Paraguaria collecta, de genere magno atque difficili Heteropteryge tractabo.

\section{C l a vis.}

I. Scpala erecta nune directa, nune leviter inclinata.

Subgenus I. Anosepalis.

1. Samarae nux \pm sphaeroidea s. obcordata et a lateribus compressa ex areola ventrali parva s. minima s. certe quidem minus lata nucis diametro. Bracteae bracteolaeque breves latiusculae \pm erectae \pm divergentes s. accumbentes.

A. Nucis endocarpium \pm in loculum prominens.

Sect. 1. Microprosopis.

a. Sepala dorso pleraque 士 carinata. Petala rosea s. rubra 士 carnoso-crassiuscula, limbo carinato medio concavo, margine integro s. subintegro saepe revoluto. Filamenta 3 antica inter se et a ceteris distantia et fere penitus discreta, cetera 7 usque $1 / 4$ inter se connata, 3 postica inter stylos 2 posticos introrsum curvata (antheris ipsorum 士 reclinatis), cetera 2 utrinque crassiora longiora suberecta. Inflorescentiae ramulique hispidulo-tomentosi \&. velutini (exc. H. sessilifolia). Bracteae bracteolaeque basi lata semiamplexicaules pleraequae crassae.

Series a. Rhodopetalis.

$\alpha$. Styli \pm crassi teretes s. triangulares apice obtuso s. subobliquo triangu lari subcapitellato linea antico-transversali stigmatifero divergentes, 2 postici inter se magis approximati sigmoidei antico suberecto s. simpliciter paulo. curvato \pm longiores. Samarae nux sphaeroidea. Pedunculi pedicellique 士 crassiusculi. Bracteae bracteolaeque apice rotundatae. Subseries $\alpha$. Bradystigma. $\alpha^{\prime}$. Samarae nux latere utroque $1-3$ alulis s. verrucarum seriebus transversis (i. e. areolae interioris margini paralellis) instructa.

Grex $\alpha^{\prime}$. Pterygopleura. 
1. Petala dorso tantum carinata, carina rix usque $1 / 3 \mathrm{~mm}$ (in $8 . H$. rufula usque $1 \mathrm{~mm}$ ) prominente.

1. Pedunculi floriferi $1 / 2-2(-4) \mathrm{mm}$ infra apicem (s. in eadem specie etiam apice) bibracteolati Filamenta crassiuscula; antherae oroideae, loculis t'directis et inter se parallelis faciei internae connectiri oblongo-ovoidei nigri affixis parumque ipsum ex cedentibus.

$†$ Folia subtus glandulis 2-6 impresso-sessilibus instructa, une semper, nune diutius quidem pilosa.

o Liana 1--3-metralis (e Pringle), ramulis ferrugineo-velutinis teretibus divaricatis, sicut rami glabrati fusci lenticellis creberrimis albidis tuberculati, internodiis usque $1^{1 / 3} \mathrm{dm}$ longis et $1 / 2 \mathrm{~cm}$ diametro. Folia e basi obtusa s. subcordata interdum inaequali nune ovata nune obovata nune ovalia, apice obtusa s. retusa et mucronata, usque $7 \mathrm{~cm}$ longa et $4 \mathrm{~cm}$ lata, margine revoluta, chartacea, novella utrinque et adulta subtus quidem lutescenti-tomentosa, supra nervis \pm impressis saepius rugosa, subtus prominentibus reticulata et glavdulis $2-6$ nigris supra basim instructa, petiolo $3-9 \mathrm{~mm}$ longo; floralia \pm minuta 2-glandulifera, glandulis breviter obconico-stipatis. Umbellae 4--6-florae ferrugineo-tomentosae dispositae in paniculas (saepe geminatim s. ternatim) axillares terminalesque digestas in paniculas foliosas ramos terminantes, umbellarum pedunculis $3 \mathrm{~mm}$, floriferis canaliculatis $4-6 \mathrm{~mm}$, pedicellis $2-4 \mathrm{~mm}$, Lracteis bracteolisque ovatis $11 / 2-2 \mathrm{~mm}$ longis. Flores 10-12 mm diametro. Sepala carinata glandulas $8(6-10)$ ovales $1-1 \frac{1}{2} \mathrm{~mm}$ longas $1 \frac{1}{2}-2 \mathrm{~mm}$ superantia. Petalorum limbus e basi sagittata ovatus s. obovatus $4 \mathrm{~mm}$, quinti margine glanduloso-ciliatus $3 \mathrm{~mm}$, unguis reflexus $2 \mathrm{~mm}$, quinti erectus crassior $3 \mathrm{~mm}$ longus. Pollen $\pm 30 \mu$ diametro. Stylorum apex a dorso ventreque compressus. Samarae nux latere utroque $1-3$ alulis dilaceratis instructa, ala dorsalis obliquoobovata, margine superiore magis currato basique in appendiculam $4 \mathrm{~mm}$ longam et vix $1 \mathrm{~mm}$ altam ascendente, 2-2\% $\mathrm{cm}$ longa, $1-1^{1 / 3} \mathrm{~cm}$ lata. - Mexicum; Anerica centralis; Columbia.

1. H. Beecheyana Juss. rar. 1. typica Ndz.: Petiolo eglanduloso.

f. 1. tomentosa (Schlechtd.) Ndz. - Banisteria tomentosa Schlechtd.: Foliis adultis supra pube t- densa hispidulis rugosis. - Mexicum (Schiede 314: pr. Laguna [Ban. tomentosa Schlechtd. in Linn. X. 244], 446: Hacienda de la Laguna et Mapilque, 656 et 660 [leg. Bar. Gros], 664: e reg. cal., et 666: Atlacomulco; Andrieux 493: inter Huanapan et Oaxaca; Ehrenberg; Galeotti s. n.: Pinotepa, 4334: Juchatengo, Oaxaca, $3500^{\circ}, 4335$ : Mirador in savannis, Vera Cruz, et 4357: Oaxaca, 3000'; Liebmann [VIII. 1841]: Mirador; Sartorius; Cumingo 1859: Oaxaca; Ervendberg 209: Wartenberg prope Tantoyuca, prov. Huasteca; U h de 714 et 1150; Bourgeau 1484 et 1882: Cordova; Kerber 125 ["Tlatlauque“]: Atoyac; Wawra 492; Pringle 3909: in calcareis, Las Canovas, San Luis Potosi; Palmer 437 [a. 1894/5]: Acapulco); Yucatan (Gaumer 892); Guatemala (Warszewiez 9; Heyde et Lux [Smith 3705]: Jumaytepeque, dep. S. Rosa, 6000'; Seler 3071: Las Palmas, et 3216: Chacula, dep. Huehuetenango, in silvis); Honduras (Oersted 30 [Jan. 1848]: pror. Segoria; Thieme [Smith 5i66] [f. sepalis eglandulosis]: San Pedro Sula, dep. S. Barbara, 1200'); Columbia (Schlim 265̃: Aguachica, prov. Ocanna, 800'; Karsten: Llano de S. Martin p. p.).

f. 2. glabriuscula Ndz.: Foliis adultis supra glabratis s. subglabratis et laeviusculis. - Mexicum (Bourgeau 3112: Orizaba); Guatemala (Heyde et Lux: dep. S. Rosa [Smith 4456: Rio Pinula, 40(10', et 6081: Las Viñas, 2000']); Columbia (Triana: Cagueza, prov. Bogota, $1700 \mathrm{~m}$ [H. Ioniceraefolia Pl. et Tr.]); Aequatoria (Eggers 14736: ins. Puna!. 
f. 3. subleiococca Ndz.: Folis adultis supra glabratis laevibus; samarae nuce hateribus nunc laeri, nune (in eodem specimine) alula unica brevi minore instructa. Mexicum (Kerber 320 [„,Matapiojo"] [f. foliis supra glabratis]: Frijol, Jalisco).

var. $\beta$. quatemalensis Ndz.: Varietati $\alpha$ similis, attamen omnibus partibus multo crassior et ramulis complanatis petiolisque apice saepissime glandulis breviter stipitatis $1 \mathrm{~s}$. etiam 2 diversa, foliis subtus tomentosis late ovatis s. subrotundis usque $9(-10) \mathrm{cm}$ longis et $6 \% \mathrm{~cm}$ latis. - Guatemala (Seler 2481: Llano grande, dep. Salama, in nemoribus, et 3092: Pueblo viejo Otuen Santo, distr. Nenton, dep. Huehuetenango, $1300 \mathrm{~m}$, in nemoribus collium calcareorum).

oo Ramuli ferrugineo-s. incano-velutini ad nodos compressi ceterumque teretes, mox, sicut rami, glabrati fusco-violacei lenticellisque albidis notati divaricati, internodiis usque $5 \mathrm{~cm}$ longis et $3 \mathrm{~mm}$ diametro. Folia e basi obtusa nunc ovalia et apice obtuso mucronulata, nune ovato-oblonga acuta usque $6 \mathrm{~cm}$ longa et $3 \frac{1}{\mathrm{c}} \mathrm{cm}$ lata, utrinque novella \pm incano-tomentosa, adulta demum glabrata, membranacea s. chartacea, nervis majoribus supra parum impressis subtus prominentibus, margine revoluto subtus glandulis $2 \mathrm{~s}$. compluribus et nervis et margini insidentibus orbicularibus, petiolo subglabrato $4-6 \mathrm{~mm}$ longo; floralia summa usque $2 \mathrm{~mm}$ diminuta, petiolo sublongiore, subtus glandulis 2 magnis orbicularibus brevissime stipitatis instructa. Umbellae 4-florae (additis gemmis abortivis et quibusdam, in apice et 2 ard axillas foliolorum $\pm 3 \mathrm{~mm}$ infra umbellas) $\mathrm{s}$. corymbi 5- -6-flori (saepius gemini ternive) dispositi in paniculas (saepius geminas ad axillas foliolorum) digestas in paniculam amplissimam ramos terminantem, umbellarum peduncu lis $1 / 3-3 / 4 \mathrm{~cm}$, floriferis bibracteolatis $1 / 2-1^{1 / 1} \mathrm{~mm}$ infra apicem $3-4 \mathrm{~mm}$, pedicellis $\pm 3 \mathrm{~mm}$, bracteis lanceolatis ovatisve $1^{1 / 2}-2^{1 / 2} \mathrm{~mm}$, bracteolis late ovatis $\mathrm{l}-1^{1 / 3} \mathrm{~mm}$ longis. Flores $1 \frac{1}{4} \mathrm{~cm}$ diametro. Sepala ovata \pm carinata glandulas 8 ovales $1-1^{1 / 2} \mathrm{~mm}$ longas $1-1^{1 / 4} \mathrm{~mm}$ superantia. Petalorum limbus e basi sagittatim emarginata ovatus \pm alatocarinatus $3-4 \mathrm{~mm}$, unguis \pm crassus reflexus (quinti erectus) $1 \frac{1}{2}-2 \mathrm{~mm}$ longus. Pollen $27-33 \mu$ diametro. Stylorum (praesertim antici) apex dorso unciformi-dilatatus. Samarae ferrugineo-pilosae: nux latere utroque instructa alula unica partita in lacinulas $2-3$ obtusiusculas $2-3 \mathrm{~mm}$ altas (superiore multo majore); ala dorsalis oblique obovata, margine superiore magis curvato et basi in appendiculam obtusissimam $\pm 5 \mathrm{~mm}$ longam et vix $1 \frac{1}{2}-2 \mathrm{~mm}$ altam producto, usque $1^{3 / 4} \mathrm{~cm}$ longa et $11 \mathrm{~mm}$ lata. - Venezuela (Bredemeyer: Caracas; Lansberge; Fendler 1903: prope coloniam Tovar; Karsten: Llano d. S. Martin p. p.).

2. H. brachiata (L.) H. B. K. ? ${ }^{1}$ )

† Folia permox etiam subtus glabrata et ad nervos s. basi marginis glandulis 2 longe stipitatis instructa.

o Ramuli compressi pube adpressa luteo-rufa subsericei divaricati, sicut rami teretes glabrati grisei lenticellisque crebris albidis tuberculati, internodiis $1-\mathbf{1} \mathrm{cm}$ longis usque $4 \mathrm{~mm}$ diametro. Folia e basi obtusa s. rotundata latissime ovata s. suborbicularia apice obtuso s. emarginato apiculata usque $7 \mathrm{~cm}$ longa et $5 \mathrm{~cm}$ lata, utrinque jam novella parce puberula, adulta glabrata, subchartaceo-membranacea, supra laevia, subtus nervis medio primariisque (utrinque $4-6$ ) prominentibus et glandulis 2 magnis obconico-stipitatis plerumque medio inter costam marginemque planum nervis primariis impositis (raro abortis),

1) Descriptio H. brachiatae (L) H. B. K. - specimine authentico mihi inviso - haec est: ,H, foliis subovatis obtusis, ramis brachiatis, ramis floriferis paniculatis. $b-$ in America calid." 
petiolo glabro gracili supra canaliculato ${ }^{1 / 2}-1 \mathrm{~cm}$ longo basi bistipulato stipulis brevissimis; floralia sensim minuta orbicularia apice emarginata 2 usque $1 / 2 \mathrm{~cm}$ diametro. Unbellae subsericeae 3--6-florae in paniculas folifferas duplo compositas digestae, pedunculis $2-3 \mathrm{~mm}$ infra apicem bibracteoliferis $5-6 \mathrm{~mm}$, pedicellis $3-4 \mathrm{~mm}$, bracteis et accumbentibus bracteolis obtuso-ovatis $1^{1 / 2}-1^{1 / 4} \mathrm{~mm}$ longis. Flores $1^{1 / 3} \mathrm{~cm}$ diametro. Sepala ovato-acuta glandulas 8 obovato-oblongas $1^{1 / 2}-2^{1 / 2} \mathrm{~mm}$ longas $1-2 \mathrm{~mm}$ superantia. Petala reflexa, limbo e basi acuta s. sagittata obovato-cymbiformi $4-5 \mathrm{~mm}$, ungui $1-1^{1 / 2} \mathrm{~mm}$ longo. Samarae sericeae (siccae) alutaceae oblique ascendentes: nux $5-7 \mathrm{~mm}$ diametro latere utroque serie verrucarum aculeiformium vix usque $1 \mathrm{~mm}$ altarum instructa: ala oblique ohovata usque $3 \mathrm{~cm}$ longa et $1 \frac{1}{2} \mathrm{~cm}$ lata, margine inferiore minus, superiore magis curvato et basi in appendiculam rotundatam ultra $1 / 2 \mathrm{~cm}$ longam et vix $1^{1 / 2} \mathrm{~mm}$ altam producto. - Mexicum (Allaman a. 1832, Andrieux 492: Totolapa in ditione Oaxacana).

oo Folia basi marginis glandulifera.

3. H. cotinifolia Juss.

$\square$ Ramuli subdiraricati lutescenti-velutini compressi, rami (nodis exceptis) demum teretes mox glabrati incani lenticellis orbicularibus creberrimis tuberculati, internodiis usque $4 \mathrm{~cm}$ longis et $4 \mathrm{~mm}$ diametro. Folia ovata usque $7 \mathrm{~cm}$ longa et $4 \mathrm{~cm}$ lata, ,basi subacuta, apice obtusa vel nonnunquam subemarginata mucronulata “2), chartacea, utrinque novella incano-sericea mox glabrata glaucaque, nervis lutescentibus medio primariisque subtus. prominentibus, supra laevia, nunc nervis lateralibus subtus, nunc margine revoluto utrinque glandulam scyphiformem obconico-stipitatam usque $1^{1 / 2} \mathrm{~mm}$ altam gerante, petiolo demum glabrato ${ }^{1 / 2}-1 \mathrm{~cm}$ longo; floralia usque $1 / 2 \mathrm{~cm}$ diminuta, petiolo paulo breviore, glandulis stipitatis. Umbellae 4--2-florae in paniculas digestae lutescenti-velutinas (pedunculo incl.) usque $7 \mathrm{~cm}$ longas axillares (saepius geminas) terminalesque et dispositas ad apicem ramorum in paniculam amplissimam foliosam, umbellarum pedunculo. $3-8 \mathrm{~mm}$ longo apice nodoso et $1-3 \mathrm{~mm}$ infra apicem 2 foliola minima 2-glandulifera. gerente, floriferis $\pm 1 \mathrm{~mm}$ infra apicem bibracteolatis $\pm 3 \mathrm{~mm}$, pedicellis $4 \mathrm{~mm}$, bracteis bracteolisque ovato-acutis $1^{1 / 4}-1^{1 / 2} \mathrm{~mm}$ longis. Flores non suppetunt. Sepala ovato-acuta glandulas 8 ovales $1-1^{1 / 2} \mathrm{~mm}$ longas $1-1^{1 / 2} \mathrm{~mm}$ superantia. Stylorum apex dorso. angulatus. Samarae nux latere utroque nunc alulis compluribus dilaceratis usque $4 \mathrm{~mm}$ altis (laciniis \pm aculeiformibus), nunc vix aculeis humilibus rugisve instructa, alis dorsalibus ascendentibus inter se angulum \pm rectum efformantibus usque $3^{1 / 3} \mathrm{~cm}$ longis et $16 \mathrm{~mm}$ latis oblique obovatis, margine superiore magis curvato et basi appendicula fere $1 \mathrm{~cm}$ longa et vix ultra $2 \mathrm{~mm}$ alta roturda instructo. Cotyledones (altera in alteram. incumbenti-) replicatae et processum epicarpii amplectentes. - Mexicum.

4. H. Gayana Juss.

f. 1. acapulcensis Ndz.: Samarae nuce alulis longiusculis instructa; glandulis foliorum margini insidentibus. - Palmer 79 [a. 1894/5]: Acapulco, et 1025 [XII. 1890]: Manzanillo; Haenke: ad Acapulco.

f. 2. typica Ndz.: Samarae nuce vix rugosa s. verrucosa; glandulis nervis lateralibus insidentibus. - Andrieux 494: Guichilona, inter Tehuantepec et flumen Guazacualcos. $\square \square$ Ramuli ramique teretes glabrati incani lenticellis creberrimis tuberculati, internodiis usque $4 \mathrm{~cm}$ longis et $2 \mathrm{~mm}$ diametro. Folia e basi subobtusa ovata acutiuscula usque$10 \mathrm{~cm}$ longa et $5^{1 / 2} \mathrm{~cm}$ lata, margine revoluta, chartacea, utrinque novella pube albida

2) Folia mihi subjecta omnia rupta laesave fuerunt. 
pilosa, mox glabrata, glauca, supra laevia, subtus nervis -- praecipue primariis - prominentibus, petiolo puberulo $4-9 \mathrm{~mm}$ longo, glandula pulviniformi stipite cylindraceo usque $1 / 2 \mathrm{~mm}$ longo nune petioli apici, nune folii margini ad basim affixa; floralia usque $2 / 3 \mathrm{~cm}$ (petiolo incl.) diminuta glandulas $1-2$ sessiles s. subsessiles gerentia. Umbellae 3--4floriferae, pedunculo infra apicem bibracteifero s. (his 2 bracteis fertilibus et ita 2 floribus additis) corymbi 5- -6-flori in paniculas dispositi lutescenti-velutinas axillares termiralesque et in paniculam compositam ramulos terminantem foliosam confertas, umbellarum pedunculis $1 / 2-1 \mathrm{~cm}$, floriferis $1-2 \mathrm{~mm}$ infra apicem bibracteolatis $5-6 \mathrm{~mm}$, pedicellis $\pm 1 \mathrm{~cm}$, bracteis ovato-acutis bracteolisque lanceolatis $2-1 \frac{1}{2} \mathrm{~mm}$ longis. Flores non suppetunt. Sepala ovata glandulas 8 oblongas $2-3 \mathrm{~mm}$ longas apice solutas $2-3 \mathrm{~mm}$ superantia. Stylorum apex dorso \pm uncinatus. Samarae nux latere utroque verrucarum s. alularum aculeiformium vix usque $1^{1 / 2} \mathrm{~mm}$ altarum serie instructa, alis dorsalibus subdivaricatis inter se angulum obtusissimum efformantibus usque $3 \mathrm{~cm}$ longis et $1^{1 / 3} \mathrm{~cm}$ latis, oblongo-obovatis apice rotundatis, margine utroque (superiore magis) curvato, superioris basi in appendiculam rotundatam $6 \mathrm{~mm}$ longam et $2 \mathrm{~mm}$ altam producto. - Mexicum (Pringle 4345: Barranca prope Guadalajara, Jalisco).

5. H. Portillana Watson

2. Frutices debiles S. scandentes 1/2--2-metrales, partibus novellis et inflorescentiis pube brevi rufo-tomentosis. Folia margine revoluta, petiolata. Corymbi 4--8-flori umbellis 2--6-floris terminati dispositi in paniculas amplas s. amplissimas foliiferas duplo s. triplo compositas ramos terminantes, ramulis saepius geminis, pedunculis floriferis apice s. (in eodem specimine) raro usque $1 \mathrm{~mm}$ infra apicem bibracteolatis, bracteis bracteolisque rotundato-ovatis \pm amplexicaulibus $1^{1 / 2}-2 \mathrm{~mm}$ longis. Filamenta subgracilia; antherae cordato-ovatae s. suborbiculares, loculis curvatis connectivum subhemisphaeroideum glanduliforme toto circuitu excedentibus.

$\dagger$ Rami diutius tomentosi sero glabrati rubiginosi s. fusco-violacei lenticellis incanis creberrimis notati, internodiis $1-15 \mathrm{~cm}$ longis usque $1 / 2 \mathrm{~cm}$ diametro. Folia basi acuta s. obtusa rotundatave, adulta quoque subtus tomentosa glandulisque sessilibus instructa, supra scabriusculo-puberula. Sepala nunc eglandulosa nune 8-glandulifera. Petala pleraque dorso tantum carinata.

o Folia lanceolato-oblonga, utrinque nunc obtusa s. rotundata et apice apiculata, nunc etiam acuta, usque $7 \mathrm{~cm}$ longa et $2^{2 / 3} \mathrm{~cm}$ lata, supra sublaevia, subtus nervis prominulis vix reticulata, petiolo usque $8 \mathrm{~mm}$ longo; floralia vix $2-1 \mathrm{~cm}$ longa s. ad bracteas lanceolatas 5-3 mm longas reducta. Umbellae 4-florae s. corymbi 6- - 8-flori saepius gemini, pedunculis ipsorum $2-6 \mathrm{~mm}$, floriferis $2-5 \mathrm{~mm}$, pedicellis $3-4 \mathrm{~mm}$ longis. Flores $1 \mathrm{~cm}$ diametro. Sepala ovata conniventia nunc eglandulosa, nunc glandulas 8 ovales $1 \mathrm{~mm}$ longas medio excavatas $\pm 1 \frac{1}{1 / 4} \mathrm{~mm}$ superantia. Petala crassiuscula, limbo orali s. obovato $3-4 \mathrm{~mm}$, quinti subreniformi $2^{1 / 2}-3 \mathrm{~mm}$, ungui reflexo $1 \mathrm{~mm}$, quinti erecto crassiore $2 \mathrm{~mm}$ longo. Samarae (siccae) rubrae: nux a latere parum compressa obcordata $1 / 2 \mathrm{~cm}$ longa, endocarpii processu $2 \mathrm{~mm}$ prominente, latere utroque rugoso- s. costatonervosa, rugis in aculeos vix ultra $1 \mathrm{~mm}$ longos transverse biseriatos excrescentibus; ala oblique obovata, margine inferiore subdirecto exappendiculato, ultra $1 \frac{1 / 2}{\mathrm{~cm}}$ longa, $1 \mathrm{~cm}$ iata. - Brasilia media. $\quad$ 6. H. trigoniifolia Juss. ${ }^{3}$ )

f. 1. eglandulosa Ndz.: Calyce eglanduloso. - Minas (Sello 11I. it. [16. III. 1819]: B 1828 c 1299: Villa rica [H. confertiflora e Griseb.]).

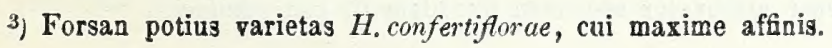


f. 2. glandulifera Ndz.: Calyce 8-glandulifero. - Minas (Sello reliqu. 3.6. I. [H. confertiflora herb. Berol.] et 1II. it. [28. X. 1818]: B 1848 e 1319: Volta da Serra [H. umbellata $\beta$. puberula Griseb.]; Martius 1172 [H. discolor]: Cujaba; Riedel 149: Ouro Preto; Lund 1056 [XI. 1833]: Mugi; .... [an Claussen?] 7 [mis. Delessert a. 1842]: Ouro Preto; Pohl 5718: in montosis ad Pirahi [H. rubiginosa herb. Vindob.]; Glazion 13599 et 14568; Schwacke 9185: Serra de Ouro Preto); Goyaz (Gardner 3620 [H trichanthera e Taubert] [foliis basi subcordatis]).

oo Folia e basi obtusiuscula s. rotundata s. rara subcordata obovata, apice obtusa s. emarginata et minute mucronulata, usque $8 \mathrm{~cm}$ longa et $5 \mathrm{~cm}$ lata, pleraque supra nervis impressis rugosa, subtus prominentibus reticulata et glandulis 2 s. compluribus parvis fuscescentibus supra basim impressis notata, petiolo $3-4 \mathrm{~mm}$ longo; floralia \pm minuta. Corymborum pedunculi $2-5 \mathrm{~mm}$, floriferi $2-3 \mathrm{~mm}$, pedicelli $3-4 \mathrm{~mm}$ longi. Flores $\pm 1 \mathrm{~cm}$ diametre. Sepala ovata $2-3 \mathrm{~mm}$ longa. Petala $4-5 \mathrm{~mm}$ longa, limbo ovali $3-4 \mathrm{~mm}$, quinti reniformi $2-2^{1 / 2} \mathrm{~mm}$, ungi reflexo $1 \mathrm{~mm}$, quinti crassiore erecto $2-3 \mathrm{~mm}$ longo. Pollen $\pm 30 \mu$ diametro. Samarae nux sphaeroidea $4-5 \mathrm{~mm}$ diametro, areola applicatoria cava orbiculari $1^{1 / 2} \mathrm{~mm}$ diametro, endocarpii processu $2 \mathrm{~mm}$ prominente, lateribus reticulato-costatis, costis saepius in aculeos excrescentibus; ala semiorbicularis, margine inferiore directo, superiore exappendiculato, $\pm 2 \mathrm{~cm}$ longa, $1 \mathrm{~cm}$ vel ultra lata. - Brasilia media.

\%. H. confertiflora Juss.

f. 1. eglandulosa Ndz.: Sepalis eglandulosis basi dorsi saepius callosis. - Rio de Janeiro (Maerkel: Parahyba; Lund [spec. fructif.] VI. 1834: in silvulis prope Franca[?]; Glaziou 7542 et 18944 p. p. $\left.{ }^{4}\right)$ ); Minas (Claussen 100 A [herb. Brusell.] resp. a. 1843 [herb. Vindob.]; Regnell II. 33: Caldas; Warming: in silvis camporum).

f. 2. glandulifera Ndz.: Calyce 8 -glandulifero, sepalis glandulas ovales obsoletas saepe nigras $1 \mathrm{~mm}$ longas $1-1^{1 / 2} \mathrm{~mm}$ superantibus. - Rio de Janeiro (Guillemin 858. [?]: V. 1839); Minas (Lund IIJ. 1835: in campis Curvello; Claussen 87 A; Mosen 1802; Glaziou 18944 p p. ${ }^{4}$ ); Matto Grosso (Pilger 280: Serrado prope Cujaba [f. petalis alulatis]).

†† Rami submox glabrati incano-ferruginei lenticellisque creberrimis albidis notati, internodiis $1 / 2-4 \mathrm{~cm}$ longis. Folia e basi \pm cordata saepiusque obliqua ovata s. ovalia, apice obtuso s. rotundato apiculata, usque $5 \mathrm{~cm}$ longa et $2^{1 / 2} \mathrm{~cm}$ lata, membranaceo-chartacea, adulta supra glabrata lucidaque, subtus - praesertim in nervis prominulis - ferrugineo-puberula et ad basim glandulis $2-6$,calathiformibus" \pm longe (usque $2 \mathrm{~mm}$ ) stipitatis e margine exeuntibus instructa, petiolo gracili $1 / 2-1 \mathrm{~cm}$ longo ferrugineo-tomentoso; floralia valde minuta, petiolo usque $1 \mathrm{~mm}$, lamina semper 2 -glandulifera usque $3 \mathrm{~mm}$. Corymbi (pauci 8 -flori) plerique ad umbellas 4 -floras reducti in paniculas duplo compositas ramum terminantes usque $1 \frac{1}{1} 2 \mathrm{dm}$ longas folioliferas dispositi, pedunculis ipsorum $1 / 2-1 \mathrm{~cm}$ longis eorumque longioribus medio bracteas 2 steriles gerentibus, floriferis paulisper infra apicem bibracteolatis $3-\tilde{\mathrm{mm}}$, pedicellis $3 \mathrm{~mm}$, bracteis lanceolato-ovatis bracteolisque late rotundato-ovatis $1 \frac{1}{2} \mathrm{~mm}$ s. ultra longis. Sepala „eglandulosa“ (cf. f. 2). Petala alulato-carinata, alula dorsali usque $1 \mathrm{~mm}$ lata. „Samarae ferrugineo-puberulae, ala oblique extrorsum ascendente obovata fere $2 \mathrm{~cm}$ longa et ultra $1 \mathrm{~cm}$ lata, latere utroque carpelli transverse muricato-cristatae, cristis breviter lacerato-

4) Sub eodem numero in herb. Berolinensi asservatur specimen quoddam $H$. pteropetalae. 
dentatis, loculus endocarpio intus prominulo subreniformis." - Rio de Janeiro ("circa Sebastianopolin“). $\quad$ 8. H. rufula Martius ms, e Juss. f. 2. glandulifera Ndz.: Sepalis glandulas $8-10$ ovales s. obovoideas $\pm 1^{1 / 2} \mathrm{~mm}$ longas $2 \mathrm{~mm}$ superantibus; foliis plerisque 2-glanduliferis. - Glaziou 8462.

f. 3. glabrata Ndz.: Foliis mox utrinque glabratis et subtus nune basi nune \pm longius supra basim glandulas 0-2 \pm stipitatas gerentibus; calyce 8-glanduloso. - Glaziou 1311. - Culta in hort. Parisiensi (leg. A. Wentzel).

I. Liana ,4--5-metralis lignosa“ (e Schomburgk) ramulis compressis rufo-velutinis, ramis glabratis: teretibus schistaceis lenticellisque crebris concoloribus tuberculatis, internodiis $1 / 2-5(-12) \mathrm{cm}$ longis usque $1 / 2 \mathrm{~cm}$ diametro. Folia e basi obtusa s. rotundata ovata s. ovato-lanceolata apice acuta s. breviter et obtusiuscule acuminata, pleraque secundum costam plicata, chartaceo-coriacea, utrinque novella rufo - velutina, adulta demum glabrata lucidaque et nervis prominulis (s. medio primariisque subtus prominentibus) reticulata concoloria, subtus serie margini paulo revoluto parallela et \pm ab ipso distante glandularum utrinque 4-7 impressa, petiolo $1 / 4-$ fere $1 \mathrm{~cm}$ longo basi biglanduloso; floralia sensim usque fcliola vix $1 / 2 \mathrm{~cm}$ longa ninuta. Umbellae s. corymbi 4--8-flori in paniculam foliola foliaque gerentem duplo s. triplo compositam digesti. Petala dorso late alato-carinata, ala $1^{1 / 2}$ — fere $2 \mathrm{~mm}$ lata, florum gemma ergo 5 -alata. Styli dorso apicis acuti s. acuminati.

1. Folia ovata s. lanceclato-ovata usque $13 \mathrm{~cm}$ longa et $61 / \mathrm{cm}$ lata \pm obliqua, nervis etiam secundariis inter se \pm parallelis. Corymbi 8 flori (i. e. additis 2 floribus paulo distantibus umbellae 6 -florae) terni in corymbum dispositi, et quidem terminalis subsessilis, 2 laterales longius ( $\pm 1 \mathrm{~cm}$ ) pedunculati, pedunculis floriferis $1^{1 / 2}-3 \mathrm{~mm}$ infra apicem bibracteolatis $3-5 \mathrm{~mm}$, pedicellis sursum valde incrassatis $3-6 \mathrm{~mm}$, bracteis bracteolisque ovato-acutis $1^{1 / 2}-2$ resp. $1-1^{1 / 4} \mathrm{~mm}$. longis. Gemmae florum subsphaeroideae $6 \mathrm{~mm}$ diametro. Flores $12 \mathrm{~mm}$ diametro. Sepala ovata apice rotundata glandulas 8 crassas ovales s. obovatas apice solutas $\pm 3 \mathrm{~mm}$ longas $1 / 3-1 \mathrm{~mm}$ superantia. Petalorum limbus $4-5 \mathrm{~mm}$, unguis $\mathrm{i}-2 \mathrm{~mm}$ longus. Antherae ovales. $1^{1 / 2}-1^{2 / 3} \mathrm{~mm}$ longae. ,Samarae subglabrae striato-nervosae cristis lateralibus irregulariter lobatis 2-4 mm latis; ala fere pollicaris falcato-oblonga, margine exteriore ultra medium rectilinea incrassata, interiore curvilinea." - Het. Lessertiana e Griseb. p. p. - Guiana anglica (Rob. Schomburgk I. 279; Rich. Schomburgk 328: Essequibo). 9. H. cristata Benth.

2. Folia lanceolato - ovata lanceolatave usque $8 \mathrm{~cm}$ longa et $3^{1 / 2} \mathrm{~cm}$ lata, nervis secundariis vix. inter se parallelis. Umbellae 6--8-florae pleraeque singulae ramulos folioliferos terminantes, pedunculis floriferis apice bibracteolatis pedicellisque $4-5 \mathrm{~mm}$,' bracteis bracteolisque ovatoobtusis $1-1^{1 / 4} \mathrm{~mm}$ longis. Gemmae florum sphaeroideae $\pm 4^{1 / 2} \mathrm{~mm}$ diametro. Flores $9 \mathrm{~mm}$ diametro. Sepala ovata apice rotundata glandulas ovales s. oblongas $1-2 \mathrm{~mm}$ longas villosas apice solutas $1 \mathrm{~mm}$ superantia. Petalorum limbus vix ultra $3 \mathrm{~mm}$, unguis $1 \mathrm{~mm}$ longus. Antherac suborbiculares $1 \mathrm{~mm}$ diametro. Samarae....- H. Lessertiana e Griseb. p. p. Guiana anglica (Rob. Schomburgk II 632: Roraima; Rich. Schomburgk 958: prope Roraima).

10. H. carinata Benth.

$\beta^{\prime}$. Samarae nux latere utroque nervis \pm prominentibus rugulosa s. verrucosa. Frutices erecti 1/2- - 3 -metrales.

Grex ' $\beta$ '. Ne uropleura.

I. Ramuli velutino-tomentosi teretes, lenticellis parvis incanis 土crebris. Folia adulta supra pilosa, subtus tomentosa, floralia pleraque vix $1-1 / 4 \mathrm{~cm}$ longa 2 -glandulifera. Umbellae 4-(-1-) florae s. corymbi 4- -8-flori in paniculas digesti breves rubiginoso-tomentosas axillares (saepius geminas s. ternas) terminalesque et dispositas in paniculas elongatas folioliferas ramulum. 
terminantes, umbellarum pedunculis $1 / 3$ - vis $1 \mathrm{~cm}$ longis, floriferis nunc apice nunc \pm infra apicem bibracteolatis. Petala carinata.

1. Rami torulosi mox glabrati fusci s. incani, internodiis $1 / 3-4 \mathrm{~cm}$ longis usque $1 \mathrm{~cm}$ diametro. Folia e basi acuta s. obtusa 士 oblonga pro genere minora vix usque $4 \mathrm{~cm}$ longa et $1^{1 / 2} \mathrm{~cm}$ lata, apice acuta s. \pm mucronulata, margine \pm revoluta, membranaceochartacea, supra hispidula obscure viridia nervisque impressis rugosa, subtus lutescentitomentosa nervisque prominentibus rubiginosis reticulata et parum manifeste prope basim biglandulosa, petiolo $2-3 \mathrm{~mm}$ longo, stipalis minutissimis et aegre conspicuis." Pedunculi floriferi $0-2 \mathrm{~mm}$ infra apicem bibracteolati $2-5(-7) \mathrm{mm}$, pedicelli $2-5 \mathrm{~mm}$, bracteae lanceolato-ovatae lanceolataeve fere $2 \mathrm{~mm}$, bracteolac ovatae $1^{1 / 4}-1^{1 / 2} \mathrm{~mm}$ longae. Flores 8-9 mm diametro. Sepala ovata glandulas $8-6$ subrotundas $1-1^{1 / 4} \mathrm{~mm}$ longas $1^{1 / 2} \mathrm{~mm}$ superantia. Petalorum limbus ovatus s. obovatus s. \pm oblongus (quinti orbicularis) $\pm 3 \mathrm{~mm}$, unguis reflexus vix $1 \mathrm{~mm}$, quinti crassus latus erectus ultra $2 \mathrm{~mm}$ longus. Stylus dorso apicis rotundatus nec angulatus. Samara rubiginosa puberula, nucis rerrucis hine inde aculeiformibus s. aluliformibus, ala semiobovata, margine inferiore \pm directo, superiore sinuato-curvato, $\pm 1^{1 / 2} \mathrm{~cm}$ longa $8 \mathrm{~mm}$ lata. - Minas (Sello Reliqu. 3. 6. Ш.: .... Martius 1171: Cujabá; Riedel 68 [U. 1839]: Pico d'Itabira resp. [in herb. Bruxell.] „a. 1840: Ouro Preto [Martius 1171] ; Claussen 9 [herb. Brusell.] et a. 1840 [herb. Candoll.]; Warming 123: Serra da Piedad; Glaziou 85 [aut 1850?] [herb. Bruxell.])

11. H. discolor Juss.

f. 2. subglabrata Ndz.: Foliis adultis subglabratis. - S. Paulo (Burchell 4032 [H. umbellata e Griseb.]).

2. Rami directi diu velutini fusco-rubiginosi, internodiis (1-) $3-12 \mathrm{~cm}$ longis et usque $4 \mathrm{~mm}$ diametro. Folia e basi obtusa s. rotundata s. subcordata ovata (s. elliptica s. obovata s. oblonga), usque $9 \mathrm{~cm}$ longa et $5 \mathrm{~cm}$ lata, apice nunc acuta $\mathrm{s}$. acuminata, nunc obtusa et saepius apiculata, margine subplana, coriacea, utrinque dense tomentosa, supra glauca et sublaevia, subtus lutescentia nervisque prominulis rubiginosis subreticulata et glandulis $2-4$ orbicularibus aegre conspicuis supra basim nervis infimis insidentibus instructa, subsessilia, petiolo crasso vix usque $2 \mathrm{~mm}$ longo tomentoso. Pedunculi floriferi $0-1 \mathrm{~mm}$ infra apicem bibracteolati $0-3 \mathrm{~mm}$, pedicelli $2-4(-5) \mathrm{mm}$, bracteac bracteolaeque oratae dorso carinatae $2^{1 / 2}-3$ resp. $1^{1 / 2}-2 \mathrm{~mm}$ longae. Flores $8-11 \mathrm{~mm}$ diametro. Sepala ovato-lanceolata carinata glandulas 8 rotundas rix $1 \mathrm{~mm}$ longas $\pm 2^{1 / 2} \mathrm{~mm}$ superantia. Petalorum limbus anguste alulato-carinatus ovalis s. obovatus $3-4 \mathrm{~mm}$, quinti suborbiculari-cordatus $2 \frac{1}{2}-3 \mathrm{~mm}$, unguis reflexus $1-2 \mathrm{~mm}$, quinti crectus fere $3 \mathrm{~mm}$ longus. Pollen 30-36 $\mu$ diametro. Styli dorso apicis angulosi. Samara ferruginea pilosa, nucis rugulis parum prominulis, ala obliquo-obovata, margine superiore magis curvato et basi in appendiculam acutam s. obtusiusculam ultra $1 / 2 \mathrm{~cm}$ longam et $\pm 2 \mathrm{~mm}$ altam producto, $2^{3 / 4} \mathrm{~cm}$ longa et $1^{1 / 3} \mathrm{~cm}$ lata. - Minas (Lund [VI. 1834]: in campis Batataes; Claussen $83 \mathrm{~A}$ et $84 \mathrm{~A}$ [herb. Bruxell.] et 537 [herb. Haun.] resp. mis. Delessert a. 1842 [herb. Candoll.]; Warming 602 [15. I. 1864]: Lagoa Santa); Goyaz (Pohl 984 [1501. d.]: Rio S. Marcos, et 985 [1502.d.] [„Oreas"]: S. Luzia, Mejaponte [H. trigoniifolia in herb. Vindob. - an e Griseb.?]); Brasilia occidentalis (Tamberlik) [f. transiens in H. pteropetalam]).

12. H. campestris Juss.

II. Ramuli norelli ferrugineo-s. incano-sericei mox glabrati. Folia mox utrinque glaberrima s. adulta subtus parum puberula. 
1. Liana ramulis ramisque divaricatis, illis compressis, his teretibus verrucosis lenticellisque creberrimis ineanis tuberculatis, internodiis $1 / 5-1^{3 / 4} \mathrm{dm}$ longis usque $1 / 2 \mathrm{~cm}$ diametro. Folia e basi obtusa s. rotundata saepe obliqua ovata s. lanceolato-ovata apice obtuso apiculata usque $1 \mathrm{dm}$ longa et $5^{1 / 2} \mathrm{~cm}$ lata, chartacea, novella utrinque rufo-subsericea, adulta supra glabrata lucidaque, stibtus - praecipue secundum costam - puberula s. demum etiam glabrata, margine reflexa, nervis primariis tantum utrinque prominulis laxe reticulata, eglandulosi, petiolo crasso $1 / 2-1 \mathrm{~cm}$ longo et apice s. infra apicem glandulis 2 magnis instructo. Umbeilae 4 -florae (incl. pedunculo $1 / 2-1 \mathrm{~cm}$ longo) vix $2 \mathrm{~cm}$ longae (s. etiam corymbuli usque 6-flori) in paniculas digestae axillares foliis breviores folioliferas dispositas in paniculam ampliorem, pedunculis floriferis $2 \mathrm{~mm}$ infra apicem bibracteolatis $\pm 3 \mathrm{~mm}$, pedicellis sursum incrassatis $3-5 \mathrm{~mm}$, bracteis bracteolisque oblongo-ovatis accumbentibus $1-1^{1 / 2} \mathrm{~mm}$ longis. Flores $1^{1 / 4} \mathrm{~cm}$ diametro. Sepala subrotundo-ovata nune eglandulosa $2^{1 / 2} \mathrm{~mm}$ longa nune glan. dulas 8 ovales $1-1^{1 / 2} \mathrm{~mm}$ longas $1-1^{1 / 2} \mathrm{~mm}$ superantia. Petala 4 valde reflexa, limbo ovatocochleariformi (quinti cordato-subplano) dorso non earinato $4-4^{1 / 2} \mathrm{~mm}$, ungui reflexo $1^{1 / 2}-2$ (quinti erecto $2-2^{1 / 2}$ ) $\mathrm{mm}$ longo. Antherae cordatae s. ovales $1 \mathrm{~mm}$ longae, Styli dorso apicis acuti s. breviter uncinati. Samarae (in specimine boliviensi tantum suppetentes) breves rufo-sericeae angulum valde obtusum in eodem fructu efformantes: nux lateribus valde reticulato-rugosa $\pm 1 / 2 \mathrm{~cm}$ diametro; ala \pm semiorbicularis usque $1^{1 / 2} \mathrm{~cm}$ longa et $1 \mathrm{~cm}$ lata, margine inferiore \pm directo $s$. etiam redunco, superiore nune simpliciter semiorbiculari nune basi paulo - vix usque $1 \mathrm{~mm}$ - in appendiculam rotundam prominente; endocarpii processu conico nsque $3 \mathrm{~mm}$ longo. - Brasilia (centralis?); Bolivia. 13. H. cochleosperma Juss. f. 1. eglandulosa Ndz.: Calyce eglanduloso. - Brasilia (centralis?) (Pohl sine numero locove [in herb. Vindob.]).

f. 2. glandulifera Ndz.: Calyce glandulifero. - Brasilia (centralis?) (Pohl 1527 [d. 15ว5]: Villa Boa [H. rhopalifolia herb. Vindob.]); Bolivia (O. Kuntze VH. 1892 [H. sericea]: Velapo, $200 \mathrm{~m}$ ).

2. Frutex metralis glaberrimus ramis gracilibus teretibus rubiginosis lenticellisque paucis albidis notatis ceterum laevissimis, internodiis $1-6 \mathrm{~cm}$ longis usque $3 \mathrm{~mm}$ diametro. Folia cordatoovata apice rotundata s. obtusa saepiusque mucronulata usque $6 \mathrm{~cm}$ longa et $4 \mathrm{~cm}$ lata, chartacea, margine rubello plano, novella parce incano-sericea, mox utrinque glaberrima et nervis - praecipue majoribus - utrinque (subtus magis) prominentibus reticulata, subtus glandulis 2-1 rubellc-zonatis supra basim nervis majoribus impressa, sessilia s. brevissime petiolata, petiolo crasso vix usque $2 \mathrm{~mm}$ longo; foralia \pm minuta vel usque ad bracteas late ovatas vix $3 \mathrm{~mm}$ longas 2 -glanduliferas reducta. Corymbi 8 - -4 -flori in ramis ramulisve axillares (interdum gemini) terminalesque in paniculas foliosas digesti, pedunculis ipsorum $1 / 2-1 \mathrm{~cm}$, floriferis apice bracteolatis $3-5 \mathrm{~mm}$, pedicellis $2-4 \mathrm{~mm}$, bracteis lanceolatis $1^{1 / 2}-3 \mathrm{~mm}$, bracteolis ovatis $\pm 1^{1 / 3} \mathrm{~mm}$ longis. Flores nondum $1 \mathrm{~cm}$ diametro. Sepala ovata glandulas 10 crassas ovales $1-1^{1 / 2} \mathrm{~mm}$ longas $\pm 1^{1 / 4} \mathrm{~mm}$ superantia. Petala crassa, limbo dorso alulato (etiam quinti) ovali s. obovato s. cordato-ovato $3-3^{1 / 2} \mathrm{~mm}$, ungui reflexo $1 \mathrm{~mm}$, quinti erecto crasso $2 \mathrm{~mm}$ longo. Pollen $30-33 \mu$ diametro. Styli apicís dorso. uncinati. Samarae non suppetunt. - Goyaz (Gardener 3621: Serra de Natividade).

14. H. sessilifolia Juss.

$\beta$. (cf. $\gamma$. ) Filamenta gracilia, sicut styli valde divergentes a lateribus - praecipue apice complanati dorso apicis angulatis. uncinati, stigmate (s. gynixo) obliquo-inteno ovali (a lateribus compresso). Samarae nux laevissima s. nervis tantum prominulis longitrorsum rugulosa necnon (sicut loculus) oblique obcordata i. e. a latere \pm compressa et apice in appendiculam 士 acutam producta, ceterum subsphaeroidea s. oroidea. Pedunculi apice s. raro (sp. 16 ct 18) infra apicem bibracteolati, bracteolis apice rotundatis.

Subseries $\beta$. Stenostigma. 
I. Folia etian adulta utrinque (praecipue subtus) tomentosa. Pedunculi pedicellique crassiusculi. Petala 4 dorso late s. latissime alata, ula sursum latiore, quinto i. e. intimo s. postico tantum carinato. Samarae nux subsphaeroidea. ${ }^{5}$ )

1. Frutex scandens (?), ramulis compressis ramisque teretibus rubiginoso- s. sulfureo-s. incanotomentosis, his sero \pm glahratis schistaceis lenticellisque incanis notatis, internodiis $1-7 \mathrm{~cm}$ longis usque $3 \mathrm{~mm}$ diametro. Folia e basi subcordata s. cordata late ovata apice nunc obtuso s. rotundato s. emarginato saepius apiculata, nune breviter acuminata, usque $5 \mathrm{~cm}$ longa et $3^{1 / 2} \mathrm{~cm}$ lata, novella utrinque, adulta subtus quidem dense tomentosa, pube nunc rubiginosa, nunc sulfurea $s$. incana, supra laevia nunc etiam \pm tomentosa, nune pube \pm decussa hispidoscabra, subtus nervis medio primariisque prominentibus et glandulis $1-6$ supra basim secundum marginem revolutum instructa, petiolo tomentoso $1 / 3-2 / 3 \mathrm{~cm}$ longo; floralia sensim usque $1 / 2 \mathrm{~cm}$ minuta. Racemi s. corymbi pluri- (usque 12.) flori terminales lateralesque dispositi in paniculas foliiferas terminantes ramulos (ipsis incl.) $1-8 \mathrm{~cm}$ longos, pedunculis cujusque ordinis crassis, floriferis apice bibracteolatis $3-6 \mathrm{~mm}$, pedicellis $3-4 \mathrm{~mm}$, bracteis bracteolisque ovatis vel oblongis vel linearibus $2-3^{1 / 2} \mathrm{~mm}$ longis. Flores ultra $1 \mathrm{~cm}$ diametro. Sepala late ovata glandulas 8 ovales $\mathrm{s}$. obovatas $1-2 \mathrm{~mm}$ longas $1^{1 / 2} \mathrm{~mm}$ superantia. Petala dorso alata, ala $3 \mathrm{~mm}$ longa et ultra $1 \mathrm{~mm}$ lata, limbo ovato $4 \mathrm{~mm}$, ungui alato 1 , quinti $2-2^{1 / 2} \mathrm{~mm}$ longo. Pollen 30-33 $\mu$ diametro. Styli minus divergentes apice in gemma tantum subtriangulares, per anthesin lateraliter compressi, stigmate \pm orbiculari, et dorso rotundati. Samarae non suppetunt. - Bahia; Minas. 15. H. rubiginosa Juss.

f. 1. typica Ndz.: Ramulis ramis inflorescentiis foliis rubiginosis; foliis cordato-ovatis apice obtusis s. rotundatis s. emarginatis apiculatisque. - Bahia (B lan chet 3626: Jacobine Moritiba, et a. 1857).

f. 2. incana Ndz.: Ramulis ramis inflorescentiis foliis sulfureis s. incanis; foliis ovatis oboratisve apice breviter acuminatis. - Bahia (Blanchet 2844 [in herb. Bruxell, errore „2344" et 2848: Catingas s. Serra d'Açurua secundum fl. S. Francisco [„H. confer H. pteropetala e Jussieu in herb. Berol. resp. "H. campestris" e Jussieu in herb. ceteris]); Minas (Princ. Neovid. [Nees V] [frutex 4- -5-pedalis]: Campo geral).

2. „Frutex erectus $1-1^{1 / 2} \mathrm{~m}$ altus parce ramosus" (e Malme) s. "suffrutex erectus" (e Schwacke) ramulis \pm compressis tomento brevi ferrugineo, ramis teretibus lutescenti-s. albido-velutinis, his sero glabratis fusco-violaceis, internodiis $1-6 \mathrm{~cm}$ longis usque $1 / 2 \mathrm{~cm}$ diametro. Folia orata s. obovata s. subrotundata, utrinque obtusa s. basi \pm cordata (s. minora acuta), usque $14 \mathrm{~cm}$ longa et $10 \mathrm{~cm}$ lata, novella utrinque ferrugineo-, adulta subtus lutescenti- s. albidotomentosa et supra \pm puberula, margine subplana, nervis supra impressis subtus \pm prominentibus rugosa et subtus glandulis $0-6$ atris orbicularibus basi s. supra basim notata, petiolo $1 / 2$ - ultra $1 \mathrm{~cm}$ longo tomentoso; floralia multo minora. Corymbi multi- (usque 12-) flori longias pedunculati et in paniculas dispositi corymbiformes longius pedunculatas folioliferas digestasque in paniculam amplam foliiferam terminalem, corymborum pedunculis (saepe $1 / 4-1 \mathrm{~cm}$ infra flores bracteis 2 sterilibus \&. gemmam abortivam fulcientibus) usque $2^{1 / 2}-3 \mathrm{~cm}$, floriferis apice s. vix $1 \mathrm{~mm}$ infra apicem bibracteolatis $3-7 \mathrm{~mm}$, pedicellis $2-4 \mathrm{~mm}$, bracteis bracteolizque ovatis divaricatis 2 resp. $1^{1 / 2} \mathrm{~mm}$ longis. Flores $1^{1 / 4} \mathrm{~cm}$ diametro. Sepala ovata dorso carinata glandulas 8 rotundas s. late ovales obovatasve $1-2 \mathrm{~mm}$ longas $2 \mathrm{~mm}$ superantia. Petala dorso latissime alata, ala usque $3^{1 / 2} \mathrm{~mm}$ longa et $2 \mathrm{~mm}$ lata, limbo oborato $4-5 \mathrm{~mm}$, quinti suborbiculari

5) Characteribus hoc loco notatis species 15-17 (stylorum indole rere:a stenostigmativae) cum spaciebus subseriei Bradystigmatis conveniunt et ita subseries Dradystigma et Stenostigma connectunt. 
et dorso tantum carinato $3-4 \mathrm{~mm}$, ungui $1-1^{1 / 2} \mathrm{~mm}$, quinti $3 \mathrm{~mm}$ longo. Filamenta 2 stylis posticis resp. petalis 3 . et 4 opposita omnibus ceteris multo crassiora. Pollen $32-36 \mu$ diametro. Styli dorso apicis acuti. Samarae „rubrae (e Schwacke) puberulae divaricatae, nuce nervis longitrorsis rugulosa verrucosaque, ala usque $2^{1 / 2} \mathrm{~cm}$ longa et $1 \frac{1}{3} \mathrm{~cm}$ lata latocultriformi, margine inferiore leviter arcuato, superiore basi ultra nucis apicem usque $4-6 \mathrm{~mm}$ stylo parallelo-ascendente deinde angulo recto decedente et \pm directo. Cotyledones membranaceae planae e basi angusta cordata obovatae medio (altera in alteram) replicatae. - Matto Grosso (Malme 13£0: ad Caxipo Mirim prope Cujabá in locis arenosis [„cerrado“]); Goyaz (Pohl 983: Rio S. Bartholomeo, et 1300 [1527 d.]: Engenho dos Bois; Glaziou 10374 [foliis supra laevibus] et 20759); „Bahia“; Minas (Martius 1170; Riedel 151 [I. 1839]: Cachoeira do campo; Casaret to 2741: Cachoeira do campo; Glaziou 10944 p. p. ${ }^{6}$ ); Schwacke 8375: Biribiry prope Diamantina); S. Paulo (Regnell H. 34). 16. H. pteropetala Juss.

3. Hoc loco inserenda esse videtur species quaedam mihi invisa - forsan varietas tantum antecedentis - cujus haec est descriptio:

„Ramuli juniores ferrugineo-tomentosi et contorto-angulati, adulti tomento diffuso pulverulenti. Folia magna, 11/2 dm longa et $8-11 \mathrm{~cm}$ lata, cordato-ovata oblique et breviter acuminata, supra glabra, subtus ferrugineo-pubescentia et densius in nervis prominulis. Inflorescentia, quae suppetit, axillaris, folio brevior, panicula in racemum contracta, pedunculis ferrugineo-tomentosis, bracteis biglandulosis. Samarae ferrugineo-puberulae ala $4 \mathrm{~cm}$ longa. - Bahia."

1\%. H. cordifolia Juss.

II. Folia adulta pleraque supra glabrata (exc. H. Martiana var. a. f. 2.) et subtus \pm puberula. Pedunculi pedicellique subgraciles. Petala tantum carinata s. paulo alata. Samarae nux ovata a lateribus \pm valde compressa.

1. Ramuli teretiusculi ferrugineo- s. lutescenti-tomentosi, rami glabrati canescentes lenticellis crebris scabri, internodiis $1^{1 / 2}-4(-8) \mathrm{cm}$ longis usque $3^{1 / 2} \mathrm{~mm}$ diametro. Folia e basi \pm cordata ovata s. elliptica apice plerumque obtuso apiculata, usque $7 \mathrm{~cm}$ longa et $4^{1 / 3} \mathrm{~cm}$. lata, margine parum revoluta, chartacea, novella utrinque, adulta (supra glabrata et obscure viridia) subtus \pm puberula, utrinque nerris prominulis reticulata, subtus ad hasim saepiusque etiam margine glandulis orbicularibus 1-4 notata, petiolo (interdum apice glandulifero) puberulo $1 / 2-1 \mathrm{~cm}$ longo; floralia sensim minuta. Corymbi 6 - -8 -flori umbellis 3 --5-floris terminati terminales axillaresque ad foliola et dispositi in paniculas folioliferas ( $s$. potius ramulos) in paniculam amplam congestas, pedunculis corymborum $1 / 2-1^{1 / 2} \mathrm{~cm}$, floriferis $2-3 \mathrm{~mm}$ infra apicem bibracteolatis $5-8 \mathrm{~mm}$, pedicellis $3-5 \mathrm{~mm}$, bracteis bracteolisque e basi dorso callosa lanceolatis resp. ovatis 2 resp. $1^{1 / 4} \mathrm{~mm}$ longis. Flores $1^{1 / 4} \mathrm{~cm}$ diametro. Sepala ovata carinata glandulas 8 ovales $2 \mathrm{~mm}$ longas $1^{1 / 4}-1^{1 / 2} \mathrm{~mm}$ superantia. Petalorum limbus obovatus basi dorsi tantum carinatus $4-5$, quinti subreniformis $4 \mathrm{~mm}$, unguis reflexus $\pm 1^{1 / 2} \mathrm{~mm}$, quinti erectus $2^{1 / 2} \mathrm{~mm}$ longus. Antherae villosulae. Pollen 27-36 $\mu$ diametro. Samarae „pubentes vel partim glabratae, fere divaricatae, facie antica cavata, ala transversa styloque subperpendicularis oblique obovata $2 \mathrm{~cm}$ longa $11 \mathrm{~mm}$ lata, juxta marginis superioris curvilinei basin Iobulo obtuso appendiculata." - Piauhy (Gardener 2073); Bahia (Blanchet 2647): Serra de Jacobina); Glaziou 10380, 10381 p. p. [in herb. Berol. $]^{\mathrm{s}}$ ), 13605,13609 et 13610.

18. H. trichanthera Juss.

2. Petala 4 exteriora anguste alulato-carinata, alula plerumque $\pm^{1 / 2} \mathrm{~mm}$ lata. Antherae glaberrimae.

6) Glaziou 18944 p. p. ad $H$. confertifloram pertinet; cf. adnot 4 .

T) Quae specimina in herb. Hauniensi et Bruxellensi permixta cum quadam Schwaniae specie.

8) Glaziou 10381 ceterum est Banisteria stellaris Griseb. f, $\alpha$. latifolia Juss. 
$\dagger$ Frutex scandens canescens, ramulis ramisque compressis incano-tomentosis usque $1 / 2 \mathrm{~cm}$ diametro, internodiis $2-8 \mathrm{~cm}$ longis. Folia e basi obtusa s. rotundata (s. acuta) obovata, apice obtuso s. rotundato apiculata, usque $5^{1 / 2} \mathrm{~cm}$ longa et $3^{3 / 4} \mathrm{~cm}$ lata, margine revoluta, chartacea, novella supra puberula subtus lutescenti-tomentosa, adulta supra glabrata, subtus puberula glaucescentia et nervis \pm prominentibus glandulisque 2 crassis orbicularibus basi s. supra basim instructa, petiolo puberulo $3-8 \mathrm{~mm}$, stipulis 2 lateralibus deciduis triangulariacutis vix $1 \mathrm{~mm}$ longis. Racemi corymbiformes 6- -12 -flori terminales axillaresque (saepe gremini) secundum ramulos plurifoliiferes in paniculas folioliferas axillares terminalesve dispositi, corymborum pedunculis ${ }^{1 / 3}-1^{1 / 4} \mathrm{~cm}$, floriferis apice bihracteolatis $4-6 \mathrm{~mm}$, pedicellis $3-5 \mathrm{~mm}$, bracteis lanceolato-ovatis $1^{2 / 3}-2 \mathrm{~mm}$, bracteolis ovatis $1-1^{1 / 4} \mathrm{~mm}$ longis. Flores $11-13 \mathrm{~mm}$ diametro. Sepala vix carinata lanceolato-ovata glandulas 8 obovato-rotundas $1 \mathrm{~mm}$ longas $2 \mathrm{~mm}$ superantia. Petalorum limbus obovatus $4-5 \mathrm{~mm}$, quinti reniformis $3-4 \mathrm{~mm}$, unguis reflexus $\pm 1^{1 / 2}$, quinti crassior erectus $2^{1 / 2}-3 \mathrm{~mm}$ longus. Pollen $33-35 \mu$ diametro. Saınarae parum puberulae divaricatae: nux longitrorsum nervosa; ala cultriformis $3 \mathrm{~cm}$ longa et $11 / 3 \mathrm{~cm}$ lata, margine inferiore leviter curvato, superiore subdirecto s. leviter sinuato basique angulo recto obtuso $\mathrm{s}$. potius aliquantulum in appendiculam obtusiusculam producto. - Minas (Schwacke 8392: Biribiry prope Diamantina). 19. H. Machaerophora Ndz. n. sp.

†† Ramuli rufo-tomentosi graciles saepe compressi, rami glabrati teretes grisei lenticellisque minutissimis conspersi, internodiis $1-5 \mathrm{~cm}$ longis vix usque $4 \mathrm{~mm}$ diametro. Folia e basi obtusa s. rotunda ovata s. lanceolato-ovata apice acuta s. cuspidata, usque $7 \mathrm{~cm}$ longa et $32 / 3 \mathrm{~cm}$ lata, margine vix revoluta, membranacea s. chartacea, novella utrinque, adulta subtus quidem rufo- s. canescenti-tomentosa s.-puberula, supra glabrata (exc. var, $\alpha$. f. 2) Iucida laevia, subtus nervis vix prominulis laxe reticulata et glandulis 2 (in majoribus interdum \pm evanidis) brevissime stipitatis patelliformibus nunc paulo supia basim nunc \pm (usque $3 \mathrm{~cm}$ ) a basi distantibus et nervis impositis instructa, petiolo gracili \pm puberulo $1 / 3-1^{1 / 2} \mathrm{~cm}$ longo; floralia usque 1/2 cm minuta. Corymbi 6- - 12-flori umbelliformes (s. umbellae 4-florae) nunc singuli axillares, nune in paniculas breves (vix usque $1 / 2 \mathrm{dm}$ longas) folioliferas axillares dispositi et cum his in paniculam foliiferam terminalem amplam congesti, pedunculis floriferis apice s. paulo infra apicem bibracteolatis pedicellisque $4-5 \mathrm{~mm}$, bracteis lanceolatis $1^{1 / 2}-3 \mathrm{~mm}$, bracteolis ovalibus $1-1^{1 / 2} \mathrm{~mm}$ longis. Flores $1-1^{1 / 3} \mathrm{~cm}$ diametro. Sepala ovata basi dorsi callosa. nunc eglandulosa $2^{1 / 2}-3^{1 / 2} \mathrm{~mm}$ longa, nune glandulas 8 subrotundas vix ultra $1 \mathrm{~mm}$ longas $\pm 11 / 2 \mathrm{~mm}$ superantia. Petalorum limbus subdenticulatns obovato - cymbiformis (quinti cordato-ovatus) $3^{1 / 2}-5 \mathrm{~mm}$, unguis valde reflexus (quinti erectus) $1-2^{1 / 2} \mathrm{~mm}$ longus. Antherae subrotundae. Styli dorso apicis acuti s. \pm uncinati. Samarae subglabratac (siccae) alutaceae: nux usque 1/2 cm longa; ala oblique obovata vix usque $2 \mathrm{~cm}$ longa et $1 \mathrm{~cm}$ lata, margine superiore plerumque magis curvato et basi subdentiformi nucem superante. A S. Paulo usque Ceará.

20. H. Martiana Juss.

var. $\alpha$. typica Ndz.: Foliis apice acutis s. breviuscule acuto-acuminatis, adultis qucque subtus subtomentosis.

f. 1. glandulifera Ndz.: Calyce 8 -glanduloso. - S. Paulo (Martius: in campis siccis prope Taubaté et Guarantinguetá).

f. 2. eglandulosa Ndz.: Calyce eglanduloso, foliis adultis quoque supra puberulis. - Ceará (Gardener 1486).

var. $\beta$. cuspidata Ndz.: Foliis cuspidatis (i. c. longe et acutissime acuminatis), adultis subtus vix puberulis; calyce eglanduloso. - Minas s. Rio de Janeiro (Glaziou 15867); S. Paulo (Comm. geogr. e geol. 3458 [leg. Löfgren]: Corrego Alegre, cerrado. [petalorum alulis usque $1 \frac{1}{2} \mathrm{~mm}$ latis]). 
y. Androcceum actinomorphum: stamina sepalis opposita alternisepalis longiora. Styli 3 inter se aequales et paralleli teretes directi s. versus apicem prorsum curvati, apice simpliciter obtusi s.a dorso compressi \pm bradystigmatici, gynixo obliquo-interno \pm orbiculari s. transverso-lineari. Samarae samaris subseriei $\beta$. II. similes, nuce \pm elongato-orata, endocarpio vix in loculum prominente. Pedunculi floriferi breves s. subnulli, pedicelli elongati. Bracteae bracteolaeque acutae, lanccolatae s. lineares.

Subseries $\gamma$. Antillis.

Liana $2^{1 / 2} \mathrm{~m}$ scandens (ex Eggers 7005) ramulis compressis luteo-sericeis gracilibus divaricatis, ramis glabratis purpureis lenticellisque albidis scabris, internodiis $1 \mathrm{~cm}-1 \mathrm{dm}$ longis vix usque 2 $\mathrm{mm}$ diametro. Folia e basi obtusa s. rotundata oralia s. ovata s. oblonga s. subrotunda apice obtuso s. emarginato mucronulata usque $5 \frac{1}{2} \mathrm{~cm}$ longa et $3 \mathrm{~cm}$ lata, margine subreroluta, membranacea s. chartacea, utrinque novella luteo-sericea, adulta glabrata (s. raro subtus puberula) et nervis laxis vix prominulis sublaevia, petiolo gracili subglabrato $1 / 4^{-}-3 / 4 \mathrm{~cm}$ longo medio s. supra medium biglanduloso. Racemi 6- -10-(כ- - 30-)flori ramulos plurifoliiferos terminantes, pedunculis floriferis apice bibracteolatis $2--3 \mathrm{~mm}$, pedicellis sursum incrassatis $4-6 \mathrm{~mm}$, bracteis bracteolisque lanceolato-acutis $1^{1 / 2}-2$ resp. $1-1^{1 / 2} \mathrm{~mm}$ longis. Flores fere $1^{1 / 4} \mathrm{~cm}$ diametro. Sepala orata apice rotundata glandulas 8 oblongas $2-2^{1 / 2} \mathrm{~mm}$ longas vix $1 / 2 \mathrm{~mm}$ superantia. Petalorum limbus e basi sagittata obovatus denticulatus basi dorsi carinatus $3 \frac{1}{2}-5 \mathrm{~mm}$, unguis $1 \frac{1 / 2}{2}-2 \frac{1}{2}$ $\mathrm{mm}$ longus. Antherae oblongo-ovales $2 \mathrm{~mm}$ longae. Samarae glabratae (siccae) alutaceae: nux oblique obcordata et extrorsum extensa fere $1 \mathrm{~cm}$ longa ex areola $31 / 2 \times 5 \mathrm{~mm}$ diametro; ala oblique oborato-oblonga s. \pm falciformis usque $2 \mathrm{~cm}(-3 \mathrm{~cm})$ longa et $9(-11) \mathrm{mm}$ lata, margine inferio:e subdirecto, superiore praccipue apice curvato et basi paulo appendiculato, appendicula rotunda vix $1^{1 / 2} \mathrm{~mm}$ alta et $3 \mathrm{~mm}$ longa. - Columbia; Venezuela; Antillae.

21. H. purpurea (L.) H. B. K.

var. $\alpha$. puberula Ndz.: Foliis adultis subtus parce puberulis; racemis usque 30-floris; stylis paulo divergentibus directis; samarae ala usque $3 \mathrm{~cm}$ longa et $11 \mathrm{~mm}$ lata. - Columbia (Karsten); Venezuela (Humboldt 75: prope Cumana).

var. $\beta$. antillana Ndz.: Foliis adultis glabratis; racemis (haud raro corymbiformibus) 3--10-floris; samarae ala usque $2 \mathrm{~cm}$ longa et $9 \mathrm{~mm}$ lata.

f. 1. oblonga Ndz.: Foliis lanceolato- s. ovato-oblongis apice acutis usque $5^{1 / 2} \mathrm{~cm}$ longis et paulo ultra $2 \mathrm{~cm}$ latis. - Martinica (Hahn 129; Steinbeil 118); Grenada (Eggers 63ว1; Broadway).

f. 2. typica Ndz.: Foliis ovatis s. oralibus s. subrotundiz usque $5 \mathrm{~cm}$ longis et $3 \mathrm{~cm}$ latis. .Ins. S. Trinitatis (Sieber 276); ins. S. Vincentii (Eggers 7005: prope Calliaquá); Barbados (Waby 50); S. Luicia (herb. Schreber; herb. Schwaegrichen [ded. Hiendlmayr; Perrottet a. 1824]); Martinica (Sieber 122; Hahn 768; Duss 1470); Guadalupa (Bertero 78; Sprengel 82; Duchassaing a. 1849; Funck et Schlim 20; Duss 2412); Mustique (Smith G 37); Antigua (Wullschlägel 79); ins. S. Eustatii (Suringar: inter Panga et Signalhill); ins. S. Crucis (Isert a. 1787; Benzon [Banisteria laurifolia]; Schmiedlein; Eggers 22. XU. 1873 et 9. U. 1874; Read; Ricksecker 49 et 107); ins. S. 'Thomae (Raon; Wydler 19: a. 1827; Krebs; Oersted 12, 13 et 14; Eggers 25. II. 1877 et 247: Boroni, in fruticetis); Portorico (Bertero 78: a. 181 $7 /$; Schwanecke; Moritz 105; Krug 150 [leg. Gundlach]; Stahl 161 et 441: prope Bayamon in silvis; Read; Sintenis 727: prope Cabo Rojo in silvis montanis, 727 b: prope Cabo Rojo in montibus calcareis, $727 \mathrm{c}$ : prope Salinas de Cabo Rojo in silvis litoralibus, $1 \measuredangle 90$ p. p.: inter Fajardo et Ceiba in montibus, $3286 \mathrm{~b}$ : prope Coamo in pratis inter Sesillos et Salinas, $35+5$ : prope Guanica in umbrosis ad Montalba, 3848: prope Guanica in fruticetis litoralibus, 5550 b: prope Rincon in 
silvis montanis ad Barrio del pueblo, 6687: prope Manati in fruticetis litoralibus; O. Kuntze 532: Guayama); Hispaniola (Bertero 273: a. 1817/9; Mayerhoff a. 1859); Cuba (de la Ossa a. 1825: Havanna); India occid. (loco speciali non indicato) (Benzon a. 1820; West. [herb. Vahl: Malpighia nitida]; herb. Schumacher [Malpighia s. Banisteria nitida]; Ryan: Pflug; herb. Rottböll [Malpighia glabra]; Nyst [Banisteria microphylla]; Moll a. 1834; Nuttall). - Culta in hort. Paris. a. 1824.

b. Petala flava s. lutea margine \pm crenulata. Styli "stenostigmatici“. Samarae nux obcordata. a lateribus compressa laevissima s. vix nervosa. Series b. Xanthopetalis. $\alpha$. Ramuli et inflorescentiae pube persistente magiz erecta tomentosi. Pedunculi floriferi supra basim s. medio s. infra apicem articulati. Bracteae bracteolaeque accumbentes crassiusculae, pleraeque ovatae apiceque rotundatae, dorso \pm carinatae tomentosae. Petala lutea.

Subseries $\alpha$. Eriorhachis. ${ }^{y}$ )

I. Folia chartaceo-coriacea. Pedunculi pedicellique crassiusculi. Petala crassiuscula.

1. Frutex $1^{1 / 2}$-metralis (e Lund 131), ramulis rufo-tomentosis, internodiis usque $3 / 4 \mathrm{dm}$ longis et. $3 \mathrm{~mm}$ diametro. Folia inferiora (ex unico specimini Hauniensi adjecto $\left.{ }^{10}\right)$ ) e basi complicata subcordata subrotundo-ovata apice minute apiculata usque $2 \mathrm{dm}$ longa et $1^{1 / 2} \mathrm{dm}$ lata, supra impresso-venosa rugosa pube brevi furcata scabra, subtus venis crasse prominentibus (primariis crassioribus arcuatis, tertiariis flexuoso-transversis) reticulata et pube longiore rufescente venisque praecipue inserta tomentosa necnon basi glandulis 2 orbicularibus atris instructa, margine plana, petiolo crasso eglanduloso vix $1 \mathrm{~cm}$ longo; floralia foliis $H$. spectabilis simillima longiuscule acuminata, inferiora oblanceolata lanceolatave $3 \mathrm{~cm}$ longa, summa in bracteas lanceolatas subtus biglandulosas vix $1 / 2 \mathrm{~cm}$ longas reducta. Corymbi umbelliformes 6 - -12 -flori pedunculo $1 / 4-1^{1 / 2} \mathrm{~cm}$ longo suffulti digesti in paniculam amplam triplo compositam folia foliolaque gerentem laxam pyramidatam, pedunculis floriferis $1^{1 / 2}-3^{1 / 2} \mathrm{~mm}$ infra apicem bibracteolatis 3-7 mm, pedicellis gemmiferis $5-8 \mathrm{~mm}$, bracteis $2 \mathrm{~mm}$, bracteolis $1^{1 / 2} \mathrm{~mm}$ longis. Flores evoluti non suppetunt. Sepala ovata glandulas 8 ovales vix usque $2 \mathrm{~mm}$ longas fere $1^{1 / 2} \mathrm{~mm}$ superantia. Petalorum limbus (e Grisebach) ,integer concavus subrotundus $3 \mathrm{~mm}$ longus". Antherae ovales $1^{1 / 4} \mathrm{~mm}$ longae. Styli dorso apicis acuti. Samarae non suppetunt. - Minas (Lund 131: Lagoa Santa [flor. Apr.--Jun.]).

22. H. verbascifolia Griseb.

2. Folia adulta supra sublaevia et pube molli \pm evanescente puberula s. plane detersa glabrata. † Frutex , subsimplex" 1-2-metralis, subscandens" (e Schwacke) ramulis ferrugineo-tomentosis, ramis demum glabratis fuseis $\mathrm{s}$. canescentibus lenticellisque creberrimis tuberculatis usque $1 / 2 \mathrm{~cm}$. diametro, internodiis 1-9 cm longis. Folia e basi \pm subcordata ovata obovatave acutissime et saepe longiuscule acuminata usque $1 \frac{1}{3} \mathrm{dm}$ longa et $8 \mathrm{~cm}$ lata, minora oblanceolata, novella utrinque tomentosa, mirgine plana, advlta supra \pm puberula s. subglabrata lucidaque sublaevia, subtus luteo- $\mathrm{s}$. incano-tomentosa, sub tomento nervis prominentibus reticulata et ad basim glan dulis 2 atris notata, petiolo crasso brevi $(3-6 \mathrm{~mm})$ tomentoso; floralia minuta usque bracteolas lanceolatas biglandulosas vix $1 / 2 \mathrm{~cm}$ longas. Umbellae s. corymbi umbelliformes 4- - 10-flori, pedunculis floriferis infra s. ad s. supra medium bibracteolatis $3-5 \mathrm{~mm}$, pedicellis $4-8 \mathrm{~mm}$, bracteis bracteolisque (raro acutis) $1^{1 / 2}-2 \mathrm{resp} .1-1^{1 / 4} \mathrm{~mm}$ longis. Flores $\pm 1 \frac{1 / 2}{\mathrm{~cm}}$ diametro. Sepala ovata apice rotundata carinata glandulas 8 oblongas

9) Quae subseriez habita valde convenit cum speciebus $6-8$ et $11-17$ et ita transitum a serie Rhodlopetalide in Xarithopetalidem adhibet.

10) Quod folium si errore tantum specimini adjectum non ad hanc speciem pertinet, $H$. verbascifulia Grisel. ab. H. spectabili discerni nequit. 
$2-2^{1 / 2} \mathrm{~mm}$ longas plerumque longitrorsum valleculatas $1^{1 / 2} \mathrm{~mm}$ superantia. Petalorum limbus e basi nune obtusa s. rotunda rune sagittata obovatus s. subrotundus saepe \pm crispulus parte inferiore carinatus 4-5 mm, unguis $2-3 \mathrm{~mm}$ longus. Antherae oblongo-ovales, loculis parallelis, $1^{1 / 2}-2 \mathrm{~mm}$ longae. Styli dorso apicis nunc rotundi s. obtusi nune acuti s. (in spee. paraguariensibus) \pm uncinati. Samarae subtomentosae (siceae) fusco-alutaceae: nux ovoidea ex areola orbiculari $3 / 4-1 \mathrm{~cm}$ longa $2 / 3 \mathrm{~cm}$ alta et vix $1 / 2 \mathrm{~cm}$ diametro; ala oblique oblongo oborata s. falciformis usque $3 \frac{1}{2} \mathrm{~cm}$ longa et $1^{2 / 3} \mathrm{~cm}$ lata, margine inferiore simpliciter curvato, superiore sigmoideo basique in appendiculam rotundam $2 / 3-1 \mathrm{~cm}$ longam $2-3 \mathrm{~mm}$ altam producto. - H. spectabilis Mart. - Brasilia (eivitate speciali non indicata) (Pohl 5714: Ribo do Frade; Glaziou 18943 a); S. Paulo (Lund VI. 1834: in campis Batataes; Raben 1. 1836: Ytu; Löfgren 25); Minas (Martius: in campis ad Contendas [H. spectabilis]; Pohl 3298 [Hamadryas, Oreas]: Rio Abaite; Regnell III. 323: Uberara; W arming: Lagoa Santa [Jul.: 26-48: Serrado; 17. VIII. 1863: Serrado; 1033; 1034: 9. IX. 1864]; Schwacke 8381: Rio das Pedras); Goyaz (Pohl 672: in desertis ad Serra dos Pilloẽs; Glaziou 20759a); Mattogrosso (Pjlger 606a: in campis ad fl. super. Kulisehu); Bolivia (M. Kuntze VII. 1892: Velasco, $200 \mathrm{~m}$ ); Paraguaria (Balansa 4580: Cordiller. de Peribebuy; Hassler 897: Cordillera de Altos, in rupestribus, 1767: in silvis prope Peribebuy, 3480 et 4087: Cordiilera de Altos, in dumetis, 5048: in altoplanitie et decliviis Sierra de Maracayú [in dumeto Ipélui], 6141: prope Tobaty inter rupes colliurn, 6681: in valle fluminis Y-acá in glareosis prope Valenzuela, et 7107: in valle fluminis Y-acá in rupestribus prope Valenzuela).

23. H. tomentosa Juss.

var. $\beta$. minor Ndz.: - H. nudicaulis Moore - H. corumbensis O. Ktze.: Foliis lanceolatis s. ovato-lanceolatis vix usque $4 \mathrm{~cm}$ longis; pedunculis floriferis $3 \mathrm{~mm}$, pedicellis $4 \mathrm{~mm}$ longis. - Mattogrosso (Moore 16 et 335 [H. nudicaulis]; O. Kuntze VIII. 1892: Corumba $[H$. commbensis $]$ ).

var. $\gamma$. glabrata Ndz:: "Frutex volubilis“ (ex Hassler) foliis adultis ramulisque mox glabratis. - Paraguaria (Hassler 7306: prope Concepcion in dumeto glareoso).

†† Rami mox glabrati usque ${ }^{1 / 2} \mathrm{~cm}$ diametro, internodiis $2-7 \mathrm{~cm}$ longis. Folia e basi rotunda s. cordata ovata s. \pm oblonga apiceque obtuso.s. rotundo apiculata vel ovato-lanceolata apiceque acuta, usque $11 \mathrm{~cm}$ longa et $5 \mathrm{~cm}$ lata, supra glabrata sublaevia et vernicosa, subtus nune etiam subglabrata (in specimine herb. Berolinensis), nune \pm tomentosa (in specimine herb. Vindobonensis), basi biglandulosa et nervis valde prominentibus reticulata, petiolo subglabrato eglanduloso crasso ${ }^{1 / 3}-1 \mathrm{~cm}$ longo; floralia petiolata subtus glandulis 2-6 magnis nigris instructa. Inflorescentiae floresque autecedentis speciei, pedunculis floriferis medio bibracteolatis $3-4 \mathrm{~mm}$, pedicellis $3-5 \mathrm{~mm}$, bracteis bracteolisque $1-1^{1 / 2} \mathrm{~mm}$ longis, floribus vix ultra $1 \mathrm{~cm}$ diametro. Sepala 4 biglandulosa. Styli dorso apicis rotundati s. acuti. Samarae puberulae rubicundae (siccae pleraeque alutaceae): nux oblique ovoideoobcordata a latere paulo compressa $\left(7 \times 5 \times 3 \frac{1}{1 / 2} \mathrm{~mm}\right)$, areola applicatoria cava ovata $\left(3^{1 / 2} \times 2^{1 / 2} \mathrm{~mm}\right)$, endocarpii processu interno $1 \mathrm{~mm}$ prominente; ala oblique obovato-oblonga s. semiobovata $\swarrow^{1 / 2} \mathrm{~cm}$ longa $1 \mathrm{~cm}$ lata, margine inferiore subdirecto s. leviter s. magis currato, superiore magis curvato et basi in appendiculam triangulari-obtusam ultra $1 / 2 \mathrm{~cm}$ longam 1-2 mm altam producto. - Bolivia (d'Orbigny 700: Chiquitos [stylis dorso apicis acutis]; Bang 2458: Coroico [stylis apicis dorso rotundis]). 24. H. falcifera Juss. ${ }^{1}$ ) 
†ो Forsan hoc loco ${ }^{12}$ ) inserenda est species quaedam in ciritate Minas collecta, cujus haec est descriptio:

"Rami juniores ferrugineo-hirtelli, mox glabrati lenticellisque crebris discoloribus scabri. Folia cuneato-obovata $8-13 \frac{1}{2} \mathrm{~cm}$ longa $4-7 \mathrm{~cm}$ lata acuminata, acumine obliquo acuto inaequi- et dissimili-latera, juniora pubescentia, mox glabrata, supra laeria et lucida, subtus nervis prominentibus laxe reticulata basique 2--4-glandulosa, glandulis orbiculatis, duabus inferioribus ad apicem petioli constantioribus, coriacea, petiolo $4-7 \mathrm{~mm}$ longo crasso nigrescente, pulvino prominente, stipulis brevibus subulatis atro-rubentibus deciduis. Corymbi 4-6-flori, florum insertionibus confertis umbelliformes axillares ant plerique foliorum summorum decremento et abortu in paniculas terminales digesti, pedunculis diversorum ordinum ferrugineo-hispidis, floriferis $4^{1 / 2} \mathrm{~mm}$ longis apice cum pedicello triente longiori articulatis, basi bracteatis et supra basin bibracteolatis, bracteis bracteolisque ovatis et in corymbo quasi imbricatis. Calycinae laciniae oblongo-ovatae $4-4^{1 / 2} \mathrm{~mm}$ longae extrorsum ferrugineohirsutae et 4 biglandulosae. Petala calyce triente longiora, ungue limbum concarum subdenticulatum fere aequante, reflexa. Stamina filamentis vix calycem aequantibus glabris, hasi in tubum coalitis, antheris glabris ohlongo-ovatis. 'Styli staminibus subaequales glabri, apice truncati, stigmate introrsum adnato. Oraria in unum dense hirsutum coalita, singula serius producta in alam loculo latiorem, margine postico crassiori rectilineam, antico tenuiori longiorique concaro-arcuatam basique lobulatam. - Minas." $\quad$ 25. H. 1hopalifolia Juss.

II. Liana ramulis ramisque gracilibus, illis paulo compressis, his teretibus diu puberulis rufis, demum glabratis canescentibus lenticellisque concoloribus parvis notatis vix ultra $2 \mathrm{~mm}$ diametro, intermodiis $1 / 3-4 \mathrm{~cm}$ longis. Folia e basi 士 subcordata ovata apice obtuso s. acuto breviter apiculata usque $5^{1 / 2} \mathrm{~cm}$ longa et $3^{1 / 2} \mathrm{~cm}$ lata, margine vix revoluta, membranacea, supra etiam adulta puberula laevia, subtus subtomentosa nervis primariis laxis vix prominulis et secundum marginem (praecipue ad basim) glandulis compluribus paulo conspicuis instructa, petiolo puberulo plerumque eglanduloso usque $2 / 3 \mathrm{~cm}$ longo; floralia sensim usque foliola $2 / 3 \mathrm{~cm}$ longa minuta. Umbellae 4-florae ad foliola axillares et corymbi 6-flori terminales usque 5 dispositi in paniculas folioliferas s. potius ramulos axillares foliis breviores, pedunculis cujusque ordinis gracilibus, illorum $1 / 2-1^{1 / 3} \mathrm{~cm}$, floriferis medio s. paulo supra medium bibracteolatis $5-9 \mathrm{~mm}$, pedicellis 4-5 mm, bracteis bracteolisque lanceolato-oratis $1^{1 / 2}-2^{1 / 2}$ resp. $1-\mathrm{i}^{1 / 4} \mathrm{~mm}$ longis. Flores $1 \mathrm{~cm}$ diametro. Sepala ovata apice rotunda dorso carinata glandulas 8 ovales $\pm 1 \frac{1}{2} \mathrm{~mm}$ longas \pm $1^{1 / 2} \mathrm{~mm}$ superantia. Petala ${ }^{13}$ ) tenuia, limbo ovato s. obovato parum concavo dorso carinato $\pm 3 \mathrm{~mm}$, ungui $1 \frac{1}{2}-2 \mathrm{~mm}$ longo. Antherae \pm orbiculares vix $1 \mathrm{~mm}$ longae. Styli subdirecti parum divergentes dorso apicis acutissimi. Samarae paberulae (siccae) rufo-alutaceae: nux valde a lateribus compressa, fere $2 / 3 \mathrm{~cm}$ longa, vix $1 / 2 \mathrm{~cm}$ alta; ala subcultriformis, margine inferiore praesertim apice curvato, superiore crenulato subdirecto, usque $2^{1 / 2} \mathrm{~cm}$ longa et $8 \mathrm{~mm}$ lata. Piauhy (Gardener 2073).

26. H. Gardeneriana Ndz. n. sp. $\left.{ }^{13}\right)$

$\beta$. Inflorescentiae et ramuli novelli sericei $\operatorname{mox} \pm$ glabrati. Pedunculi floriferi pedicellique \pm graciles. Petala flava.

Subseries $\beta$. Sericorhachis.

$\alpha^{\prime}$. Stylorum apex dorso acuto-angulatus s. \pm uncinatus. Samarae ala (saepe in eodem specimine s. quidem in eadem specie) variabilis, nunc cultriformis, nunc falciformis, quid affirmare.

12) Forsan vero $H$. rhopalifolia potius $H$. cochleospermae affinis est. Specimine authentico mihi inviso, nequeo certi

13) Petalorum color (luteus aut ruber?) in specimine sicco non satis distincte apparet, Ceterum H. Gardeneriana trausitum adhibet in subseriem Sericorhachidem. 
nunc obovata. Folia chartacea, novella utrinque sericea, fere semper mox utrinque glabrata, supra laevia, subtus nervo medio prominente, primariis paucis laxis parum prominulis.

Grex $\alpha^{\ell}$. Acrocoryphe.

I. Folia omnia inter se similia.

1. Folia ovata s. lanceolata subtus in nervis 1-vel 2 -glandulifera, petiolo eglanduloso. Corymbi pluriflori in corymbos dispositi terminantes ramulos 2 - -10 -foliiferos usque $1^{1 / 2} \mathrm{dm}$ longos. Sepala ovata. Styli - praecipue 2 postici - reeurvi graciles.

$\dagger$ Folia distincte petiolata, petiolo $1 / 4-1 / 4 \mathrm{~cm}$ longo.

* Frutex „semiscandens“ (e Löfgren 957), ramulis compressiusculis rufo-sericeis nune mox glabratis, nunc diatius pubescentibus, ramis teretibus plerumque lenticellis creberrimis incanis scabris usque $4 \mathrm{~mm}$ diametro, internodiis ${ }^{1 / 3}-7 \mathrm{~cm}$ longis. Folia e basi \pm cordata s. rotunda s. obtusa ovata s. lanceolata, apice acuta s. breviter acuminata apiculatave, usque $41 / 2 \mathrm{~cm}$ longa et $3 \mathrm{~cm}$ lata, margine subrevoluta, membranaceo-chartacea, novella utrinque rufo- $s$. canescenti-sericea, adulta subtus puberula et glandulis $1-2$ orbicularibus nervis primariis infimis supra kasim insidentibus jnstructa, petiolo $1 / 4-3 / 4 \mathrm{~cm}$ longo 士puberulo. Corymbi compositi (plerique 3-corymbuliferi) ramulos usque 10-foliiferos et usque $1 \frac{1}{2} \mathrm{dm}$ longos terminantes, corymbulis 6 --14-floriferis, pedurculis $1-4 \mathrm{~mm}$ infra apicem bibracteolatis $6-8 \mathrm{~mm}$, pedicellis $3-5 \mathrm{~mm}$, bracteis bracteolisque ovatis lanceolatisve 2-3 resp. $1 \frac{1 / 2}{2} 2 \mathrm{~mm}$ longis. Flores $\pm 1 \frac{1}{\mathrm{c}} \mathrm{cm}$ diametro. Sepala ovata s. ob. longo-ovata apice rotundata glandulas 8 ovales $1-1^{2 / 3} \mathrm{~mm}$ longas $1^{1 / 4}-2^{1 / 2} \mathrm{~mm}$ superantia. Petalorum limbus obovatus obscurius costato-carinatus 4-5 $51 / 2 \mathrm{~mm}$, quinti cordatorotundatus $3 \mathrm{~mm}$, unguis $1-2 \mathrm{~mm}$, quinti $3-4 \mathrm{~mm}$ longus. Styli dorso apicis \pm uncinati. Samarae rubellae parce puberulae: nux lateraliter compressa obcordata s. subtriangularis $5-6 \mathrm{~mm}$ longa, endocarpii processu vix $1 \mathrm{~mm}$ longo; ala $\pm 1^{1 / 2} \mathrm{~cm}$ longa $3 / 4 \mathrm{~cm}$ lata, margine superiore basi appendicula $1 \mathrm{~mm}$ alta instructo, nunc semiohovata, margine inferiore subdirecto, superiore simpliciter areuato, nunc subfalciformis, inferiore magis curvato, superiore sigmoideo. - Goyaz (Pohl 978 [Schüch 5685] [H. Martiana herb. Vindob.]: S. Luzia, Oreas); Minas (S. Hilaire a. $1818\left[{ }_{n} H\right.$. affinis umbeilatce vel Mar'tianae" e Jussieu in schedula herb. Bruxell.]: Minas Novas); S. Paulo (Raben [Banisteria]: Ytu [f. foliis ramulisque saepius ternatis], et III. 1836 [Triopteris] [f. foliis eglandulosis]; Comm.geogr. e geol. de S. Paulo 957 [leg. Löfgren]: Araraguara, Cerrado, et $s . n$. [leg. Hammer 14 XI. 1901]: Mozy-mirim, Cerrado). 2\%. H. anceps Ndz. n. sp. ${ }^{14}$ )

** Frutex scandens (?), ramulis rufo-sericeis nonnunquam subalternis, ramis glabratis usque $3 / 4 \mathrm{~cm}$ diametro, cortice incano laeviusculó vel lenticellis scabro, internodiis $1 / 2-4(-5)$ $\mathrm{cm}$ longis. Folia pleraque (cf. var. $\beta$ et $\gamma$ ) syringiformia i. e. e basi \pm subcordata ovata obtusa s. acutiuscula, usque $6 \mathrm{~cm}$ longa et $4 \mathrm{~cm}$ lata, saepe secundum costam mediam complicata, margine revoluta, tenui-coriacea, utrinque novella aureo-sericea, mox glabrata (ef. var. $\gamma$ ), supra laevia, subtus nervis primariis laxis prominentibus et plerumque infra medium glandulis 2 substipitatis nervis lateralibus affixis, petiolo subglabrato supra canaliculato $1 / 2-1^{1 / 4} \mathrm{~cm}$ longo; floralia minora \pm lanceolata. Corymbi pluriflori apice ramorum ramulorumque in corymbos folioliferos congesti rufo-subsericei, plerumque floribus 2 infimis longius a ceteris $6--12$ distantibus longiusque pedunculatis, pedunculis floriferis apice, fructiferis $\pm 2 \mathrm{~mm}$ infra apicem bibracteolatis usque $1 \mathrm{~cm}$ vel ultra, pedicellis vix usque $1 / 2 \mathrm{~cm}$, bracteis lanceolatis $2^{1} / 2-4 \mathrm{~mm}$, bracteolis ovatis $2-2^{1 / 2} \mathrm{~mm}$ longis. Flores $1^{1 / 4} \mathrm{~cm}$

14) Stylorum indole neglecta, $H$. anceps $H$, umbellatae maxime affinis videtur, 
diametro. Sepala orata glandulas 8 suborbiculares vix $1 \mathrm{~mm}$ longas $2 \mathrm{~mm}$ s. ovales \pm $1^{1 / 2} \mathrm{~mm}$ longas $1^{1 / 2} \mathrm{~mm}$ superantia. Petalorum limbus suborbiculari-oratus crispulns crenulatus dorso latiuscule $(1 / 2-1 \mathrm{~mm})$ alulato-carinatus $4 \mathrm{~mm}$, unguis $1 \frac{1}{2}-2$, quinti $3 \mathrm{~mm}$ longus. Styli dorso a picis obtusis. (in var. $\beta$ ) subrotundi. Samarae subglabratae rubescentes: nux subtriangularis, margine superiori-dorsali emarginato, lateribus compressiusculis, usque $2 / 3 \mathrm{~cm}$ longa, areola ventrali orbiculari $1 \mathrm{~mm}$ diametro, endocarpii processu interno a lateribus compresso $2 \mathrm{~mm}$ longo; ala ultra $2 \frac{1}{2} \mathrm{~cm}$ longa et $1 \mathrm{~cm}$ lata, nunc falciformis, margine inferiore valde curvato, superiore basi appendicula $1 / 2 \mathrm{~cm}$ longa et $2 \mathrm{~mm}$ alta rotunda instructo sigmoideo, nunc semiobovata (in var. $\beta$ ). - Rio Grande do Sul (Sello IV. it. d. 1754: inter Rio Parde et Bagé); Paraguaria (Hassler 8516 [f. foliis plerisque oblongo-ovatis]: ad marginem silvae in regione cursus superioris fluminis Apa).

28. H. syringifolia Gris.

var. 8 . acuminata $\mathrm{Ndz} \cdot{ }^{15}$ ): Foliis lanceolato-ovatis s. lanceolatis usque $8 \mathrm{~cm}$ longis et $3^{1 / 3} \mathrm{~cm}$ latis acuminatis inaequilateris, glandulis typicis, ala samarae semiobovata, margine inferiore directo, superiore simpliciter arcuato. - Minas (Regnell J. 31 [H. eglandulosa]: Caldas, et HI. 321: Caldas; Widgren 397 [resp. in herb. Bruxell. etiam 746, 756 et 1003] [f. calyce eglandulosso]; Warming 28. XII. 1863 [H. umbellata e Gris.]: Lagoa Santa).

var. $\gamma$. puberula Ndz.: Foliis lanceolato-oblongis apice obtuso apiculatis, etiam adultis utrinque \pm puberulis. - Paraguaria (Hassler 5786: Yeruti, in dumeto).

var. d. Pilgeri Ndz.: Foliis usque $7 \frac{1}{2} \mathrm{~cm}$ longis et $5 \mathrm{~cm}$ latis, glandulis 2 folii basi s. apici petioli affixis; pedunculis jam sub anthesi usque $5 \mathrm{~mm}$ infra apicem bibracteolatis. Mattogrosso (Pilger 606: in campis sccundum marginem silvae ripariae ad fl. super. Ronuro); Paraguuria (Hassler 7714 [,frutex ${ }^{1 / 2}$-metralis"]: prope Concepcion in campo Ycuáponá).

var. $\varepsilon$. piauhiensis $\mathrm{Ndz}$ : Corymbulis s. umbellis simplicibus ramulos 10 -foliiferos terminantibus; samarae ala intense falciformi. - Piauhy (Gardener 2069).

if Frutex $1 / 2-4 \mathrm{~m}$ scandens glaberrimus, partibus jam novellis floralibusque vix subpuberulis, ramulis ramisque alutaceis et lenticellis creberrimis scabris, internodiis ${ }^{1 / 2}-3 \mathrm{~cm}$ longis usque $4 \mathrm{~mm}$ diametro. Folia ovato- s. oblongo-cordata apiculata usque $6 \mathrm{~cm}$ longa et $3^{1 / 2} \mathrm{~cm}$ lata, margine revoluta, coriaceo-chartacea, utrinque glaberrima nervisque parum prominulis reticulata, supra lucida, subtus glauca et saepius glandulis 2 obsoletis nerrisque lateralibus insidentibus instructa, scssilia s. subsessilia, petiolo 0-2 $\mathrm{mm}$ longo, et subamplexicaulia; floralia minuta. Umbellae 4-florae corymbique 5- -8-flori umbellis terminati dispositi in paniculas terminantes ramos ramulosque foliatos, pedunculis floriferis $0-2 \mathrm{~mm}$ infra apicem bibracteolatis $4-7 \mathrm{~mm}$, pedicellis $2-5 \mathrm{~mm}$, bracteis bracteolisque lanceolato - ovatis acutis $\pm 1^{1 / 4}-2$ resp. $1-1^{1 / 4} \mathrm{~mm}$ longis. Flores $1-1^{1 / 2} \mathrm{~cm}$ diametro. Sepala ovata apice rotundata glandulas 8 oblongas $1 \frac{1}{2}-2 \mathrm{~mm}$ longas $1-1 \frac{1}{2} \mathrm{~mm}$ superantia. Petalorum limbus rotundato-ovatus dorso carinatus $3-5 \mathrm{~mm}$, unguis $1-2 \mathrm{~mm}$ longus. Styli dorso apicis acuti s. \pm uncinati. Samarae angulo recto inter se divergentes alutaceae glaberrimae: nux a latere compressa subtriangularis s. potius tetraëdriformis, loculi processu antico-apicali minimo, $7 \mathrm{~mm}$ alta, endocarpii processu interno $1-1^{1 / 2} \mathrm{~mm}$ prominente; ala cultriformis, marginibus inter se parallelis, apice oblique rotundata, $1^{1 / 3} \mathrm{~cm}$ longa, $5-6 \mathrm{~mm}$ lata, margine superiore appendicula basali triangulari $3-4 \mathrm{~mm}$ longa et paulo ultra $1 \mathrm{~mm}$ alta instructo. - H. sessilifolia e Chodat. - „Brasilia australis super lapides ad Corro de

15) Stylorum indole ad $H$. umbellatam spectat. 
Chapiaci in Missionibus"; Paraguaria (Balansa 2400: Assuncion; Hassler 1295: in dumetis prope ...16), 1588: in dumetis prope Itacurubi, 2983: Cordillera de Altos, in silva, 3338: San Bernardino, in dumeto, 4088: Cordillera de Altos, in dumeto, 6376: prope Tobaty in dumeto collium, 7228: prope Concepcion in dumetis glareosis, 7228a: prope Concepcion in dumetis apricis, et 72286: prope Concepcion in dumetis). 29. H. hypericifolia Juss.

2. Frutex erectus 2-3-metralis glaber, partibus jam novellis parce sericeis mox glabratis, ramis gracili-virgatis teretibus incano-viridibus laevibus s. lenticellis minimis albidis notatis, internodiis 1-7 $\mathrm{cm}$ longis usque $3 \mathrm{~mm}$ diametro. Folia lanceolata s. linearia usque $9 \mathrm{~cm}$ longa et $2 \mathrm{~cm}$ lata, margine revoluta, nervo medio subtus prominente, lateralibus vix prominulis, subtus nune 1- vel 2-glandulifera nune eglandulosa, petiolo 1/s -3/4 cm longo nune eglanduloso, nunc 1 - vel 2 -glandulifero, glandulis saepe \pm stipitatis. Racemi proprii ramos ramulosque terminantes foliatos, pedunculis cujusque ordinis glabratis, fructiferis $2-5 \mathrm{~mm}$ infra apicem libracteolatis $8-15 \mathrm{~mm}$, pedicellis $2-5 \mathrm{~mm}$, bracteis lanceolatis s. ovato-lanceolatis $2^{1 / 2}-4 \mathrm{~mm}$, bracteolis ovatis (petiolo crasso incl.) $2 \mathrm{~mm}$ longis. Flores $1 \frac{1}{3}-2 \mathrm{~cm}$ diametro. Sepala ovatooblonga s. oblonga glabrata dorso carinata glandulas 8 ovales $1 \frac{1}{2}-2 \mathrm{~mm}$ longas $2-3 \mathrm{~mm}$ superantia. Petalorum limbus e basi cordata s. obtusa obovatus s. oblongo-obovatus erispulus crenulatus dorso subalulato-carinatus $5-7 \mathrm{~mm}$, unguis alato-crassiusculus $1-2^{1 / 2} \mathrm{~mm}$ longus. Styli crassiusculi suberecti s. leviter recurvi. Samarae purpureae (ex Hassler) glabratae: nux a lateribus compressa triangularis $6 \mathrm{~mm}$ longa, areola applicatoria subplana ovata apice acuminata $4 \mathrm{~mm}$ longa fere $3 \mathrm{~mm}$ lata, endocarpii processu minimo ancipite vix usque $1^{1 / 2} \mathrm{~mm}$ lato s. fere plane reducto; ala cultriformis s. oblique obovata $2 \mathrm{~cm}$ longa $1 \mathrm{~cm}$ lata, margine inferiore subdirecto s. leviter curvato, superiore magis curvato e basi appondicula rotundata vix $1 \mathrm{~mm}$ alta instructa.

30. H. angustifolia Griseb.

f. 1. lanceolata Ndz: Foliis obtusiusculis s. acutis, majoribus lanceolatis usque $6 \mathrm{~cm}$ longis et $2 \mathrm{~cm}$ latis saepius subtus 1-vel 2-glandulosis; racemis plerisque brevibus corymbiformibus apice umbelliformibus, pedunculis pedicellisque saepe brevioribus; stylis dorso apicis nune tantum acutis, nunc + uncinatis. - Paraguaria (Balansa 2411 [f. transitum ab H. syringi. folia in H. angustifoliam adhibens]: in collibus incultis prope Villa-Rica; Hassler 4322: in uliginosis prope fl. Tapiraguay, 6350: prope Tobaty inter rupes denudatos collium, 6713: in valle fluminis $\mathrm{Y}$-acá inter rupes in collibus, 70c0: in ralle fluminis $\mathrm{Y}$-acá inter rupes aridos prope Valenzuela, 7868 et $7868 \mathrm{a}$ : in campis siccis in regione cursus superioris fluminis Apa); Argentinia (Lefèbre a. 1891 [H. glabra]: Lachabuasca; Bettfreund-Köster 65̃1: BuenosAires); Uruguaria (Pamplin a. 1860; Lorentz et Hieronymus 108: in fruticetis ripariis secundum Rio Uruguari prope Concepcion, 160: Concepcion, 265: in fruticetis maritimis prope Concepcion, et 576: in fruticetis ripariis S. Candida prope Concepcion); S. Paulo (LundX. 1833: in fruticetis et silvis secundariis prope S. Bernardo). - Culta sub nomine Banisteria tenuis Lindl. ${ }^{617}$ ) in hortis Londin. a. 1839 et Berol. a. 1849 et 1868.

if. 2. sinuata Ndz.: Liana $2^{1 / 2}-4$-metralis a f. 1 diversa foliis laxe sinuatis subtus infra medium biglandulosis, petiolo eglanduloso, umbellis 4-floris, pedunculis floriferis apice bibracteolatis vix $4 \mathrm{~mm}$, pedicellis $1-2 \mathrm{~mm}$ longis, floribus vix ultra $1 \mathrm{~cm}$ diametro. - Paraguaria (Has sler 7484: prope Concepcion in dumeto in arenosis salsis).

'f. 3. typica Ndz.: Foliis omnibus lineari-lanceolatis linearibusve acutis usque $9 \mathrm{~cm}$ longis et $1-1^{1 / 2} \mathrm{~cm}$ latis saepius margine revoluto denticulatis, dentibus subtus \pm glanduliferis; racemis

16) Schedula inde combusta.

17) Jussieu Banisteriam tenuem Lindl. synonymam $H$. glabrae habet. 
propriis \pm elongatis (usque $6 \mathrm{~cm}$ longis), pedunculis pedicellisque longioribus gracilibus; stylis dorso apicis pediformi-uncinatis. - Paraguaria (Balansa 2397: Caaguazu, et 2398 [H. pseudoangustifolia Chodat]: in pratis Borja prope Villa-Rica; Iassler 4564: in dumeto prope fl. Carimbuhuy, et 6298: prope Tobaty ad ripam rivuli); Rio Grande do Sul (Sello IV. it. d 15็6: ..... et d 3:559: Bauhado, P. do Jacuy; . . . 1823 [herb. Warming]). f. 4. angustissima Ndz.: A f. 3 diversa foliis angustissime linearibus usque $12 \mathrm{~cm}$ longis et vix 2/3 cm latis. - Paraguaria (Hassler 1894b: ... ${ }^{18}$ ), et 7777 ; in palude in regione cursus superioris fluminis Apa).

1I. Folia ramulorum floralium ceterorumque abbreviatorum minuta et pleraque nummularii-orbicularia, basi apiceque emarginata $1^{1 / 2}-^{1 / 3} \mathrm{~cm}$ longa, petiolo $2-4 \mathrm{~mm}$ longo. Umbellae (pleraeque 4 -florae) ramulos foliatos vix ultra $4 \mathrm{~cm}$ longos terminantes. Glandulae foliorum, bractearum et bracteolarum longiuscule stipitatae.

1. Fruticulus debilis vix metralis, partibus novellis rufo-sericeis mox glabratis, ramulis annotinis brevissimis, ramis teretibus usque $4 \mathrm{~mm}$ diametro, cortice incano lenticellisque scabro et saepe rugoso, internodiis $1 / 5-2^{1 / 2} \mathrm{~cm}$ longis. Folia pro genere minima, e basi rotundata s. subcordata saepius obliqua orata s. oblongo-lanceolata apice obtusa usque $3 \mathrm{~cm}$ longa et $1 \% / 3 \mathrm{~cm}$ lata, margine subrevoluta, nervo medio subtus prominente, petiolo $2-4 \mathrm{~mm}$ longo, glandulis plerumque 2 nune subtus basi laminae, nune petiolo apice s. infra apicem affixis. Umbellae 4--1-florae ramulos vix ultra $3 \mathrm{~cm}$ longos 2-folioliferos terminantes, pedunculis foriferis $1-3 \mathrm{~mm}$ infra apicem bibracteolatis vix $5-7 \mathrm{~mm}$, pedicellis \pm $3 \mathrm{~mm}$, bracteis bracteolisque e basi angusta ovatis $1^{1 / 2}-2 \mathrm{~mm}$ longis, bracteola altera saepius 1-glandulosa. Flores vix $1^{1 / 4} \mathrm{~cm}$ diametro. Sepala ovata glandulas ovales $2 \mathrm{~mm}$ longas vix ultra $1 \mathrm{~mm}$ superantia. Petala lutea, limbo orbiculari-obovato parte inferiore alulato-carinato crenulato $4-\dot{\mathrm{mm}}$, ungui crassiusculo 1 resp. $2 \mathrm{~mm}$ longo. Samarae glabrae rubellae: nux obcordata s. potius ovoidea cum appendicula apicali, lateribus rugosonervosa $1 / 2 \mathrm{~cm}$ longa, areola applicatoria plana orbiculari $3 \frac{1}{2} \mathrm{~mm}$ diametro, endocarpii processu interno parvo ancipite vix ultra $1 \mathrm{~mm}$ promineute; ala nunc cultriformis, margine superiore subdirecto, nunc falciformis vel obovata, illo $\mathbf{S}$-formi vel simpliciter convexo et semper basi appendicula brevi humili rotundata instructo, inferiore fere semper conveso (rarissime inferiore directo et superiore convexo). - Paraguaria (Balansa 2399 [H. umbellata e Chodat]: La Trinitad, et 2399a [H. glabra e Griseb.]: Paraguari; Hassler 7382 : prope Concepcion in dumetis apricis).

31. H. paraguariensis $\mathrm{Ndz}, \mathrm{n} . \mathrm{sp}^{1{ }^{19}}$ )

2. Frutex scandens s. subscandens usque $4-5 \mathrm{~m}$ altus, ramulis compressis luteis albido-puberulis, ramis mox glabratis teretibus incanis laevibus, lenticellis vix conspicuis, internodiis ${ }^{1} / 3-3 \mathrm{~cm}$ longis usque $3 \mathrm{~mm}$ diametro. Folia e basi rotundata s. obtusa s. subcordata ovata s. lanceolato-ovata, apice obtusa s. emarginata s. pauca acuta, inaequilatera, usque $7 \mathrm{~cm}$ longa et $3^{1 / 3} \mathrm{~cm}$ lata, margine subplana, subtus parte superiore biglandulosa, petiolo albido-puberulo $1 / 3 \ldots 2 / 3 \mathrm{~cm}$ longo. Unubellae 4 -florae terminantes ramulos breves (vix ultra $4 \mathrm{~cm}$ longos) 2 -folioliferos ad axillas foliorum delapsorum, pedunculis fructiferis $1 / 3-{ }_{-2} / 3 \mathrm{~cm}$ infra apicem bibracteolatis $\pm 11 / 2 \mathrm{~cm}$, pedicellis $\pm 1 / 2 \mathrm{~cm}$, bracteis subtus basi glanảulis 2 stipitatis instructis bracteolisque (inferiore 1-glandulifera) folioliformibus orbicularibus petiolo incluso 3-6 mm resp. 2-3 $\mathrm{mm}$ longis. Flores ultra $1 \mathrm{~cm}$ diametro. Sepala ovata apice rotundata glandulas primum orbiculares $1 \mathrm{~mm}$, demum ovales usque $2 \mathrm{~mm}$ longas $2--1 \mathrm{~mm}$.

18) Schedula inde et fere plane combusta.

19) Forsan hand specifice diversa a sequente. 
superantia. Petalorum limbus orbicularis crenulatus parte dorsi inferiore alulato - carinatus $\pm 4 \mathrm{~mm}$, unguis $1-1^{1 / 2}$, quinti $2^{1 / 2} \mathrm{~mm}$ longus. Samarae subglabratae rubescentes: nux fuscior obcordata a lateribus compressa $6 \mathrm{~mm}$ longa, areola ventrali ovali $1^{1 / 3} \times 2 / 3 \mathrm{~mm}$ diametro; ala pallidior usque $2^{1 / 2} \mathrm{~cm}$ longa et $1^{1 / 4} \mathrm{~cm}$ lata falciformis s. obovata s. cultriformis, margine inferiore semper convexo, superiore nune simpliciter directo s. convexo nec basi appendiculato, nunc convexo s. S-formi et basi appendicula rotundata instructo. Paraguaria (Hassler 6664: prope Paraguary in dumeto humido); Argentinia (Lorentz 143: Tncuman, et 319: prop La Cruz; Lorentz et Hieronymus 377: in silvis prope S. Lorenzo, Jujuy, 469: ad Rio del Tara, Catamarca, et 492: Oran ad Cerros).

32. H. glabra Hook, et Arn.

-3. Styli apex dorso rotundatus capiti \pm similis s. quidem obtusus. Samarae puberulae s. \pm glabratae, nuce potius fusca. Pedunculi foriferi pedicellis duplo — triplo longiores (. pedicelli supra medium articulati“). Bracteolae petiolatae (s, e basi petioliformi) oratae apice obtusae s, rotundatae.

Subseries $\beta$. Strongylocoryphe.

I. Frutex usque $2^{1 / 2-m e t r a l i s ~ e r e c t u s ~ s . ~ I ~ s c a n d e n s, ~ r a m u l i s ~ g r a c i l i b u s ~ f l e x i l i b u s ~ a l u t a c e i s, ~ n o v e l l i s ~ p u b e ~}$ appressa subsericeis, ramis glabratis schistaceis lenticellisque \pm crebris tuberculatis, internodiis ${ }^{1 / 2}-5 \mathrm{~cm}$ longis usque $2 / 3 \mathrm{~cm}$ diametro. Folia e basi cordata s. obtusa ovata s. lanceolata, apice obtusa s. acuta usque $5 \mathrm{~cm}$ longa et $3 \mathrm{~cm}$ lata (pleraque vero minora), chartacea, utrinque novella incano-sericea, adulta glabrata (raro subtus \pm puberula), supra virentia, subtus pallidiora basique secus nervum medium (s. raro paulo supra basim ad nerros infimos) biglandulosa, glandulis discoideis prominentibus, nervo medio subtus prominente, primariis (utrinque 3-6) vix prominulis, petiolo diutius puberulo 2-4 mm longo. Corymbi apice umbelliformes pubescentes pluri-(usque 12-) flori, additis saepe $2(-4)$ floribus distantibus ad axillas foliolorum minimorum (saepe vix $1 / 2 \mathrm{~cm}$ longorum), terminantes et ramos terminales et ramulos \pm abbreviatos laterales \pm foliatos (quorum summis 2 tantum foliola \pm bracteiformia insident), pedunculis floriferis saepe apice, fructiferis usque $3 \mathrm{~mm}$ infra apicem bibracteolatis $5-10 \mathrm{~mm}$, pedicellis $3-4 \mathrm{~mm}$, bracteis lanceolatis ( $\mathrm{s}$. raro lanceolato-ovatis) $1^{1 / 2}-3(-4) \mathrm{mm}$, bracteolis e basi angusta petioliformi ovatis $1^{1 / 4}-1^{1 / 2}$ mm longis. Flores $\pm 1 \mathrm{~cm}$ diametro. Sepala ovata s. orato-oblonga apice rotundata glandulas 8 orales s. subrotundas $2 / 3-1 \mathrm{~mm}$ longas $1^{1 / 4}-2 \mathrm{~mm}$ superantia. Petala flava, limbo dorso obscure carinato ovato s. obovato $3 \mathrm{~mm}$, ungui $\pm 2 \mathrm{~mm}$, quinti $2^{\frac{1}{2}} \mathrm{~mm}$ longo. Pollen $27 \mu$ diametro. Styli 2 postici e basi valde recurvi. Samarae rubiginosae demum subglabratae: nux ovoidea s. obcordata $3^{1 / 2}-5 \mathrm{~mm}$ longa, areola ventrali cava orbiculari vix $1 \mathrm{~mm}$ diametro, endocarpii processu interno brevissimo vix usque $1 / 6-1 / 4$ prominente; ala oblique ascendens oblique obovata 1-2 $\mathrm{cm}$ longa $2 / 3-1 \mathrm{~cm}$ lata, margine inferiore raro subdirecto, superiore plerumque basi in appendiculam rotundatam vix ultra $1 \mathrm{~mm}$ altam producto. - H. Regnelli Miq. ${ }^{20}$ ) Minas (Séllo III. it. B . . . . c. 1287 [18. VIll. 1818]: Parauna, et B. 1837 - c. 1301 [f. foliis adultis quoque subtus paulo sericeis petalisque \pm alulato-carinatis]: [Volta da Serra: 28. X. 1818, S. Antonio do Monte: 19. XI. 1818, et Pompeo: 11. XII. 1818]; Lund 363: Capoẽs; Claussen 92 [XI. 1839], 387: Sabara, et Congonhas do Campo; Stephan: Congonhas do Campo; Raben 764; Regnell I. 32 [H. Regnelli Miq. $\left.\left.{ }^{20}\right)\right]$ : Caldas, et III. 320: Uberava; Widgren a. 1845 [n. 1004 in herb. Bruxell]; Lindberg 232: Caldas; Pohl 1509 d; Weddell 923; Warming M. 18 [XIJ. 1863]; Burchell 5841: Tejuco, Rio Paranahyba; Mendonça 245 et 5.9: Caraça; Schenck 3218: Sitio, in campis; Schwacke 7550: Morro da Forca prope

20) H. Regnelli Miq. nulla nota a forma typica H. umbellatae Juss. abhorret, qua tantum omnibus partibus crassior corymbisque paulo elongatis transitum ab $H$. syringifolia in formam typicam $H$. umbellatae adhibet. 
Ouro Preto, 8747: Serra de Antonio Cerreira, 8803: Cachoeira do Campo, et 8862: José Correa prope Ouro Preto); S. Paulo (Sello IV. it. 5556; Lund 1057 [Banisteria hypericifolia]: Taubate [XI. 1833]; Comm. geogr. e geol. de S. Paulo 297 [leg. Löfgren]: Sarapuhy. Campo, 404 [leg. Löfgren]: Itapetininga, Campo, s. n. [leg. Edwall XI. 1897]: Botucatú, Campo, et s. n. [leg. Padre Russel 151: 20. XI. 1897]: Ytú, Campo); Paraná (Sello IV. it. 5062); Glaziou 14569; Paraguaria (Hassler 7571: prope Concepcion in dumetis glareosis).

33. H. umbellata Juss.

f. 2. brevialata Ndz.: Samarae ala $1^{1 / 4}-1^{1 / 3} \mathrm{~cm}$ longa $7-8 \mathrm{~mm}$ lata semiorbiculari, margine inferiore subdirecto, superiore exappendiculato; foliorum glandulis saepius a basi remotis nervisque infimis insidentibus. - Minas (Claussen 399: Caxoeira, et 404).

IJ. Frutex usque $5 \mathrm{~m}$ scardens (e Lorentz et Hieron. 28), ramulis gracilibus compressis rufosericeis, ramis virgatis glabratis teretibus incanis lenticellisque notatis, internodiis $1 / 2-7 \mathrm{~cm}$ longis usque $4 \mathrm{~mm}$ diametro. Folia e basi obtusa s. acuta s. subcordata nvata vel lanceolata apice acuta usque $5 \mathrm{~cm}$ longa et $3 \mathrm{~cm}$ lata, membranacea, novella utrinque rufo-sericea, adulta supra glabrata, subtus parce incano-sericea et glandulis, $2-6$ in nervis reticulatis ${ }^{*}$ s. 2 basi ad nervum medium notata, margine undulato revoluta, petiolo puberulo $4-7 \mathrm{~mm}$ longo; floralia minuta ovalia $\mathrm{s}$. \pm orbicularia $1 / 4-1 \mathrm{~cm}$ longa, apice emarginata apiculataque, subtus s. basi 2- -6-glandulifera, petiolo interdum apice 2-glandulifero $1-3 \mathrm{~mm}$ longo. Cory $\mathrm{m}$ bi compositi $2-8$ umbellis plerisque 4-floris s. \pm reductis, in ligno vetusto ad axillas foliorum delapsorum postumi folioliferi vix usque $4 \mathrm{~cm}$ longi, pedunculis umbellarum usque $1^{1 / 2} \mathrm{~cm}$, floriferis $0-4 \mathrm{~mm}$ infra apicem bibracteolatis usque $1 \mathrm{~cm}$, pedicellis $1 / \mathrm{s} \mathrm{cm}$, bracteis bracteolisque petiolatis oratis (petiolo incl.) $3-4 \mathrm{~mm}$ resp. 2-21/2 mm longis. Flores praecoces $1^{1 / 4} \mathrm{~cm}$ diametro. Sepala ovali-orata glandulas ovali- $\mathrm{s}$ obovato-suborbiculares $2 / 3-1^{1 / 2} \mathrm{~mm}$ longas $1^{1 / 2}-2 \mathrm{~mm}$ superantia. Petala aurea (e Lorentz et Hieron. 28) s. flava, limbo ovato $\pm 4 \mathrm{~mm}$, ungui (praecipue quinti) $上$ saturate purpureo 11/2-2 mm longo. Samarae glabrae: nux ovoidea processu apicali aucta fere $1 / 2 \mathrm{~cm}$ longa, areola ventrali orbiculari $1^{1 / 2}-2 \mathrm{~mm}$ diainetro, endocarpii processu interno ultra $2 \mathrm{~mm}$ longo; ala cultriformis $1 \frac{1 / 2}{\mathrm{~cm}}$ longa, margine superiore directo exappendiculato, inferiore apice valde curvato. H. bicolor aut. p. p. nec Juss. ${ }^{21}$ ) - Goyaz (Burchell 8177: Conceiçao - Natividade [„H. affinis Martianae" resp. H. bicolor e Griseb.]); Minas (Patr. da Silva Manso VIII. 1832: Cujabá, Morro do Ernesto $=$ Martius $1174[H$. bicolor aut. nee Juss.]); Rio de Janeiro (Martius 219 . [H. bicolor]); S. Paulo (Burchell 5603 [H. Martiana e Griseb.]); Argentinia (Lorentz et: Hieronymus 28 [H. glabra]: Oran).

34. H. praecox Nd\%. n. sp.

B. Samarae nux \pm sphaeroidea tota areolaventrali plana, endocarpio nequaquam in loculum prominente. Partes novellae inflorescentiaeque aureo- s. aeneo-sericeae. Folia. supra glabrata lucidaque. Umbellae 4-florae s. rarius corymbi usque 8-flori umbellis terminati. in paniculas s. corymbos axillares dispositi, pedunculis floriferis "medio articulatis “i. e. pedicellis \pm subaequilongis. Petala lutea valde redunca (excepto quinto) et - praecipue in serie $\mathbf{c}-$ \pm crassiuscula, limbo parte basali dorsi (necnon ungui) carinato et supra secundum medianam. cavo margineque reflexo. Androeceum \pm actinomorphum: stamina exteriora (i. e. petalis. opposita) - praecipue in serie c - interioribus breviora, antheris \pm resupinatis, loculis. parallelis connectivo adnatis ipsumque basi excedentibus. Subsect. B. Homaloprosopis. a. Pedunculi floriferi medio s. supra medium bibracteolati. Stamina stylique panlo. exserti. Antherae glaberrimae. Styli stenostigmatici* dorso apicis acuminati. Folia

21) $H$ bicolor Juss. propria, ad quam pertinentia mihi hae sunt specimina subjecta: Gaudichaud 970 et 971 : Rio de Janeiro, Lorentz 113: ...., Pohl 3524 (1511 d): Minas: ante Duas Pontes, Warming Pr. M. 13: Minas. Geraës, re - vera Tetrapterys est. 
acuminata, adulta subtus subsericea et basi marginis s. apice s. sub apice petioli glandulis 2 impressa. Ramuli vix compressi t aureo-s. rufo-subsericei, rami teretes glabrati schistacei s. rubiginosi lenticellisque albidis crebris parvis tuberculati. Series a. Mesolepis.. ${ }^{22}$ )

I. Frutex s. liana fruticosa, ramis subgracilibus usque $4 \mathrm{~mm}$ diametro, internodiis $1-11 \mathrm{~cm}$ longis. Folia e basi nune rotunda s. obtusa nune acuta lanceolata s. oblongo- s. ovato-lanceolata acuminata usque $1 \mathrm{dm}$ longa et $4^{1 / 2} \mathrm{~cm}$ lata, margine subplano undulata, chartacea, supra laevia viridia, subtus etiam adulta aureo-s. rufo-sericea (s. demum partim glabrata), nervis medio primariisque laxis prominulis, basi marginis glandulis 2 magnis impressa, ceterum eglandulosa, petiolo eglanduloso sericeo 1/2 -1 cm longo; summa sensim minuta. Umbellae 4- (-6-) florae dispositae in paniculas axillares vix usque $4 \mathrm{~cm}$ longas saepe digestas in paniculam folifferam terminalem, pedunculis floriferis pedicellisque $3-5 \mathrm{~mm}$, bracteis bracteolisque ovatis \pm acutis $1-1^{1} / 3 \mathrm{resp} .1 / 2-{ }^{2} / 3 \mathrm{~mm}$ longis. Flores 9-12 mm diametro. Sepala late ovata apice rotundata dorso carinata s. basi callosa, 4 biglandulosa. Petalorum limbus crenulatus s. subinteger e basi rotunda s. - praecipue interiorum, semper quinti - cordata s. potius obtuse hastata suborbiculari-ovatus $\pm 3 \mathrm{~mm}$, unguis \pm reflexus 1-2 (quinti saepe erectus usque 3) mm longus. Antherae ovales $1-1^{1 / 3} \mathrm{~mm}$ longae. Samarae non suppetunt. - Paraguaria.

35. H. Hassleriana $\mathrm{Ndz}, \mathrm{n}$. sp.

f. 1. amblyobasis Ndz.: Foliis e basi rotunda s. quidem obtusa ovato-lanceolatis longiuscule acuminatis; pedunculis floriferis infra apicem bibracteolatis; sepalis glandulas oblongo-ovales 士 $2^{1} / \mathrm{g} \mathrm{mm}$ longas $1-\mathrm{I}^{1 / 2} \mathrm{~mm}$ superantibus; petalorum limbo basi plerumque rotundo. - Hassler 6825: in valle cursus superioris fluminis $\mathrm{Y}$-acá inter rupes collium.

f. 2. acrobasis Ndz.: Foliis e basi acuta oblongo-lanceolatis breviter acuminatis; pedunculis floriferis medio s. infra medium bibracteolatis; sepalis glandulas ovales $1 \frac{1}{3}-2 \mathrm{~mm}$ longas $1 \%$ - $2 \mathrm{~mm}$ superantibus; plerorumque petalorum limbo basi obtuse hastato (s. cordato). - Lorentz 24. I. 1879: in fruticetis prope Villa occidental; Hassler 8025: in regione cursus superioris Auminis Apa, in silvis prope Bellavista.

II. Rami usque $4 \mathrm{~mm}$ diametro, internodiis 5-7 $\mathrm{cm}$ longis. Folia e basi cuneata obovata breviter et abrupte (interdum e sinu) acuminata usque $9 \mathrm{~cm}$ longa et $5 \mathrm{~cm}$ lata, margine revoluta, coriacea, supra laevia, subtus pube rufa demum canescente subsericeo-tomentosa et nervis medio primariisque (inter se subparallelis, utrinque 6-8) prominentibus neenon secundariis prominulis reticulata eglandulosa, petiolo $\pm 1 \mathrm{~cm}$ longo puberulo $1-4 \mathrm{~mm}$ infra apicem biglanduloso. Umbellae usque 4- (- 5 -) florae dispositae in paniculas simplices s. duplo compositas axillares usque $1 \mathrm{dm}$ longas rufo-subvelutinas, pedunculis floriferis \pm medio bibracteolatis 2 -3, pedicellis $4-5 \mathrm{~mm}$, bracteis bracteolisque ovatis \pm acutis $1^{1 / 2}-2$ resp. vix $1 \mathrm{~mm}$ longis. Flores ultra $1 \mathrm{~cm}$ diametro. Sepala late ovata apice rotundata basi dorsi callosa $3 \mathrm{~mm}$ longa. Petalorum limbus e basi plerumque hastata s. rarius obtusa suborbiculari-ovatus vix erenulatus $2^{1} / 2-3 \mathrm{~mm}$, unguis $2-2^{1 / 2} \mathrm{~mm}$ longus. Antherae ovales s. basi cordatae $1 \frac{1}{4}-1^{1 / 2} \mathrm{~mm}$ longae. Samarae non suppetunt. - Minas (Warm ing: Lagoa Santa - Piedade). 36. H. Warmingiana Ndz.n. sp.

b. Pedunculi floriferi apice bibracteolati.

$\mathbf{a}^{\prime}$. Ramuli - sicut rhachis - ancipites sericei mox glabrati fuscique, rami teretes canescentes. Folia oblonga acuminata, utrinque novella sericea mox glabrata, glandulis 2 basi marginis impressa. Series b. Madarophyllis.

I. Rami schistacei rugosi lenticellisque creberrimis concoloribus scabri usque $1 / 2 \mathrm{~cm}$ diametro, internodiis $1 / \mathrm{c}-6 \mathrm{~cm}$ longis. Folia longiuscule $\left(1 / 2-1^{1 / 4} \mathrm{~cm}\right)$ acuminata usque $12 \mathrm{~cm}$

22) Quae series transitum a Xanthopetalidis subserie Eriorhachide in seriem Metallophyllidem adhibet; samaris vero adbac ignotis haud plane apparet, an pertineat ad Xarthopetalidem aut ad Homaloprosopidem. 
longa et $4^{1 / 2} \mathrm{~cm}$ lata, margine paulo revoluta, subtus opaca et nervis medio primarisque (utrinque 7 -10) tantum prominentibus laxe reticulata eglandulosa (sc. exceptis 2 glandulis Iaterali-basalibus), petiolo $1 / 2-1^{1 / 2} \mathrm{~cm}$ longo glabrato; superiora sensim minuta. Umbellae 4 florae, pedunculis floriferis $5-6 \mathrm{~mm}$, pedicellis $6-9 \mathrm{~mm}$, bracteis lanceolatis acutis $1^{1 / 2}-2 \mathrm{~mm}$ longis. Flores $1^{1 / 3} \mathrm{~cm}$ diametro. Sepala suborbicularia nunc eglandulosa $2^{1 / 2} \mathrm{~mm}$ longa nune glandulas 8 ovales $1-1^{1 / 2} \mathrm{~mm}$ longas $\pm 1^{1 / 2} \mathrm{~mm}$ superantia. Petalorum limbus crenulatus e basi rotunda $\mathrm{s}$. \pm hastata suborbicularis $\pm 4 \mathrm{~mm}$, unguis $2-3 \mathrm{~mm}$ longus. Stamina stylique exserti. Antherae $\pm 1^{1 / 2} \mathrm{~mm}$ longae, loculis puberulis. Styli ,stenostigmatici", anticus a posticis inter se approximatis subdirectis arcuatim divergens. Samarae pro genere amplissimae sericeae (siccae) alutaceo-rufae: nux subsphaeroidea basi apiceque paulo producta usque $12 \mathrm{~mm}$ alta ceterum $8 \mathrm{~mm}$ diametro; ala supra basim usque $8-12 \mathrm{~mm}$ contracta ceterum semiobovata usque $5^{1 / 2} \mathrm{~cm}$ longa et $2^{1 / 3} \mathrm{~cm}$ lata, margine inferiore directo. - Rio de Janeiro.

37. H. megaptera Juss.

f. 1. glandulifera Ndz.: Calyce 8-glanduloso; bracteolis acutis. - Luschnath (H. Leschenaultiana $\beta$. elliptica in sched. herb. Engler [in herb. Berol.]): Praya Restinga; ex herb. Martii (herb. Bruxell.): Rio.

f. 2. eglandulosa Ndz: Calyce eglanduloso; bracteolis rotundato-oratis $1-1^{1 / 4} \mathrm{~mm}$ longis. Schott 5894 (herb. Vindob.).

II. Rami cinerei Ienticellis sparsis tuberculati ceterum laeves usque $1 / 3 \mathrm{~cm}$ diametro, internodiis 1-4 cm longis. Folia breviter (usque $1 / 3 \mathrm{~cm}$ ) acuminata usque $1^{1 / 3} \mathrm{dm}$ longa et $4 \mathrm{~cm}$ lata, margine parum revoluta, subtus etiam lucida necnon nerris non solum primariis (utrinque 8-12) sed etiam secundariis (immo minus) prominulis densius reticulata et. glandulis crebris obsoletis nervisque impressis instructa, petiolo demum glabrato $3 / 4-1 / 2 \mathrm{~cm}$ longo. Inflorescentiae et flores parvi (vix $9 \mathrm{~mm}$ diametro) plane idem, qui in H. banksiifolia. Samarae non suppetunt.

38. H. bahiensis $\mathrm{Ndz} . \mathrm{n} \cdot \mathrm{sp}^{23}$ )

$b^{\prime}$. Folia subtus metallico-nitentia. Pedunculi floriferi apice bibracteolati. Sepala ovata glandulas 8 crassas oblongo-obovoideas s. ovales apice solutas haud vel tantum breviter superantia. Petalorum limbus margine sukinteger s. denticulatus s. \pm glandulosociliatus. Stamina stylique inclusi $s$. breviter exserti. Filamenta usque $1 / \frac{1}{1}-1 / 2$ connata, antheris glaberrimis perfecte resupinatis. Styli breves crassi triangulares, apicis obtusi dorso nune rotundo nunc obtuso s. acuto, aequilongi subdirecti s. sursum leviter divergentes. Series c. Metallophyllis. a. Samarae nux lateribus inappendiculata ("laevis“). Petala inter se inaequalia, 4 exteriorum limbo orato s. oborato basi cordato- s. sagittato-biauriculato, margine subintegro s. lacerato-denticulato eglanduloso s. versus basim tantum subglanduloso-undulato, quinti toto circuitu longius ciliato-glandulifero. Subseries $\alpha$. Chrysoheteropterys Griseb.

I. Folia coriacea. Pedunculi pedicellique crassi. Samarae \pm crassae, nuce $\pm 1 \mathrm{~cm}$ diametro, ala plerumque tota (i. e. etıam secundum marginem superiorem) \pm crasso-coriacea, supra basim non s. vix s. parum constricta.

1. Frutex erectus (?) ramulis ancipiti-complanatis aureo- $\mathrm{s}$ subrufo-sericeis, ramis glabratis primum biangulosis ochraceis lucidis, demum teretibus opaco-canescentibus, lenticellis inconspicuis, internodiis $1 / 2-5 \mathrm{~cm}$ longis usque $3 / \mathrm{cm}$ diametro. Folia e basi longe cuneata obovata apice acuta s. obtusa breviterque acuminata s. obtuso vel retuso vel repando \pm apiculata

23) Forsan potius varietas mox plane glabrata $H$, banksiifoliae $\$$, alius specie: seriei Metallophyllidis, qua de re - samaris ignotis - nil certi affirmare ausim. 
usque $9 \mathrm{~cm}$ longa et fere $\check{5} \mathrm{~cm}$ lata, rigido-coriacea, supra glabrata lucida sublaevia, subtus aeneo-s. aureo-sericea et margine revoluto parce glandulifera, nervo medio subtus prominente et primariis utrinqne $7(6-9)$ directis inter se parallelis et secundariis inter se subparallelis atrinque prominulis, petiolo dilatato supra canaliculato $5-8 \mathrm{~mm}$ longo apice glandulis 2 magnis instructo (additis raro 2 glandulis ad basim folii sitis); summa diminuta usque $1^{1 / 2} \mathrm{~cm}$. Umbellae 4-florae ternae s. quinae (laterales saepius in flores singulos reductae s. plane obsoletae) dispositae in paniculas folioliferas terminantes ramulos hornotinos laterales terminalesve, pedunculis cujusque ordinis profundius valleculatis, floriferis complanatis $6-7 \mathrm{~mm}$, pedicellis 6-8 $\mathrm{mm}$, bracteis bracteolisque lineari-oblongis apice rotundatis dorso carinatis margine revolutis $3-5 \mathrm{~mm}$ resp. 3-31/2 $\mathrm{mm}$ longis. Flores $1^{1 / 4} \mathrm{~cm}$ diametro. Sepala dorso carinata glandulas $2^{1 / 2}-3^{1 / 2} \mathrm{~mm}$ longas $1^{1 / 3}-2 \mathrm{~mm}$ superantia. Petala redunca (quintum oblique erectum), limbo e basi cordata undulata ovato apiceque rotundo $4-5 \mathrm{~mm}$, nngui $\pm 2 \mathrm{~mm}$ longo. Antherae oblongo-ovales $1^{1 / 4}-1^{1 / 2} \mathrm{~mm}$ longae. Styli \pm sigmoidei. divergentes. Samarae rufo-sericeae saepissime in eodern fructu 2 abortivis singulae, rarius 1 abortiva binae, rarissime trinae fertiles et tunc angulum valde obtusum efformantes subhorizontales: nux ovoideo-lentiformis lateraliter compressa $7 \times 9 \times 10 \mathrm{~mm}$ diametro; ala tota rigido-coriacea ovata nucem sursum et extus amplectens $3-4 \mathrm{~cm}$ longa $1^{1 / 2}-1^{3 / 4} \mathrm{~cm}$ lata; cotyledones apice replicatae, altera alteram amplectens. - Rio de Janeiro (Glaziou $8590,10359,13595$ et 16730 ).

39. H. Glazioviana Ndz. n. sp.

2. Folia majora quidem basi obtusa s. rotundata s. subcordata, petiolo 2--6-glandulifero. Bracteae bracteolaeque ovatae $1^{1 / 2}(-2) \mathrm{mm}$ non excedentes. Samarae in eodem fructu angulum rectum s. I obtusum efformantes.

$\dagger$ "Arbor semiscandens" (ex Edwall) s. "liana ${ }^{*}$ (e Schenck) ramulis compressis luteosericeis, ramis mox glabratis 士 teretibus luteo-canescentibus lenticellarumque albidarum copia notatis, demum griseis rugosis lenticellisve verrucosis, internodiis $1 / 2-6 \mathrm{~cm}$ longis usque $4 \mathrm{~mm}$ diametro. Folia ovalia s. ovata obovatave s. I oblonga utrinque obtusa rotundatave s. apice breviter et obtuse acuminata usque $1^{1 / 2} \mathrm{dm}$ longa et $8 \mathrm{~cm}$ lata, crasso-coriacea, supra glabrata lucida, subtus aureo-sericea et margine revoluto hine dentato obsolete glanduloso, utrinque nervis subaequaliter prominulis irregularibus (vix primariis inter se parallelis) reticulata, nervo medio subtus prominente, petiolo basi biglanduloso crasso $1 / 2-3 \mathrm{~cm}$ longo. Corymbi umbelliformes usque 10-flori s. umbellae 3-6-florae nune simpliciter (saepius gemini) axillares, nune usque quini dispositi in paniculas breves saepe 2 -foliiferas digestas in paniculam ampliorem terminalem, pedunculis floriferis pedicellisque canaliculatis $4-7$ resp. $6-15 \mathrm{~mm}$, bracteis ovatis $1^{1 / 2}-2 \mathrm{~mm}$, bracteolis ovato-rotundis $1-1^{1 / 2} \mathrm{~mm}$ longis. Flores $1-1^{1 / 2} \mathrm{~cm}$ diametro. Sepala ovata glandulas $2-3 \mathrm{~mm}$ longas vix usque $1 \mathrm{~mm}$ superantia. Petalorum limbus e basi sagittata ovatus nune tantum $3^{1 / 2}$ nune usque $5 \mathrm{~mm}$, unguis crassus $2-3 \mathrm{~mm}$ longus. Antherae ovoideae usque $2 \mathrm{~mm}$ longae, loculis basi connectivum $1 / 2-3 / 4 \mathrm{~mm}$ excedentibus. Pollen $36-42 \mu$ diametro. Samarae (siccae) alutaceo-lutescentes: nux glabrata lucida longitrorsum nervosa, transversim $\% \mathrm{~cm}$, ceterum ultra $1 \mathrm{~cm}$ diametro; ala sericea tota crasso-coriacea oblique ovalis s. obovata $3^{1 / 2}-5^{1 / 2} \mathrm{~cm}$ longa et usque $1^{3} / 4-2^{1 / 4} \mathrm{~cm}$ lata, margine inferiore simpliciter et deorsum minus, sursum magis curvato, superiore nunc (basi exappendiculato) simpliciter, nune (basi appendiculato) duplo arcuato. - Banisteria chrysophylla Lam. - Rio de Janeiro (Gaudichaud a. 1824 et 973 [a. 1834]: ad Rio ; Raben 444; Riedel; Luschnath; Jussieu; Lund; Mikan 55: Tocaja; Schüch 5678 [Pohl d. 1560]; Warming 1825: ad Rio; Burchell 2854; Schenck 3835: Cabo Erio, 
Bestinga); S. Paulo (Sello IV. it. 5582 p. p. ${ }^{24}$ ); Guillemin 591 [II. 1839]: Ubatuba; Comm. geogr. e geol. de S. Paulo 1806 et 1813 [leg. Edwall]: Ubatuba, Morro dá prainha, ad litus maris). - Culta in hortis Paris. a. 1823, Monspel., Gener. a. 1845, Petropolit., Berolin. a. 1845, 1884, 1897, Lipsiensi a. 1848 et 1850, Bogoriensi a. 1895 [Chrysophyllum speciosum]. 40. H. chrysophylla (Lam.) H. B. K.

f. 2. longifolia Griseb.: Foliis elongatis usque $2 \mathrm{dm}$ longis et $6 \mathrm{~cm}$ latis, basi acutis, nune oblongis apiceque breriter et obtuse acuminatis (in specimine Selloano), nune oblongo-lanceolatis longius et acute acuminatis (in spec. Glazioviano); inflorescentiis laxioribus. - Rio de Janeiro (Glaziou 6106: Gavea, prope litus maris); S. Paulo (Sello IV. it. 5732 p. p. $\left.{ }^{25}\right)$ ).

†† Folia nervis et primariis et \pm etiam secundariis inter se parallelis instructa saepe utrinque prominulis, petiolo ad s. supra medium s. infra apicem biglanduloso.

* Folia supra sublaevia nerris paulo prominulis, subtus medio primariisque multo magis quam secundarii prominentibus. Petala late ovata oboratave ad basim glandulosoundulata. Samarae rufo-alutaceae sericeae: nux linea transversa $2 / 3$, ceterum usque $1 \mathrm{~cm}$ diametro; ala usque $6^{1 / 3} \mathrm{~cm}$ longa et $2^{1 / 2} \mathrm{~cm}$ lata semiobovata, margine superiore nunc inde a nuce simpliciter curvato, nune supra basim paulo depresso et ita basi in appendiculam rotundam humilem producto, inferiore plerumque directo usque apicem rotundatum (in $H$. macrostachya var. oblonga parte basali etiam recurvo).

$\uparrow$ Frutex scandens, raro erectus, ramulis complanatis ancipitibus (s. interdum \pm alatis) pube rufa s. pallescente s. lutescente sericeis aut \pm tomentoso-velutinis, ramis sero glabratis incanis primum angulatis demum teretibus rugosis, lenticellis inconspicuis, internodiis $1-10 \mathrm{~cm}$ longis usque $3 / 4 \mathrm{~cm}$ diametro. Folia ovata obovatave s. \pm oblonga apice brevissime acuminata $\mathrm{s}$. obtuso vel rotundato emarginatove apiculata usque $2^{1 / 3} \mathrm{dm}$ longa usque $1^{1 / 4} \mathrm{dm}$ lata tenui-coriacea, supra nunc diutius puberula nunc (saepius nervo medio excepto) glabrata, subtus sericea s. \pm subtomentosa margine tantum (saepius dentato et tune sub dentibus) glandulifera, petiolo 士 longo (usque $2^{1 / 2} \mathrm{~cm}$ ) saepe 4- - 6-glandulifero. Corymbi usque 8-floris. umbellae usque 6-florae in corymbos dispositi plerosque folioliferos axillares longiuscule pedunculatos (re vera ramulos axillares), pedunculis floriferis $5-8 \mathrm{~mm}$, pedicellis canaliculatis $3-5 \mathrm{~mm}$, bracteis bracteolisque ovato-acutis \pm . $1^{1 / 2} \mathrm{~mm}$ (raro ultra) longis. Flores $1^{1 / 4}-1^{1 / 2} \mathrm{~cm}$ diametro. Sepala ovata glandulas ovales s. oblongas inter se discretas $2-3 \mathrm{~mm}$ longas $1-1 \frac{1}{3} \mathrm{~mm}$ superantia. Petalorum limbus basi nune rotundus s. cordatus nune \pm hastatus s. sagittatus $4-5 \mathrm{~mm}$, unguis \pm reduncus $1 \frac{1 / 2}{2}-2^{1 / 2} \mathrm{~mm}$ longus. Antherae paulo ultra $1 \mathrm{~mm}$ longae. Styli angulo acuto divergentes vix $1 \frac{1}{2} \mathrm{~mm}$ longi dorso apicis acuti. - Banisteria sericea Car. - S. Paulo; Rio de Janeiro; Minas. 41. H. sericea (Cav.) Juss.

var. $\alpha$ subtomentosa Ndz.: Ramulis foliisque pube mox pallescente tomentosovelutinis, his ovatis supra diu puberulis, nervis subtus medio tantum primariisque sub tomento prominulis.

f. 1. Bracteis floriferis usque $4 \mathrm{~mm}$, bracteolis ultra $2 \mathrm{~mm}$ longis; petalis basi hastatis. - S. Paulo (Sello VI. it. 547).

f. 2. Bracteis bracteolisque $\pm 1 \frac{1}{2} \mathrm{~mm}$ longis; petalis basi rotundatis s. cordatis. - Minas (Glaziou 18943; Schwacke 8372 [„frutex erectus“]: Diamantina).

24) Cf. 44. H. banksiifoliam var, ancipitem!

25) Sello IV. it. 5732 p. p. ad 48. H. aeneam pertinet; cf, not. 27. 
var. $\beta$. typica Ndz.: Ramulis foliisque sericeis, his p'erisque toblongis supra mox glabratis (nervo medio interdum excepto), subtus nervis medio primariisque acute prominentibus et secundariis quoque prominulis; bracteis $2-2^{1 / 2}$, bracteolis $1-1^{1 / 2} \mathrm{~mm}$ longis; petalis basi nune cordatis, nune hastatis (vel sagittatis). - Minas (Ackerma inn; Martius: prope Ouro Preto; Pohl 109 [foliis late ovatis]: Queluz, ad Queiroz; Glaziou 20226 [foliis late ovatis]; Schwacke 8969 [leg. Araujo]: Rio Novo, et 10865 [ „liana alte scandens succo resinoso"]: Corrego do carangejo prope Rio Noro); Rio de Janeiro (Princ. Neovid. IX.-X. 1815: in fruticetis ad viam ad fl. Parahyba; Sello 11I. it. [27. X. 1820] B 1836-c 1390: Sumidurio [?]; Gaudichaud 972; Maura [?] [in herb. Griseb.]; G]aziou 4769, 6769: Serra d' Estrella, 7j41: S. d' Estrella, et 16726! - Culta in hort. Berolin.a. 1831 et 1833 [Pterocarpus argentea] et 1845 [Banisteria argentea] et Paris. a. 1839 [Banisteria srmentosa].

$\uparrow \uparrow$ Liana, sarmentis crassis alte scandens", ramulis complanatis rufo-sericeis, ramis demum teretibus glabratis incanis saepe striatis lenficellisque notatis, internodiis $1-8 \mathrm{~cm}$ longis usque $2 / 3 \mathrm{~cm}$ diametro. Folia orata obovatave vel \pm oblonga basi obtusa s. rotunda s. \pm subcordata, apice breviter acuminata s. apiculata, usque $2 \mathrm{dm}$ longa usque $1 \mathrm{dm}$ lata, subtus sericea atque glandulis instructa et marginalibus oksoletis et \pm conspicuis dispositis in seriem utrinque margini parallelam longiusque ab ipso distantem, petiolo subbrevi (vix ultra $1 \mathrm{~cm}$ longo) medio biglanduloso. Umbellae 2- - 4-florae corymbique umbellis 3 constantes breviter pedunculati floriferi (pedunculo incl.) vix ultra $3 \mathrm{~cm}$ longi bracteas tantum gerentes et saepe bini ternive ad axillas conferti dispositi in paniculas elongatas folioliferas, pedunculis floriferis pedicellisque $3-4(-6) \mathrm{mm}$, bracteis bracteolisque ovatis apice rotundatis $1 \frac{1}{2}-1 \mathrm{~mm}$ longis. Flores $1 \frac{1}{1} \mathrm{~s}-1^{2} / \mathrm{s} \mathrm{cm}$ diametro. Sepala glandulas 8 crassas oblongas s. sigmoideo-curvatas inter se \pm conglutinatas s. interdum connatas $2^{1 / 2}-4 \mathrm{~mm}$ longas $0-1 \mathrm{~mm}$ superantia. Petalorum limbus e basi sagittata $\mathrm{s}$. hastata ovata $3^{1 / 2}-5 \mathrm{~mm}$, unguis valde reduncus $1^{1 / 2}-2^{1 / 2} \mathrm{~mm}$ longus. Filamenta usque $1 / 3 \mathrm{~s}$. ultra medium connata. Antherae oblongo-orales $1 \frac{1}{1 / 2}-2 \mathrm{~mm}$ longae. Styli basi directi sursum reclinati $1^{1 / 2}-2 \mathrm{~mm}$ longi apice paulo dilatati dorsoque acuti. - H. apiculata Miq. - A Brasilia septentrionali et Peruvia usque ad Antillas minores.

42. H. macrostachya Juss.

f. 1. oblonga Ndz: Foliis oblongis usque $2 \mathrm{dm}$ longis et $8 \mathrm{~cm}$ latis; samarae ala parte basali marginis interioris \pm recurva. - Guiana gallica (Poiteau a. 1824; Mélinon 38, 188 et 297: Maroni); Guiana batava (Kappler 1915 [Heteropterys apiculata Miq.]: ad fl. Marowyne med;; Wullschlägel 1900: e regione Marowyna); Guiana anglica (Rob. Schomburgk I. 222 p. p. [in herb. Berol.]: Essequibo; Jenman 4843: ad fl. Demerara). - Culta in hort. bot. Schoenbrunn. a. 1813 et 1840 (Banisteria chrysophylla), Monac. a. 1831 (Banisteria fulgens).

f. 2. ovata Ndz.: Foliis ovatis obovatisve usque $1^{1 / 2} \mathrm{dm}$ longis et fere $1 \mathrm{dm}$ latis. Amazonas (Spruce 1962: inter Barcellos et San Isabel secus Rio Negro); Guiana gallica (Poiteau: Cayenne; Sagot 92: Acaronary); Guiana batava (Hos tmann 897); Guiana anglica (Rob. Schomburg k I. 222 p. p. [in herb. Vindobon. et Candolleano]: Essequibo); Venezuela (Humboldt: Caracas; Bredemeyer: Caracas); Columbia (Schlim 661: Enllanada, prov. Ocaña, 3000'; Karsten 94; Goudot: S. Fé de Bogota); ins. S. Trinitatis (Eggers 1131 et $1185 \mathrm{~b}$ : in silvis ad Arima, et 1434: ad Caroni flumen; Bot. Gard. herb. 1769 et 2365 [e reliquiis Crüger, 
Purdie etc.7); Tabacum (Eggers 5536: ad Frenchfield, 400'); Hispaniola (M eyerboff a. 1859: S. Domingo). - Culta in hort. bot. Berol. (Banisteria chrysophylle in herb. Braun. et herb. Link.), Schoenbrunn. (Ban. chrys.), Monac. (e seminibus a Martio missis [Heteropterys chrysophylla]) a. 1838 et 1849.

f. 3. transiens Ndz.: Foliis chartaceis s. chartaceo-coriaceis obovatis acuminatis usque $2 \mathrm{dm}$ longis et fere $1 \mathrm{dm}$ latis neenon samaris similibus eis $H$. nitidae et in eodem fructu angulum rectum s, acutum efformantibus transitum in $H$. nitidam adhibens. - Peruvia orientalis (Spruce 3947: prope Tarapoto); Venezuela (Warming 1891/2).

* Frutex 2-3 m altus $\mathrm{v}$. caules scandentes (e Sintenis) v. prostrati radicantes (e Bello), ramulis adpresse pilosis mox glabrescentibus, ramis teretibus griseis, lenticellis minutis, internodiis usque $2^{1 / 2} \mathrm{dm}$ longis usque $1 / 2 \mathrm{~cm}$ diametro. Folia e basi rotunda s. subcordata ovata $s$. lanceolata longiuscule acuminata usque $1 \mathrm{dm}$ longa et ${ }^{3 / 4} \mathrm{dm}$ lata, rigido-coriacea, utrinque valde nervosa nervis non solum primariis sed etiam subaequaliter secundariis prominentibus supra glabrata lucidaque, subtus ferrugineos. aureo-sericea atque margine plano novella summaque denticulata et sub dentibus glandulifera, adulta integerrima glandulis quoque evanidis, petiolo $6-12 \mathrm{~mm}$ longo ad medium biglanduloso. Umbellae 4--2-florae s. corymbi umbellis usque 3 compositi axillares ad folia minuta, pedunculis fructiferis $8-10 \mathrm{~mm}$, pedicellis $4-5 \mathrm{~mm}$, bracteis bracteolisque $2 / 3-1 \mathrm{~mm}$ longis. Flores $3 / \mathrm{cm}\left(\right.$ ?) diametro. Sepala ovata glandulas $2^{1} / \mathrm{c}^{-3} \mathrm{~cm}$ longas $1 / 2-1 \mathrm{~mm}$ superantia. Petala , calyce paulo longiora, limbo parvo lineari-obovato integro" (e Jussieu), resp. "oblongo-spathulata longe unguiculata $2^{1 / 2} \mathrm{~mm}$ longa (ex Urban). Samarae rufo-sericeae: nux ovoideo-lentiformis $6 \times 10 \times 12 \mathrm{~cm}$ diametro, ala (dente magno basali marginis superioris omisso) oblique semiobovata $\mathbf{s .}$ subfalciformis margine inferiore $\perp$ directo s. simpliciter curvato, superiore sigmoideo basi distincte appendiculato, appendicula magna acuta 8 . obtusa $3-6 \mathrm{~mm}$ alta $\pm 1 \mathrm{~cm}$ longa, et ita supra hasim constricto. Cetera sicut in $H$. sericea. - H. Bellonis Urb. - Portorico ("Ahorca caballo") (Sintenis 192: prope Marica juxta rivulum ad Indiera fria, 3892: prope Sabana grande in declivibus juxta flumen Estero, et 60\$3: prope Lares in fruticetis ad Callejones).

43. H. Wydleriana Juss.

II. Folia 士 chartacca. Pedunculi pedicellique graciles s. subgraciles. Samarae nux paulo ultra $1 / 2 \mathrm{~cm}$ diametro, ala secundum marginem superiorem membranacea, spathulata i. e. supra basim constricta et hoe loco vix $1 / 2-1 / 3$ partis superioris lata.

3. Liana ramulis patentibus achraceo- $\mathrm{s}$. rufo-sericeis nunc compressis ancipitibus nunc complanatis alatis, ramis glabratis rugoso- $s$. alato-striatis tortis rufo- $\varepsilon$. flavido-canescentibus usque $1 / 2 \mathrm{~cm}$ diametro, lenticellis nunc crebris, nune inconspicuis, internodiis $1 \mathrm{~cm}$ - fere $2 \mathrm{dm}$ longis. Folia e basi \pm rotunda lanceolato-oblonga 8 . lineari-lanceolata, apice acuta s. longius a cuminata usque $2 \mathrm{dm}$ longa usque ${ }^{1 / 2} \mathrm{dm}$ lata, subcoriaceo-chartacea, supra glabrata sublaevia sublucida, subtus ochraceo-s. rufo-sericea et mágine vix revoluto suepiusque dentato (sub dentibus) glandulosa, costa media crassa subtus valde prominente, nervis et primariis (utrinque $10-20$ ) et secundariis inter se subparallelis utrinque \pm prominulis, petiolo crassiusculo supra canaliculato $1 / 2-1 \mathrm{~cm}$ longo apice s. sub apice biglanduloso. Corymbuli umbelliformes 4--8.-multiflori dispositi in paniculas corymbiformes duplo s. triplo compositas folioliferas axillares, pedunculis cujusque ordinis striatis \pm gracilibuz, floriferis $3-10 \mathrm{~mm}$, pedicellis $5-7 \mathrm{~mm}$, bracteis ovatis \pm acutis $2-1 \mathrm{~mm}$, bracteolis ovatis obtusis vix $1 \mathrm{~mm}$ longis. Gemmae floriferae parvae depresso-globosac $3 \mathrm{~mm}$ longae $4 \mathrm{~mm}$ diametro. Flores vix ultra $1 \mathrm{~cm}$ diametro. Sepal a glandulas $2-2^{1 / 2} \mathrm{~mm}$ longas vix $1 / 2 \mathrm{~mm}$ superantia. Petala omnia. 
\pm redunca, limbo cordato-ovato rotundato (in 4 exterioribus ad basim longius glanduloso ciliato) $\pm 3 \mathrm{~mm}$, ungui $2-21 / 2 \mathrm{~mm}$ longo. Antherae orales $1 \mathrm{~mm}$ longae. Samarae (siccae) rufo-alutaceae sericeae oblique erectae inter se angulum rectum efformantes: nux $4 \times 6 \mathrm{~mm}$ diametro; ala oblique spathulata apice rotundata, margine inferiore subdirecto, superiore sigmoideo, usque $4^{1 / 2} \mathrm{~cm}$ longa, sub apice $2 \mathrm{~cm}$, supra basim constricta vix $1 / 2-4 / 5 \mathrm{~cm}$ lata. S. Paulo; Minas.

44. H. banksiifolia Griseb. var. $\alpha$. Martiana Griseb, in sched.: Ramulis complanatis bialatis pube longiuscula rufa subrelutino-subsericeis, ramorum lenticellis conspicuis c rebris; foliis lanceolato-oblongis usque $2 \mathrm{dm}$ longis et $1 / 2 \mathrm{dm}$ iatis margine subintegris s. rarius dentatis; corymbis multifloris dense rufo sericeis. - S. Paulo (Martius: in campis ad Pendamhongaba; Schott 5672; Burchell 5274).

var. $\beta$. anceps Ndz.: Ramulis compressis ancipitibus ochraceo-sericeis; foliis oblongis apice obtuso brevissime apiculato-acuminatis edentatis; corymbulis 6--2-floris; varietas ad $H$. nitidam spectans. - S. Paulo (Sello IV. it. 5582 p.p ${ }^{26}$.); Comm.geogr. e geol. de S. Paulo 2851 [leg. Campos Novaes]: Campinas).

var. $\gamma$. Selloana Ndz.: Ramulis compressis ancipitibus pube appressa ochracea parce sericeis, ramorum lenticellis inconspicuis; foliis lineari-lanceolatis usque $1 \frac{1 / 2}{\mathrm{dm}}$ longis et vix usque $1 / 3 \mathrm{dm}$ latis longius acuminatis distincte dentatis; corymbulis 8--4-floris parce ochraceosericeis. - Minas (SeJlo III. it. [II. 1819]: B. 1831 - c. 1293: Guidowald).

2. "Frutex erectus" (e Schwacke) S. "liana“ (e. Schenck) ramulis complanatis ancipitibus aeneo- s. aureo-sericeis, ramis angulatis demum glabratis fusco rubiginosis lenticellisque creberrimis incanis obtectis usque $3 / 4 \mathrm{~cm}$ diametro, internodiis $1-10 \mathrm{~cm}$ longis. Folia e basi obtusa breriter attenuata oblonga s. rara ovato-ovalia, apice rara acuta s. acuminata, pleraque obtuso s. retuso s. repando breviter apiculata, usque $2 \mathrm{dm}$ longa et $8 \frac{1}{2}(-10) \mathrm{cm}$ lata, margine subplano s. revoluto leviter repanda, supra fusca laevia glabrata lucida, subtus aeneo-s. aureo-sericea et nervis medio primariisque (utrinque 8-12) inter se parallelis acuto-prominentibus necnon secundariis inter se parallelis prominulis reticulata atque serie glandularum nervis impositarum utrinque simplici (s. raro duplici) a margine longius remota ipsique subparallela instructa, petiolo sericeo subgracili eglanduloso $1 / 2-2 \mathrm{~cm}$ longo; floralia sensim minuta. Umbellae 4-(-2-) florae singulae s. ternae in corymbulos compositae ad foliola asillares atque digestae in paniculas folioliferas axillares terminalesque et dispositas in paniculam amplam ramos terminantem, umbellarum pedunculo saepissime 2 internodiis constante et ad nodum bifoliolifero s. bibracteifero, pedunculis floriferis $4-8 \mathrm{~mm}$, p edicellis $3-5 \mathrm{~mm}$, bracteis ovato-acutis $1-1^{1 / 4} \mathrm{~mm}$, bracteolis ovato-rotundis $1 / 2$ - vix $2 / 3 \mathrm{~mm}$ longis. Flores $1-1^{1 / 4} \mathrm{~cm}$ diametro. Sepala glandulas $2-3 \mathrm{~mm}$ longas $0 \ldots 2 / 3 \mathrm{~mm}$ superantia. Petala redunca quintum. erectum), limbo cordato-ovato plerumque ad basim glandulifero $4 \mathrm{~mm}$, quinti subrotundo $3 \mathrm{~mm}$, ungui 1-2 mm longo. Antherae ovoideae vix $1 \mathrm{~mm}$ longae. Samarae aureo-sericeae: nux 3-4 mm diametro; ala spathulata $3-4(-5)$ cm longa et supra basim constricta 8 -- vix $4 \mathrm{~mm}$, infra apicem rotundum $1^{1 / 2}-2 \mathrm{~cm}$ lata, margine inferiore subdirecto s. simpliciter curvato, superiore sigmoideo. - Banisteria nitida Lam. - Minas (Regnell III. 331: Caldas; Schwacke 11835: Rio Novo, ad rivulos prope Capoeirinna [samarae alis asque $\mathbf{5} \mathrm{cm}$ longis]); Rio de Janeiro (Sello I. it. a. 1814: Serra d' Estrella; Karwinski 1I.-III. 1823: prope Mandioca; Riedel IIl. 1823: in fruticetis in collibus siccis pl. Mandico [?], Serra Estrella; Martius 569 p. p.; Lhotzky 30. VIIJ. 1832: Corcorado; Vauthier 451 et 519: a. 1833;

26) Cf. notam 24 sub $H$, chrysophylla! 
Eques a Seneloh a. 1834; Raben 128, 132, 394, 441, 442 et a. 1835; Luschnath; Lund: ad Rio de Janeiro; Peckolt 184: Canta Gallo; Schüch; Pobl 5712 [d. 1555]: ad Curral falso non procul S. Cruz, et ... [d. 1554]; Casaretto 1524 [a. 185̃7]; Weddell 123 et 231 [a. 1858]; Wawra et Maly 554; Bunbury a. 1863; Schwarz [Exped. Novara]: Tijueca; Burchell 931 et 1528; Warming 10. VI. 1866; Glaziou 720, 1062 et 10367; Schenk 2036: Gavea ad viam prope hort. botan.); S. Paulo (Sello III. it. [4. IIl. 1819]: B. 1835 - c. 1299: S. Pinto; Burchell 3534; Comm. geogr. e geol. 3295 [leg. Edwall]: S. Paulo [culta], et s. n. [leg. Löfgren 14. VII. 1898]: Purungaba).

45. H. nitida (Lam.) H. B. K.

$\beta$. Samarae nux alulis 2 lateralibus (utrinque 1) dorsi basi plerumque confluentibus instructa. Folia subtus margine revoluto glandulis obsoletis instructa, ceterum eglandulosa, petiolo sericeo.

Subseries $\beta$. Peixotopterys Griseb.

1. Folia corjacea supra lucida, nervo medio subtus prominente, ceteris creberrimis - etiam primariis tenuibus - utrinque prominulis irregulariter reticulata, petiolo (fere semper) ad medium biglanduloso. Samarae ala ascendens, margine postico a basi subdirecta simpliciter, antico sigmoideo-curvato.

1. „Frutex 1-metralis" (e Warming) s. "liana“ (e Schenck) et ramulis \pm compressis et diutius ramis teretibus pube rufa velutino-sericeis, lenticellis minimis albidis creberrimis, internodiis $2-7 \mathrm{~cm}$ longis usque $3 / \mathbf{c m}$ diametro. Folia e basi nunc angustato-acuta, nunc obtusa ovata s. ovalias. 士 oblonga, apice obtuso s. repando breviter mucronulata, usque $11 \mathrm{~cm}$ longa usque $5 \frac{2}{3} \mathrm{~cm}$ lata, petiolo raro eglanduloso (Gardner 5399), plerumque ad s. infra medium biglanduloso $1 / 2-1 \mathrm{~cm}$ longo; floralia sensim diminuta usque $1 / 2 \times 1 / 3 \mathrm{~cm}$. Umbellae 2- -4 -florae dispositae in paniculas amplas duplo compositas foliiferas, pedunculis ipsarum $1 / 2$-fere $2 \mathrm{~cm}$, floriferis $3-8 \mathrm{~mm}$, pedicellis $3-7 \mathrm{~mm}$, bracteis ovato-acutiusculis $1^{1 / 2}-2 \mathrm{~mm}$, bracteolis ovato-obtusis $1 \mathrm{~mm}$ longis. Flores nondum $1 \mathrm{~cm}$ diametro. Sepala ovatoacutiuscula glandulas $2^{1 / 2}-3^{1 / 2} \mathrm{~mm}$ longas apice recurvas vix superantia. Petala valde (quintum minus) reclinata inter se \pm aequalia, limbo e basi rotunda oblongo-ovali margine denticulato vixque (etiam in quinto) glandulifero $3-3^{1 / 2} \mathrm{~mm}$, ungui $1-1^{1 / 2} \mathrm{~mm}$ longo. Antherae ovales $1 \mathrm{~mm}$ longae. Styli breves apice oblique obtusi. Samarae sericeae (siccae) rufo-alutaceae, pleraeque valde ascendentes alis \pm subparallelis: nux vix $4 \mathrm{~mm}$ diametro, alulis lateralibus in vaginam lobatam usque $4 \mathrm{~mm}$ latam connatis; ala subspathulata s. oblique oblongo-obovata usque $3 \mathrm{~cm}$ longa usque $1^{1 / 4} \mathrm{~cm}$ lata. - $H$. coleoptera et $H$. metallochroa Juss. - Piauhy (Martius: in campis s. d. agrestibus [H. sericea e Griseb.]); Bahia (Sello s. n.: inter Vittoria et Bahia; Blanchet 2048); Rio de Janeiro (Ackermann a. 1830 [Martius 569 p. p.]: prope Sebastianopolim ad margines silvarum, et 4. VI. 1836 [n. 149 catal. provis.]: prope Rio; Riedel: Itahype prope Castel(?)novo; Martius 1169 [in herb. Monac.]; Raben 380 et a. 1835; Claussen 14, 48 [H. Chrysophyllum], 67, 2048 et 2067 [a. 1842]; G ardner 5399; Weddell 104; Vauthier; Warming 2. VII. 1866: Restinga prope Copacabana; Glaziou 53: Restingas de Copacabana prope Rio, 718, 7803 et 10368; Schenck 2267: Restinga prope Copacabana). -- Culta in horto Berolinensi a. 1886 (H. chrysophylla).

46. H. coleoptera Juss.

f. 2. macrccarpa Ndz.: Partibus floralihus $1 / 4$, samaris \pm duplo majoribus, nuce $\pm 3 / 4 \mathrm{~cm}$ diametro, alulis lateralibus usque $6 \mathrm{~mm}$ latis, ala usque $6 \mathrm{~cm}$ longa et $2^{1 / 3} \mathrm{~cm}$ lata. Rio de Janeiro (Glaziou 10382).

2. "Liana" (e Schenck) ramulis compressis demum glabratis, ramis teretibus griseis, lenticellis. minimis creberrimis, internodis usque $6 \mathrm{~cm}$ longis usque $4 \mathrm{~mm}$ diametro. Folia lanceolato-ovata 
basi obtusa s. rotundata apice acuta usque $7 \mathrm{~cm}$ longa usque $3^{1 / 3} \mathrm{~cm}$ lata margine subdentata et sub dentibus glandulosa, petiolo $\pm 1 / 2 \mathrm{~cm}$ longo supra medium biglanduloso. Umbellae corymbulique umbellis ternis compositi axillares terminalesque dispositi in paniculam amplissimam foliiferam, lateralium pedunculo 2 internodiis constante $2 \cdot$ bracteifero $\pm 1 \mathrm{~cm}$, terminalium simplici $1 / 2 \mathrm{~cm}$, pedunculis floriferis $3-4 \mathrm{~mm}$, pedicellis $4-.5 \mathrm{~mm}$, bracteis bracteolisque orato-acutis 2-1 mm longis. Flores non suppetunt. Samarae, rubellae" (e Schenck) (siccae rufo-alutaceae) sericeae: $\mathrm{nux} 1 / 2 \mathrm{~cm}$ diametro lateraliter vix cristata, crista utraque in tuberculorum seriem humilium reducta; ala oblongo-falcata usque $2^{1 / 2} \mathrm{~cm}$ longa et $3 / 4 \mathrm{~cm}$ lata apice rotundata. - Rio de Janeiro (Schenck 3994 [H. aenea]: Cabo Frio, in fruticetis „Restinga“).

4\%. H. Schenckiana Ndz.n. sp.

1]. „Liana“" (e Schenck) s. „frutex" (ex Ule) ramulis compressis canescenti-sericeis, ramis teretibus glabratis griseis fere usque $1 / 2 \mathrm{~cm}$ diametro, lenticellis minimis, internodiis $1-2^{1 / 2} \mathrm{~cm}$ longis. Folia elliptica vel oblongo-s.ovato-s. obovato-elliptica vel \pm oblonga, basi acuta s. obtusa, apice obtusa vel acuta s. abrupte et brevissime obtuso-acuminata $21 / 2-12 \mathrm{~cm}$ longa $11 / 2-5^{1 / 2} \mathrm{~cm}$ lata, chartace 0 -coriacea, supra la evia saepiusque lucida, subtus pubeappressa aenea sericea nervisque medio tantum prominente primariis inter se subparallelis vix prominulis sublaevia, petiolo eglanduloso usque ${ }^{1 / 2}-1 \mathrm{~cm}$ longo. Umbellae 2 - - 4florae s. corymbuli umbellis ternis compositi terminales et axillares ad folia in ramulis hornotinis vix ultra $1^{1 / 3} \mathrm{dm}$ longis $2--8$ - foliferis, pedunculis floriferis $5-6 \mathrm{~mm}$, pedicellis striatis sursum incrassatis $7-8 \mathrm{~mm}$, bracteis bracteolisque ovatis obtusis $\mathrm{s}$. acutiusculis $1-1^{1 / 2} \mathrm{~mm}$ longis. Flores 10-12 mm diametro. Sepala glandulas oblongas $2-2^{1 / 2} \mathrm{~mm}$ longas $1-1^{1 / 2} \mathrm{~mm}$ superantia. Petala divaricata, limbo e vasi rotunda s. subhastata late s. suborbiculari-ovato dorso crasso-carinato margine crenulato (quinti glanduloso-ciliato) $3^{1} / 2-4 \mathrm{~mm}$, ungui crasso $1^{1 / 2}-2$ mm longo. Antherae ovales $1 \mathrm{~mm}$ longae. Pollen $30 \mu$ diametro. Samarae rufo-sericeae: nux $1 / 2 \mathrm{~cm}$ diametro, cristis lateralibus vix $2 \mathrm{~mm}$ latis; ala ovato-s. obovato-oblonga s. \pm falciformis usque $4 \mathrm{~cm}$ longa et $13 / \mathrm{s} \mathrm{cm}$ lata directa obliqua, alis ejusdem fructus inter se angulum obtusum efformantibus, margine inferiore subdirecto s. leviter curvato, superiore nune simpliciter nune duplo arcuato. - S. Paulo (Sello IV. it. 5732 p. p. ${ }^{27}$ ) [H. chrysophylla in sched. herb. Berol.]; Mosen 2802: Santos; Comm. geogr. e geol. de S. Paulo 2617 [leg. Löfgren et Edwa11]: Conceiçao Itanhaëu, et 2655 [leg. Löfgren]: Rio Una da Aldeia, Jguape; Sa. Catharina (Schenck 1062: Itajahy, in fruticetis secundum litus maris; Ule 488: Itajahy, in paludosis); Rio grande do Sul (Sello IV. it. d. 2591 [f. foliis tantum usque 5 cm longis $2^{2} / 3 \mathrm{~cm}$ latis et samarae ala $2 \mathrm{~cm}$ longa usque $9 \mathrm{~mm}$ lata]: inter Porto Allegre et Serra do Herval).

48. H. aenea Griseb.

2. Umbellae pleraeque 4-(כ- -1-) florae dispositae in paniculas \pm elongatas duplo s. triplo compositas axillares terminalesve, pedunculis floriferis saepe nullis s. suknuliis s. quidem pedicellos non aequantibus (,pedicellis infra medium s. supra basim s. basi articulatis") et apice bibracteolatis. Petala flava s. lutea. Androeceum zygomorphum tri-vel didynamium: stamina nune 3 nune tantum 2 stylis posticis opposita ceteris erassiora, filamentis 3 posticis s. etiam quibusdam ceteris prorsum sigmoideo-incurvis. Styli \pm graciles stenostigmatici ${ }^{4}$ (exc. in $\mathrm{n}$. 5\&-60). Samarae (in serie Holopetalo nondum notae) brunneo-alutaceae: nux obtusoconoidea, areola applicatoria \pm totam faciem ventralem orbicularem occupante suplana s. medio tantum paulo excavata. 
A. Pedunculi cujusque ordinis graciles, floriferi raro subnulli s. nulli („Pedicelli raro subsessiles s. sessiles"); bracteae bracteolaeque lanceolatae s. subsetaceo-lineares acutae \pm divaricatae s. recurvae. Sepala fere semper in eadem specie nunc glandulifera nunc eglandulosa. Petala flava, limbo membranaceo cochleariformi denticulato. Androeceum tridynamium: stamina 3 stylis opposita ceteris longiora crassioraque. Styli arcuati basi divergentes, apice convergentes. Samarae nux \pm obscura, endocarpii processu interno \pm magno in loculum prominente conico caro; ala nune semiovalis s. semiobovata, margine inferiore arcuato, superiore nunc simpliciter curvato, nunc basi in appendiculam parvam obtusam s. rotundatam producto. Cotyledones tenues plicatae altera super alteram - circum endocarpii processum.

Subsectio A. Stenophyllarion Griseb.

I. Styli apex dorso re vera rotundatus. Folia membranacea s. membranaceo-chartacea, pleraque + lanceolata acuminataque, petiolo \pm longo grăcilique.

1. Liana ramulis pedunculisque compressis s. ancipitibus pube brevissima lutescentibus, ramis teretibus glabratis fusco-purpureis s. pruinoso-canescentibus, lenticellis saepissime inconspicuis. Folia e basi obtusa s. rotundata (s. raro subcordata) lanceolata vel lanceolato-orata vel ovata \pm longe acuminata, usque $16 \mathrm{~cm}$ longa, usque $8 \mathrm{~cm}$ lata, novella utrinque rufo-pulverulenta, adulta utrinque glabrata et saepe lucida, subtus nervis \pm prominentibus reticulata et (fere semper) glandulis compluribus orbicularibus latis planis s. impressis nigris secundum marginem nervis impositis notata, petiolo usque $2 \mathrm{~cm}$ longo gracili glabrato; floralia \pm minuta s. saepissime in bracteas lineares saepe bi- (s. raro pluri-) glandulosas reducta. Paniculae pleraeque duplo (s. etiam triplo) compositae umbellis 4-(5- - 2 -) floris terminales axillaresque, nunc folioliferae $\mathrm{s}$. etiam ramulos foliferos terminantes, nunc tantum bracteiferae eaeque axillares ad folia ramorum superiora (pleraeque geminae vel etiam ternae) et ita in paniculas amplas superioris ordinis congestae, pedunculis floriferis $0-2$ (rarissimis -4 ) $\mathrm{mm}$, pedicellis $1 / 2-1 \mathrm{~cm}$, bracteis linearibus (s. raro lanceolatis) $1^{1 / 2}-7 \mathrm{~mm}$, bracteolis oblongis s. linearibus (s. raro ovato-lanceolatis) $1-2 \mathrm{~mm}$ longis. Flores $1-\mathrm{l}^{1 / 4} \mathrm{~cm}$ diametro. Sepala ovato-oblonga nunc eglandulosa (glandulis \pm obsoletis) $\pm 2 \% \mathrm{~mm}$ longa, nunc (saepius in eodem specimine) glandulas 8 lineari-oblongas $1 \frac{1 / 3}{-2} \mathrm{~mm}$ longas et apice solutas reflexasque $1 / 2-1 \mathrm{~mm}$ superantia. Petalorum limbus e basi rotunda ovalis obovatusve (quinti e basi sagittata ovatus) $3-3 \frac{2}{3} \mathrm{~mm}$, unguis $1 \frac{1}{2}-31 / 2 \mathrm{~mm}$ longus. Styli basi divergentes sursum incurvi. Samarae puberulae angulo recto $\mathrm{s}$ obtuso divergentes: nux fusca inde ab areola 4-5 $\mathrm{mm}$ longa, areola $3-4 \mathrm{~mm}$ diametro, endocarpii processu usque ${ }_{/ 3}^{2 / 3}-4 / 5$ loculi promi nente; ala oblique oblonga s. ovalis, margine superiore magis curvato basique rotundata nucem nunc paulo, nunc usque duplo superante, usque $2 \mathrm{~cm}$ longa et $11 \mathrm{~mm}$ lata. $-H$. obtusata, intermedia et aceroides Griseb. $\left.{ }^{28}\right)-H$. Lindleyana Juss. ${ }^{25}$ )

49. H. aceroides Griseb. ${ }^{29}$ ) aucta

f. I. Grisebachiana Ndz.: Foliis e basi obtusa s. rotundata lanceolatis s. rarius majoribus orato-lanceolatis ovatisve usque $15 \mathrm{~cm}$ longis et $6 \mathrm{~cm}$ latis, petioli basi eglandulosa. $H$. aceroides Griseb. et $H$. oblusata Griseb.

subf. 1. elongata Ndz.: Foliis etiam majoribus elongato-lanceolatis (long.: lat. $=4-3: 1$ ) usque $16 \mathrm{~cm}$ longis et $5^{1 / 3} \mathrm{~cm}$ latis longissime acuminatis.

26) Notis Grisebachianis e samarae indole sumptis ne specimina quidem authentica Selloana quadrantibus ceterisque vix potioris momenti censendis species tres Grisebachianae vix formae resp. ne formae quidem unius speciei frequentissinae habendae sunt, 
a. Ca Jjce eglanduloso. - Sa. Catharina (Bade [?] a. 1E34); S. Paulo (Sello IV. it. 5411; Comm. geogr. e geo]. 3206 [leg. Campos Novaes]: Campinas, Capoeira); Rio de Janeiro (Sello Il. it. 202-269-350: inter Campos et Vittoria); Matto Grosso (Patricio da Silva Manso 379 [X. 1825]: Cujacá); Paraguaria (Hassler 6775: in valle fluminis $\mathrm{Y}$-acá, in dumeto prope Piribebuy).

b. Calyce glandulifero. - Sa. Catharina (U1e 712: Blumenau: Velha, in silva, et 1009: Tubarão, ad limites silvae monticolae); Paraguaria (Hassler 5969 [glandulis 2-4 petioli apici s. sub apice s. folii basi appositis]: in silva prope $\mathrm{fl}$. Tapiraguay).

subf. 2. typica Ndz.: Foliis majoribus ovato-lanceolatis (long.: lat. $=5-4: 2$ ), usque 12 : $\mathrm{cm}$ longis et $5^{1 / 2} \mathrm{~cm}$ latis mediocriter acuminatis.

a. Calye eglanduloso. -- S. Paulo (Comm. geogr. e geol. 4157 [leg. Campos Novaes]: Jundiahy, Capoeira); Rio de Janeiro (Ackermann a. 1833; Vauthier 453 et 454; Schüch a. 1840 et .... Sebastianopolis [H. intermedia Griseb.]; Barboza; ... herb. Zuccarini; Schott 5893: Tijuco; Glaziou 3889 et 3890: Gavia; Schenck 2102 [lign. n. 270]: Rio de Janeiro, prope hortum botanicum; .... herb. Grisebach: ex herk. Kew. [H. intermedia Griseb.]\%.

b. Calyce glandulifero, - Sa. Catharina (U le 741: Blumenau in silva seeundum fl. Itajahy, et 1009: Tubarão ad limites silvae monticolae); S. Paulo (Mosen 2800; Comm. geogr. e geol. 3377 [leg. Edwall]: Botucatu, Capoeira, et s.n. [leg. Campos Porto]: Campo, 2a Parada); Rio de Janeiro (Schüch 347 [Banisteria]" et 5686; Glaziou 716); Sello s. n. locove [H. obtusata Griseb.].

subf. 3. ovata Ndz: Foliis majoribus late ovatis (long.: lat. $= \pm 3: 2$ ), usque $12 \mathrm{~cm}$

longis et fere $8 \mathrm{~cm}$ latis, breviter et \pm abrupte acuminatis; calyce glandulifero. - Rio de Janeiro (Gaudichaud a. 1824; Glaziou 6107).

f. 1I. intermedia (Juss.) Ndz.: Foliis e basi rotundata s. subcordata ovato-lanceolatis ovatisve s. rarius lanceolatis vel subcordatis, petioli basi 2 -glandulifera.

subf. 1. lancifolia Ndz.: Foliis etiam majoribus lanceolatis (long.: lat. $=6-5: 2$ ), usque

$15 \mathrm{~cm}$ longis et $5 \mathrm{~cm}$ latis, petioli glandulis parvis s. saepius (in eodem specimine) obsoletis.

a. Calyce eglanduloso. - S. Paulo (Martius [XII. 1817]: in campis circa urbem S. Pauli); Rio de Janeiro (W awra et Maly 526: Corcovado'.

b. Calyce glandulifero. - Rio de Janeiro (Gaudichaud 969; Guillemin 283: Lac de Freytas'.

subf. 2. Lindleyana (Juss.) Ndz. - H. Lindleyana Juss.: Foliis majoribus ovato-lanceolatis ovatisve (long.: lat. $=5-3: 2$ ), usque $13 \mathrm{~cm}$ longis et $7 \mathrm{~cm}$ latis, petioli glandulis semper conspicuis.

a. Calyce eglanduloso. - Sello reliq.: sine num. locove; Bahia (Wawra et Maly 318: llheos).

b. Calyce glandulifero. - Sello s. n. locove; Rio Grande do Sul (Sello IV. it. 2472); Sa. Catharina (Ule 1008: in sivula prope Tubarão); S. Paulo (Com m. geogr. e ge ol. $282_{2}$ [leg. Campos Novaes]: Campinas); Rio de Janeiro (A ckermann: Rio Doce; Pcckolt 123: Canto Gallo; Schenck 2909: Theresopolis, Serra dos Orgaos, in silva; Moura 647 et 651 : Theresopolis [glandulis calyeinis vix ${ }^{2} / 3 \mathrm{~mm}$ longis]); Minas (Regnell I. 33; Lindberg 234 [in herb. Bruxell.] [H. Lindleyana var. calyce glandulifero e Griseb. in sched.]: prope Caldas). 
subf. 3. tiliifolia Ndz.: Foliis majoribus basi subcordatis tiliiformibus usque $8 \mathrm{~cm}$ longis et $6 \mathrm{~cm}$ latis, petioli glandulis conspicuis, internodiis usque $1^{1 / 2} \mathrm{dm}$ et ultra longis ${ }^{29}$ ). - Sello s. n. locore [Hiraea platyptera Griseb. in herb. Berol.]; S. Paulo (Comm. geogr. e geol. 1807 [leg. Edwall]: Ubatuba, Capoeira maritima); Sa. Catharina (Ule 713: in silva regionis,, Velha*).

2. Liana ramulis gracilibus tomento ferrugineo "spurce" pubentibus, ramis glabratis incanis $\$$. schistaceis, lenticellis plerumque inconspicuis, internodiis $1-4 \mathrm{~cm}$ longis vix usque $3 \mathrm{~mm}$ diametro. Folia lanceolata s. elliptico-lanceolata \pm longe acuminata usque $8 \mathrm{~cm}$ longa et $3^{1 / 3}(-4) \mathrm{cm}$ lata, novella utrinque pube ferruginea relutina, adulta supra plane glabrata lucidaque, subtus tomento ferrugineo in nervis densiore et diutius persistente conspersa, membranaceo-chartacea, eglandulosa, petiolo ferrugineo-pubescente tenui eglanduloso s. basi glandulifero $1 / 2$ - ultra $1 \mathrm{~cm}$ longo. Paniculae ferrugineo-pubescentes simpliciter $3-9$ umbellis 4-(-1-)floris compositae bracteoliferae, singulae axillares ad folia fere subduplo longiora, umbellarum pedunculis $3-8 \mathrm{~mm}$, floriferis $1-5 \mathrm{~mm}$, pedicellis $3-6$ $\mathrm{mm}$, bracteis linearibus oblique erectis s. revolutis $1^{1} / 2-2 \mathrm{~mm}$, bracteolis oblongis accumbentierectis $1 / 2-2 / 3 \mathrm{~mm}$ longis. Flores $\pm 1 \mathrm{~cm}$ diametro. Sepala oblongo-ovata nunc eglandulosa nunc glandulas $6-8$ orales $1-1^{1 / 2} \mathrm{~mm}$ longas $1 \frac{1}{2}-2 \mathrm{~mm}$ superantia. Petalorum limbus e basi acuta $\mathrm{s}$. (in interioribus et praecipue quinto) sagittata ovatus $\pm 3 \mathrm{~mm}$, unguis $1-3 \mathrm{~mm}$ longus. Styli 3 erecti \pm paralleli. Samarae puberulae (siccae) alutaceae verticaliter erectae et ita 士 parallelae, saepius vero (carpellis 2 abortivis) singulae: nux usque $6 \mathrm{~mm}$ longa, areola ventrali fere $4 \mathrm{~mm}$ diametro; ala usque $2 \% \mathrm{~cm}$ longa et $1 \mathrm{~cm}$ lata subcultriformis s. subfalcata, marginibus subparallelis subdirectis s. leviter curvatis, superiore. (s. potius interiore) appendicula basali rotundata vix $1 / 2 \mathrm{~cm}$ longa et $2 \mathrm{~mm}$ alta instructo. - Rio de Janeiro; S. Paulo.

50. H. paticiflora Juss.

f. 1. glandulifera Ndz.: Calyce 8-glandulifero. - Rio de Janeiro (Riedel - Karwinski

I.-III. 1823: prope Mandiocea; Pohl 5684 [1483 d.]: Dryas; Schott: Bras. austr.; Glaziou 1500 et 10256); S. Paulo (Comm. geogr. e geol. 2854 [leg. Campos Novaes]: Campinas).

f. 2. eglandulosa Ndz.: Calyce eglanduloso. - Rio de Janeiro ( . . : herb. Zuccarini; Glaziou 8291); S. Paulo (Comm. geogr. e geol. 671 [leg. Löfgren]: Capoeirao, Morro Grande prope Rio Claro).

1I. Styli dorso apicis angulosi s. \pm acuminatim producti.

1. "Arbor triorgyalis“ (e Jussieu) inflorescentiis ramulis ceterisque partibus norellis rufo-tomentosis, ramis cinereis rugosis lenticellisque paucis concoloribus notatis, annotinis usque $3 \mathrm{~mm}$ diametro, internodiis $1 /-3 \mathrm{~cm}$ longis. Folia e basi acuta vel cuneata oblonga s. oblanceolata, apice rara breviter acuminata, pleraque obtusa s. rotundata s. emarginata, $1 \frac{1}{2}-5 \frac{1}{2} \mathrm{~cm}$ longa, $2 / 3-2 \frac{1}{2} \mathrm{~cm}$ lata, margine valde revoluto subcrenata, chartacea, adult a supra glabrata opaca laevia, subtus aureo- s. incano-tomentosa nervo medio tantum vix sub tomento prominente, petiolo tomentoso $1 / 2-1^{1 / 4} \mathrm{~cm}$ longo. Umbellae pleraeque 4 -florae s. (additis 2 floribus paulo distantibus) corymbi 6 -flori dispositi in paniculas simplices bracteiferas axillares terminalesque et digestas in paniculas foliiferas ramulos breves terminantes, pedunculis umbellarum $1 \frac{1}{2}-3 \mathrm{~mm}$, floriferis $0 \mathrm{~mm}$, pedicellis (sessilibus) $5-7 \mathrm{~mm}$, bracteis umbellas fulcientibus lanceolato-linearibus $3-4 \mathrm{~mm}$, floriferis bracteolisque ovatoacutis 2 resp. $1 \frac{1}{4} \mathrm{~mm}$ longis. Flores $1 \mathrm{~cm}$ diametro. Sepala (an semper?) eglandulosa

29) Internodiis ceterarum formarum vix $3 / 4 \mathrm{dm}$ superantibus. 
ovata $2^{1 / 2} \mathrm{~mm}$ longa. Petala sigmoideo-redunca, limbo cochleariformi-obovato integro $3-\delta^{1 / 2} \mathrm{~mm}$, ungui valde redunco $2-2^{1 / 4} \mathrm{~mm}$ longo. Antherae ovales glaberrimae 1 mm longae. Styli dorso apicis acuti. Samarae non suppetunt. - Bahia (B lanchet 3265: d' Igreja Velha [in sched. herb. Bruxell.] s. ,in silvulis [vulgo catingas] de solidade [e Jussieu]).

51. H. catingarum Juss.

2. Partes noveilae rufo- $s$. ferrugineo-sericeae mox glabratae. Folia adulta utrinque mox s. demum glabrata lucida nervosa.

† Liana ramulis compressis et striatis, sicut rami glabrati canescentes, lenticellis sero conspicuis, internodiis $1 / 2-12 \mathrm{~cm}$ longis usque $3 \mathrm{~mm}$ diametro. Folia e basi acuta s. obtusa ovalia s. raro ovata s. I oblonga apice nunc breviter et abrupte acuminata, nune obtusa s. emarginata, usque $7 \mathrm{~cm}$ longa et fere $4 \mathrm{~cm}$ lata, chartacea, utrinque novella parce subsericea, adulta demum glabrata lucida et nervis creberrimis prominulis - medio praesertim subtus prominente - dense reticulata, margine subplano crenata et subtus in sinubus glandulifera, petiolo glabrato tenui curvato $1-1^{1 / 2} \mathrm{~cm}$ longo hasi biglanduloso. Umbellae pleraeque 4 -florae s. (ad basim paniculae) - additis 2 floribus distantibus - corymbi 6-flori dispositi in paniculas simplices axillares terminalesque vix ultra $4 \mathrm{~cm}$ longas bracteiferas et digestas in paniculam foliiferam ramos terminantem, pedunculis umbellarum $10-2 \mathrm{~mm}$, floriferis vis usque $1 \mathrm{~mm}$, pedicellis sessilibus s. subsessilibus $6-10 \mathrm{~mm}$, bracteis umbellas fulcientibus lanceolato-linearibus $2-4 \mathrm{~mm}$, floriferis bracteolisque lanceolato-acutis $1^{1 / 2}-1 \mathrm{~mm}$ longis. Flores antecedentis, sed antherae locali puberuli et styli dorso apicis paulo acuminati. Samarae non suppetunt. - Minas; Rio de Janeiro (?).

52. H. crenulata Griseb.

f. 1. eglandulosa Ndz.: Calyce eglanduloso, - Rio de Janeiro (?' (Glaziou 13608).

f. 2. glandulifera Ndz.: „Calyce 8-glanduloso" (e Griseb.). - Minas ${ }^{\mathbf{3 0}}$ )

if Liana glaberrima, inflorescentiis tantum et ramulis novellis ferrugineo-sericeis, ramis ramuligque laevissimis incanis $\mathrm{s}$. fuscis, lenticellis sero conspicuis, internodiis $2-5 \mathrm{~cm}$ longis usque $3^{1 / 2} \mathrm{~mm}$ diametro. Folia e basi obtusa s. rotundata pleraque ovata s elliptica s. elliptico-oblonga et abruptim breviter obtuseque acuminata, usque $10 \mathrm{~cm}$ longa et $5 \mathrm{~cm}$ lata, s. ovato-rotunda (usque $7 \times 5 \mathrm{~cm}$ ) s. oblongo-lanceolata et longius acuteque acuminata (usque $11 \times 5 \mathrm{~cm}$ ), chartaceo-s. pleraque rigido-coriacea, utrinque concolori-viridia glaberrima lucidaque et nervis prominulis (subtus primariis medioque magis prominentibus) reticulata, margine revoluto remote glanduligera s. eglandulosa, petiolo fusco glaberrimo crassiusculo $1 / 2-1 \frac{1 / 4}{\mathrm{~cm}}$ longo ima basi glandulis 2 lateralibus orbicularibus instructo; floralia omnia ad bracteas lineares $2-4 \mathrm{~mm}$ longas sursum reflexas s. revolutas basi biglandulosas reducta. Inflorescentiae is $H$. pauciftorae simillimae axillares vix folia dimidia aequantes s. raro superantes: $3-7$ umbellae 3--4-florae (s. raro etiam corymbi 5 - -6 - flori) pedunculo $3-8 \mathrm{~mm}$ longo stipitatae bracteisque biglandulosis fultae in paniculas usque $7 \mathrm{~cm}$ longas dispositae, pedunculis floriferis $2-3(-5) \mathrm{mm}$, pedicellis $4-7 \mathrm{~mm}$, bracteis bracteolisque oblongis linearibusve saepe sursum reflexis $\mathrm{s}$. revolutis $1-3 \mathrm{~mm}$ longis. Flores $\pm 1^{1 / 3} \mathrm{~cm}$ diametro. Sepala ovata apice rotundata nunc eglandulosa $3-3^{1} / 2 \mathrm{~mm}$ longa, nunc glandulas 8 lineari-oblongas $2-3 \mathrm{~mm}$ longas apice solutas et 士 revolutas $0-1 \mathrm{~mm}$ superantia saepe apice recurva. Petala saepe (sicca quidem) involuta s. revoluta, limbo ovato s. cordato s. (praecipue quinti) sagittato $3-4 \mathrm{~mm}$, ungui $2-4$ $\mathrm{mm}$ longo. Stamina stylique graciles. Stamina 2 stylis posticis resp. petalis 3 . et 4 . (i.

30) Quod specimen authenticum non vidi, 
e. postico-lateralibus) opposita ceteris valde crassiora (et anthera et praecipue filamento). Antherae glaberrimae. Styli apicis dorso rectanguli s. obtusiuscule angulosi. Samarae puberulae fcrrugineae s. alutaceae angulo recto s. obtuso inter se divergentes: nux inde ab areola $6 \mathrm{~mm}$ longa, areola $5 \mathrm{~mm}$ diametro, endocarpii processu interno I. usque medium in loculum prominente; ala semiobovata $1^{1 / 2} \mathrm{~cm}$ longa $3 / 4 \mathrm{~cm}$ lata, margine inferiore subdirecto, superioris appendicula basali vix $1 / 2 \mathrm{~cm}$ longa et $2 \mathrm{~mm}$ alta. - H. Leschenaultiana et $H$. Wiedeana Juss. - H. cynanchoides Griseb. - Rio de Janeiro; Minas.

๖3. H. Leschenaultiana Juss. ${ }^{3 \prime}$ ) aucta

var. $\alpha$. lanceolata Ndz.: Foliis chartaceo-coriaceis oblongo-lanceolatis sensim longius et acute acuminatis usque $11 \mathrm{~cm}$ longis et $5 \mathrm{~cm}$ latis; inflorescentiis paulo amplioribus. 1. 1. glandulifera: Calyce 8-glanduloso. - Rio de Janeiro (Sello s. n.; Lund [H.cynanchoides Griseb.]: Caldas; Pohl s. n.: in via a Magaritava ad Jaguay (f. corymbis quoque]; Glaziou 61C5 [H. aceroides var. pachyphylla Griseb.]: ad Mage, et 7543); Minas (Lindberg 235: prope Caldas).

f. 2. eglandulosa: Calyce eglanduloso. - Rio de Janeiro (Warming 144; Meñdonȩa 235: Friburgo).

var. $\beta$. Wiedeana (Juss.) Gris. - H. Wiedeara Juss.: Foliis rigido-coriaceis \pm ovatis ellipticisve abruptim breviter et obtuse acuminatis usque 7-10 $\mathrm{cm}$ longis et $5 \mathrm{~cm}$ latis; inflorescentiis plerisque minus amplis; calyce 8-glanduloso. -- Rio de Janeiro.

f. 1. oblonga: Foliis oblongo-ovatis s. -ellipticis. - Schüch s. n.: Dryas; Bunbury; Schenck 3740: in silvis ad Morro do koa Vista; Schwacke 10866.

f. 2. rotunda: Foliis rotundo-ovatis s. -ellipticis. - Dö llinger; Schüch 5675; Glaziou 1327.

f. 3. orata: Foliis majoribus ovatis s. obovatis. - Princ. Neuwied: I. 1817 (Nees ab Esenbeck IV; Glaziou 1060).

$\mathrm{f}_{\dagger}$ Hue pertinere videtur species quaedam nova floriferisque tantum speciminibus nota valde atfinis $H$. aceroidi f. 11 . intermediae subt. 2. Lingleyance et praecipue stylorum indole ab ipsa diversa:

Liana ramulis novellis (necnon inflorescentiis) compressis rufo-sericeis, ramis mox glabratis teretibus striatis s. rugosis demum canescentibus usque $4 \mathrm{~mm}$ diametro, internodiis $1 / 4-1^{1 / 4} \mathrm{dm}$ longis. Folia e basi obtusa s. rotunda (raro acuta) ovata s. oblongo-ovata longe (fere usque $4 \mathrm{~cm}$ ) et acutissime acuminata $8 \mathrm{~cm}-2 \mathrm{dm}$ longa $4 \mathrm{~cm}-1 \mathrm{dm}$ lata, margine subplana, chartaceo-membranacea, utrinque mox glabrata atque nervis creberrimis non solum primariis sed etiam secundariis inter se parallelis et prominulis (medio primariisque utrinque $6-10$ prominentibus) dense reticulata, petiolo glabrato basi biglanduloso saepe volubili $1^{1 / 2}-3^{1 / 2} \mathrm{~cm}$ longo; floralia i. e. umbellas s. paniculas secundarias fulcientia omnia in bracteas lineari-lanceolatas $7-2 \mathrm{~mm}$ longas reducta. Umbellae 4-florae s. corymbi 6 -flori plerique sessiles s. breviter pedunculati et dispositi in paniculas duplo compositas axillares terminalesve, pedicellis sessilibus $6-11 \mathrm{~mm}$, bracteis bracteolisque ovato-acutis s. linearila nccolatis $1 / 2-1^{1 / 4} \mathrm{~mm}$ longis. Flores $\pm 1^{1 / 4} \mathrm{~cm}$ diametro. Sepala ovata s. ovato-lanceolata nune eglandulosa $2^{1 / 2}-3 \mathrm{~mm}$ longa, nune glandulas 8 ovales s. suborbiculares $\pm 1^{2 / 3} \mathrm{~mm}$ longas $1^{1 / 2}-2 \mathrm{~mm}$ superantia. Petalorum limbus crenulatus e basi cuneata obovatus s. oblanceolatus $3^{1 / 2}-5 \mathrm{~mm}$, unguis valde reflexus $1-2 \mathrm{~mm}$ longus. Stamina stylis 2 posticis opp osita valde, antico oppositum paulo ceteris longiora crassioraque, antheris

31) H. Leschenautiona var, Earboziana Griseb. e specimine authentico herb. Bruxell. necnon specimina quaedam,quibus a Grisebach $H$. Leschencultiana var. Wiedcana inscripta est, ad genus Tetrapterygem pertinent. 
ovalibus s. oblongo-ovalibus 1 resp. usque $1^{1 / 2} \mathrm{~mm}$ longis. Styli postici sigmoidei antico subdirecto multo crassiores, omnes dorso apicis longe pediformiuncinati. Samarae non suppetunt. - Rio de Janeiro. 54. H. transiens Ndz.n. sp. ${ }^{32}$ ) f. eglandulosa Ndz.: Calyce eglanduloso. - PohI 5730: in silvis ad Pirahy, S. Jono (H. intermedia e Griseb. in sched. herb. Vindob.).

f. 2. glandulifera Ndz: Calyce 8-glandulifero. - Glaziou 16725. - Culta in horto Berolin. a. 1835 et 1841 sub nomine "Tetrapterys latifolia Klotzsch" et a.1862 sub nomine „Heteropterys ovata.

B. Pedunculi floriferi nulli („Pedicelli sessiles s. basi articulati ${ }^{6}$ ). Petala lutea. Androeceum didynamium: stamina tantum 2 stylis posticis opposita ceteris crassiora. Samarae (in $H$. argyrophaea tantum notae): nucis endocarpium planum neque in loculum prominens. Cotyledones directae crasso-carnosae.

Subsectio B. Aptychia.

a. Folia subtus sericea. Umbellae s. corymbi pedunculo $2-6 \mathrm{~mm}$ longo suffulti, peduneulis cujusque ordinis gracilibus, bracteis umbellas paniculasve secundarias fulcientibus linearilanceolatis subtus basi biglandulosis. flores fulcientibus bracteolisque \pm linearibus. Petalorum limbus membranaceus cochleariformis denticulatus.

Series a. Argyria. Liana canescens, ramulis complanatis incano-sericeis, ramis glabratis teretibus cinereis lenticellisque crebris concoloribus tuberculatis, internodiis $1 / 2-8 \mathrm{~cm}$ longis usque $1 / 2 \mathrm{~cm}$ diametro. Folia e basi obtusa s. rotundata s. subcordata nune ovata vel obovata vel elliptica apice acuta s. mucronulata $3-10 \mathrm{~cm}$ longa $1^{1 / 2}-5^{1 / 2} \mathrm{~cm}$ lata, nunc ovato-lanceolata lanceslatave et saepius acuminata usque $10(-14) \mathrm{cm}$ longa et $4-5(-6 \%) \mathrm{cm}$ lata, membranacea s. chartacea, supra glabrata subtus incano-sericea, nervis medio primariisque (utrinque 5-9) subtus prominentibus, secundariis prominulis, supra omnibus vix prominulis reticulata, petiolo puberu lo supra canaliculato basi biglanduloso 4-12 $\mathrm{mm}$ longo; floralia (i. e. paniculas corymbosque superiores fulcientia) ad bracteolas triangulari-lineares $8-3 \mathrm{~mm}$ longas reducta. Umbellae 4 -florae et (additis 2 floribus saepe rudimentariis) corymbi 6 - flori dispositi in paniculas breves s. corymbos terminales et axillares (superiores ad bracteas, imae ad folia minora) efformantes paniculam \pm amplam ramulos plurifoliiferos terminantem, pedicellis $4-7 \mathrm{~mm}$, bracteis bracteolisque $1^{1 / 2}-2$ resp. $1-1^{1 / 2} \mathrm{~mm}$ longis. Flores vix ultra $1 \mathrm{~cm}$ diametro. Sepala lanceolata glandulas 8 suborbiculares s. ovales $1 / 2-2 / 3 \mathrm{~mm}$ longas $2 \mathrm{~mm}$ superantia. Petala sigmoideo-recurva, limbo vix ultra $3 \mathrm{~mm}$, ungui valde redunco $2-2^{1} / \mathrm{mm}$ longo. Filamenta $4 \mathrm{~mm}$, antherae ad $1 \mathrm{~mm}$ longae. Styli paulo curvati vix $3 \mathrm{~mm}$ longi. Samarae alutaceo-brunneae sericeae \pm ascendentes; nux ultra $1 \mathrm{~cm}$ longa et $6 \times 8 \mathrm{~mm}$ diametro, semine \pm conico; ala nune semiovata nune subfaleiformi-obovata. - S. Paulo; Minas; Paraguaria.

55. H. argyrophaea Juss.

f. 1. lanceolata Ndz.: Foliis lanceolatis; stylis dorso apicis subrobundatis; samarae ala linea directa a nuce abeunte \pm semiovata, margine inferiore subdirecto, superiore sirnpliciter curvato, usque $3^{1 / 2} \mathrm{~cm}$ longa et $1^{1 / 2} \mathrm{~cm}$ lata. - S. Paulo (Comm, geogr.e geol. 1566 [leg. Puiggari]: Jundiahy, Capoeira); Paragnaria (Hassler 65う9: prope Paraguary in silva).

f. 2. ovata Ndz.: Foliis majoribus \pm ovatis; stylis dorso apicis acutis; samarae ala arcu s. angulo a nuce abeunte \pm falciformi oblique obovata, margine inferiore simpliciter et valde, superiore duplo curvato, usque $3 \frac{1}{2} \mathrm{~cm}$ longa usque $1^{3} / \mathrm{cm}$ lata. - Paraguaria (Balansa 2410: in silvis, et 2644: Villa Rica; Hassler 3514: Cordillera de Altos,

32) Quae species transitum a Stenophyllario in Holopetalum adhibet. 
in silva, 5375: Sierra Maracayu, in silva, et 7958: in silva arboribus depauperata prope Bellavista in regione cursus superioris fluminis Apa).

f. 3. eglandulosa Griseb : Foliis orato-lanceolatis usque $14 \mathrm{~cm}$ longis et $61 / 2 \mathrm{~cm}$ latis; stylis dorso apicis acutis; samaris .... (non suppetentibus). - Minas (Warming 6. IV....: Lagoa Santa).

b. Folia subtus nune glabra nune tomentosa atque nerrosa, nervis non modo primariis, sed etiam creberrimis secundariis inter se parallelis. Umbellae ramuligenae sessiles, bracteis paniculas secundarias umbellasque fulcientibus subulato-linearibus basique glandulis 2 magnis instructis, pedicellis (sicut pedunculi cujusque ordinis) crassis (praecipue sursum), bracteis floriferis bracteolisque latis brevibus crassis involucrum efformantibus. Petalorum limbus cordato-s. ovato-s. obovato-cymbitormis margine integerrimus, unguis \pm alatus. Stamina praesertim 2 stylis posticis opposita (rarius etiam antico oppositum) omnibus ceteris multo longiora crassioraque necnon sigmoideo-curvata. Styli dorso apicis acuti s. breviter uncinatim producti, 2 postici sigmoideo-curvati antico \pm directo longiores. Samarae (adhuc nullius speciei suppetunt). Series b. Holopetalum Gris.

I. Styli graciles a lateribus compressi sursum secundum medianam dilatati et vertice ipso acuti.

1. Ramuli pedunculique cujusque ordinis pube rufa subsericeo-velutini angulati striati, illi ramique $\operatorname{mox}$ glabrati cortice rimoso griseo obtecti, lenticellis paucis, internodiis $1 / 4-9 \mathrm{~cm}$ longis usque $2 / 3 \mathrm{~cm}$ diametro. Folia \pm oblongo-lanceolata utrinque obtusa $6-11 \mathrm{~cm}$ longa $2^{1 / 2}-4^{1 / 2} \mathrm{~cm}$ lata, utrinque novella subsericea; adulta glabrata et sublucida, churtaceo-coriacea, supra laevia, subtus nervis \pm prominentibus reticulata et glandulis multis obsoletis ad nervorum ramificationes impressa, petiolo glabrato eglanduloso subgracili $3 / 4-1 \frac{1}{2} \mathrm{~cm}$ longo. Paniculae pyramidatae usque $1 \mathrm{dm}$ longae ramulos usque 8 -folifferos terminantes, pedunculis secundariis patentibus, bracteis ipsos fulcientibus $1 / 3-1 / 5 \mathrm{~cm}$ longis, pedicellis $5-8 \mathrm{~mm}$, bracteis bracteolisque vis ultra $1 \mathrm{~mm}$ longis. Flores $1^{1 / 3} \mathrm{~cm}$ diametro. Sepala rotunda ${ }^{+} 0$ - ovata glandulas 8 ovales $\pm 1^{1 / 2} \mathrm{~mm}$ longas vix ultra $1 \mathrm{~mm}$ superantia. Petala dorso subalulato-carinata. Antherae oblongae usque $2 \mathrm{~mm}$ longae. Siyli dorso apicis producti. Samarae...? - S. Paulo (Sello IV. it. 5823 p.p.; Comm. geogr. e geol. de S. Paulo s. n. [leg. Edwall Vl. 1901]: Rais da. Serra, in silva primaeva).

56. H. patens (Griseb.) Juss.

2. Ramuli pedunculique cujusque ordinis pilis erecto-patentibus rufo-hispidi compressi, rami quoque diu hispiduli sero glabrati grisei teretes, internodiis $2-3\left({ }^{1} / 2-5\right) \mathrm{cm}$ longis usque $3 \mathrm{~mm}$ diametro. Folia e basi cordata lanceolata longiuscule s. longe acuminata $4-16 \mathrm{~cm}$ longa $1 \frac{1}{4}-6 \mathrm{~cm}$ lata, novella utrinque rufo-tomentosa, adulta quoque subtus - praesertim secundum nervos - hispida ceterum glabrata sublucidaque et nervis medio primariisque prominentibus, secundariis prominulis reticulata necnon glandulis minimis obsoletis ad nervos impressa et secundum marginem revolutum glanduloso-dentata s.-ciliata (praecipue in acumine), ciliis brevibus (rarissimis $1 \mathrm{~mm}$ superantibus), petiolo hispido crassiusculo $1 / 2$-ultra $1 \mathrm{~cm}$ longo basi glandulis 2 magnis instructo. Paniculae et axillares ad folia superiora et terminales congestae in paniculam superioris ordinis ramum unultifoliatum terminantem, bracteis ramificationes fulcientibus subulatis usque $4 \mathrm{~mm}$ longis nunc incurvis, nunc recurvis, bracteis bracteolisque pedicellos involucrantibus $\mathrm{s}$. vaginantibus semiorbicularibus vix $1 \mathrm{~mm}$ longis. Flores ... (nondum evoluti). Sepala rotundato-ovata, glandulis 8-9 ovalibus. Petala 1-3 intima \pm glanduloso-ciliata, limbo suborbiculari carinato. Antherae ovales. Styli dorso apicis nunc tantum acuti, nunc breviter producti. Samarae... ? - Rio de Janeiro (Widgren 750 [in herb. Bruxell. ex herb. Martiano]: a. 1844; Glaziou 3885 et 4767$)$.

57. H. crinigera Griseb. 
U. Styli - praecipue sursum - 士 subtriangulares striati, plerique crassiusculi, apice ipso eodem modo, quo in Stigmatophylli subgenere Baeopteryge, dilatati. Folia \pm late atque saepius subrotundo-ovata apice acuminata s. apiculata s. rotundata emarginatave, petiolo basi biglanduloso. 1. Liana ramulis et pedunculis cujusque ordinis ancipitibus s. angulatis striatisque necnon pube ferrugineo-lutescenti sericeis, ramis teretibus glabratis griseis lenticellisque tubereulatis, internodiis $2-6(-12) \mathrm{cm}$ longis usque $1 / 2 \mathrm{~cm}$ diametro. Folia e basi obtusa s. rotunda s. 土 subcordata 士 late ovata s. subrotunda s. obovata (s. etiam elliptica vel 士 oblonga) apice nune \pm longe acuminata, nune tantum apiculata vel cuspidato-rotundata s. -emarginata (atque interdum + biloba), usque $18 \mathrm{~cm}$ longa usque $13 \mathrm{~cm}$ lata, utrinque novella pube ferrugineo-lutescenti sericantia, adulta glabrata, chartaceas. coriacea, supra laevia opacaque, subtus sublucida, nervis medio et primariis (utrinque usque 8) prominentibus, secundariis tantum \pm prominulis reticulata atque in nervis et secundum marginem revolutum glandulis crebris minimis obsoletis impressa (in speciminibus quibusdam glanduloso-dentata s. -ciliata), petiolo glabrato gracili curvato $1 / 3-1 / 5$ longitudinis folii $i . e$. usque $4 \mathrm{~cm}$ longo. Paniculae axillares (ad folia s. bracteas) terminalesque in paniculam superioris ordinis elongatam amplissimam dispositae, bracteis ramificationes fulcientibus subulatis usque $6 \mathrm{~mm}$, pedicellis $8 \mathrm{~mm}$, bracteis bracteolisque ipsos involucrantibus semiorbicularibus $1 \mathrm{~mm}$ longis. Flores $1 \frac{1}{2} \mathrm{~cm}$ diametro. Sepala rotundato-ovata dorso carinata eglandulosa vix $3 \mathrm{~mm}$ longa. Petala redunca, limbo e basi sagittata rotundato cochleariformis. cucullato-cymbiformi usque $\% / 3$ dorsi alulato-carinato (quinti denticulato) $4--\tilde{\mathbf{b}}^{1 / 2} \mathrm{~mm}$, ungui redunco $3-3^{1 / 2} \mathrm{~mm}$ longo. Antherae oblongae $1^{1 / 2}-2 \mathrm{~mm}$ longae. Styli dorso apicis producti. Samarae ... . - Rio de Janeiro (Guillemin 996 [V. 1839]: Scrra dos Orgaos; Glaziou 2944, «945, 8299, 11814, 18165 [foliis elliptico-s. obovato-oblongis]; Schwacke 1112 [leg. Schreiner]: ad Canta gallo); Bahia (Luschnath a. 1840: 1lheos [glandulis folia marginantibus usque $1 \mathrm{~mm}$ longis]).

58. H. anomala Juss. f. 2. Calyce 8 -glandulifero, sepalis glandulas ovales $1^{1 / 4}-1^{1 / 4} \mathrm{~mm}$ longas $\pm 2 \mathrm{~mm}$ superantibus: Schüch 5674; Glaziou 10369; S. Paulo (Comm. geogr. e geol. de S. Paulo 1804 [leg. Edwall]: Morro da prainha prope urbem Ubataba, Capoeira maritima).

2. Folia cordato-ovata breviter apiculata necnon novella utrinque, adulta subtus quidem, sicut ramuli et pedunculi cujusque ordinis, pube ferruginea dense velutino-tomentosa, petiolo velutino crasso $2 \mathrm{~cm}$ non excedente.

† Liana ramulis ramisque angulatis, his demum glabratis griseis striatis, internodiis $2-12$ $\mathrm{cm}$ !ongis usque $3 / 4 \mathrm{~cm}$ diametro. Folia usque $12 \mathrm{~cm}$ longa et $9 \mathrm{~cm}$ lata, apiculo vix usque $1 / 2 \mathrm{~cm}$ longo, adulta supra glabrata (exceptis interdum nervis medio primariisque) et opaca necnon laevia s. tantum secundum nervos majores impressa, chartaceo-coriacea, subtus densissime tomentosa, nervis medio primariisque (utrinque 6-8) sub tomento prominentibus, et secundum marginem glandulis minutis instructa $1--2 \mathrm{~cm}$ longa. Paniculae axillares (infimae paucae ad folia, plurimae ad bracteas) terminalesque dispositae in paniculam amplissimam elongatam, pedunculis cujusque ordinis crassis patentibus, bracteis ramificationes fulcientibus brevibus (vix $3 \mathrm{~mm}$ ) crasso-subulatis, pedicellis $5-6 \mathrm{~mm}$, bracteis bracteolisque ipsos involucrantibus semiorbicularibus nondum $1 \mathrm{~mm}$ longis. Flores paulo ultra $1 \mathrm{~cm}$ diametro. Sepala rotundato-ovata glandulas 8 ovales longitrorsum adnatas $1 \frac{1}{4}-2 \% \mathrm{~mm}$ longas $2 \mathrm{~mm}$ superantia. Petala valde redunca, limbo e basi sagittata suborbiculari-cochleariformi et basi dorsi carinato $4-5 \mathrm{~mm}$, quinti glandulosociliato plano suborbiculari vix $3 \mathrm{~mm}$, ungui valde redunco $\pm 2 \mathrm{~mm}$ longo. Antherae ovales $1 \frac{1}{2}-2 \mathrm{~mm}$ longae. Styli dorso apicis in uncum producti. Samarae..... . S. Paulo (Sello IV. it. 5823 p. p. $\left.{ }^{93}\right)$ )

59. H. thyrsoidea (Griseb.) Juss.

33) Sello IV. it. 5323 p. p. ad 56, H, patentem pertinet. 
† Liana ramulis pedunculisque subteretibus pube ferruginea subsericeo-subvelutinis, internodiis usque $1 \mathrm{dm}$ longis usque $3 \mathrm{~mm}$ diametro. Folia apice \pm acutiusculo breviter $(2 \mathrm{~mm})$ apiculata usque $13 \mathrm{~cm}$ longa et $8^{1} / 2 \mathrm{~cm}$ lata, etiam adulta subtus \pm pube persistente velutino-tomentosa, membranaceo-chartacea, margine plano subdenticulata et glandulosociliata, ciliis glanduliferis usque $2 \mathrm{~mm}$ longis, supra laevia, subtus nervis medio primariisque (utrinque 5-8) sub tomento prominentibus et secundariis prominulis reticulata, petiolo $1 / 2 \mathrm{~cm}$ longo. Paniculae duplo compositae axillares (infimae ad folia) terminalesque in paniculam superioris ordinis dispositae, umbellis usque 4 -floris arcte sessilibus, bracteis ramificationes fulcientibus obtuse subulatis $5-2 \mathrm{~mm}$, pedicellis gracilioribus $5-7 \mathrm{~mm}$, bracteis bracteolisque raginatim connatis vix $1 / 2-3 / \mathrm{sm}$ longis. Flores $\pm 11 / \mathrm{cm}$ diametro. Sepala obtuso-ovata glandulas $8-9$ ovales s. oblongas $1-1 \frac{1}{2} \mathrm{~mm}$ longas praecipue parte superiore solutas atque substipitatas $1-1^{1 / 2} \mathrm{~mm}$ superantia. Petala patentia, limbo e basi acuta s. subsagittata obovato-cymbiformi margine revoluto dorso carinato 3-5 mm, ungui 2-2 $2^{1 / 2} \mathrm{~mm}$ longo. Antherae ovales $1^{1 / 2} \mathrm{~mm}$ longae. Styli \pm graciles dorso apicis uncinati et vertice ipso distincte dilatati. Samarae ....? - Rio de Janeiro s. Minas (?) (Glaziou 9678).

60. H. ciliata Ndz. n. $s p$.

II. Sepala orato-lanceolata s. lanceolata a pice revoluta. Petala flara s. raro lutea, limbo membranaceo denticulato s. crenulato. Stamina exteriora $i$. e. petalis opposita alternis breviora, et inter illa et inter haec stylis 3 opposita ceteris crassiora, omnia basi filamenti paulo connata, ceterum 4-adelphia: medio-posticum (i. e. petalo quinto oppositum) a ceteris separatum et inter stylos posticos inflexum; 9 ceterorum terna altius inter se connata. Antherae loculi plerique arcuati (exe. H. pannosa) connectivum ovoideum glanduliforme et apice paulo et praecipue basi excedentes. Samarae endocarpium a facie rentrali (raro vix usque $1 / 2 \mathrm{~mm}$, plerumque vero) non in loculi cavitatem prominens. Folia \pm coriacea et - subtus quidem - nervosa.

\section{Subgenus II. Euheteropterys.}

1. Racemi breves s. breviusculi s. mediocri longitudine, plerique pauci-(2--10-)flori, rari (in n. $70-72$ ) usque $16-(-20$-) flori. Samarae ascendentis (s. in $n .72$ etiam horizontalis) ala tantum secundum marginem inferiorem firmo-coriacea, ceterum membranacea, obovato- s. semiobovato-oblonga, margine superiore basi appendiculato et ita $\zeta$-formi.

Sect. 3. Stenopterys.

A. Racemi apice corymbitormes, nunc breves, nunc interrupti laxiflori. Bracteae obovatae orataeve apice rotundatae et subplanae s. facie superiore parum cavae.

Subsect. A. Homalolepis.

I. Pedunculi cujusque ordinis crassi (floriferi $1 \mathrm{~mm}$ diametro) et (primum quidem) pilis \pm erectis

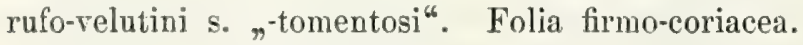

1. Frutex velutino-tomentosus, ramulis compressis tomento rufo, ramis teretibus canescente velutinis et virgatis, internodiis $1 / 2--6 \mathrm{~cm}$ longis usque $4 \mathrm{~mm}$ diametro. Folia (saepius ternata) e basi rotunda lineari-oblonga apice acuta s. obtusa (s. rotundata) usque $1 \mathrm{dm}$ longa et vix usque $3 \mathrm{~cm}$ lata, adulta supra tomento canescente pruinosa 8 . \pm ipso deterso glabrata lucidaque et nervis vix prominulis sublacvia, subtus densissime aurato-s. cinere-tomentosa et nervo medio etiam sub tomento prominente lateralibusque prominulis reticulata, brevissime petiolata, petiolo crasso vix 1-2 mm longo. Racemi simplices usque 10 -flori et $1 / 2 \mathrm{dm}$ longi vel paniculae racemis parris (vix usque $3 \mathrm{~cm}$ longis $2 \cdot-6$-floris) paucis (usque 5) compositae nune axillares, nunc ramulos foliiferos terminantes, pedunculis floriferis $2-4$ $\mathrm{mm}$, pedicellis $3-6 \mathrm{~mm}$, bracteis bracteolisque ovalibus s. ovatis obovatisve $2-3 \mathrm{~mm}$ longis. Flores $\pm 13 / 4 \mathrm{~cm}$ diametro. Sepala orato-lanceolata glandulas ovales $\pm 2 \mathrm{~mm}$ longas $2^{1 / 2}-3 \mathrm{~mm}$ superantia. Petalorum limbus \pm orbicularis $5-7 \mathrm{~mm}$, quirti $4 \mathrm{~mm}$, 
unguis $\pm 2 \mathrm{~mm}$, quinti $3-4 \mathrm{~mm}$ longus. Antherae loculi subdirecti parum excedentes connectivum apiculo verticali instructum et vix s. parce piliferum. Pollen 33-39 $\mu$ diametro. Styli apicis dorso (in eodem specimine) nune tantum angulati s. etiam \pm rotundati, nune brevissime apiculati. Samarae non suppetunt. - Goyaz (Pohl 1940 [d. 15̋0]: Serra S. Felis ad Rio Custodio).

61. H. pannosa Juss.

2. Folia \pm cordata, subtus sericea s. \pm glabrata. Antherae suborbiculares. Styli dorso apicis breviter apiculati.

$\dagger$ Frutex rigidus ramis teretibus plerumque diu pruinoso-velutinis demum canescentibus usque $6 \mathrm{~mm}$ diametro, internodiis $1-7 \mathrm{~cm}$ longis. Folia e basi \pm cordata ovata s. ovatooblonga apice acuta s. breviter acuminata $3-15 \mathrm{~cm}$ longa $1^{1 / 2}-7 \mathrm{~cm}$ lata, nervis crebris supra prominulis subtus prominentibus reticulata, margine subplana, utrinque tomento aureo brevissimo appresso pruinoso-sericea s. demum \pm glabrata, subtus glandulis paucis $(4-10)$ praecipue secundum marginem nervis impressis, petiolo $1-4 \mathrm{~mm}$ longo crasso. Nunc racemi subsimplices $4-12 \mathrm{~cm}$ longi, nune paniculae usque $1^{1 / 2} \mathrm{dm}$ longae axillares $\mathrm{s}$. ramulos 2- -6-foliiferos terminantes, pedunculis floriferis $3-6 \mathrm{~mm}$, pedicellis $4-8 \mathrm{~mm}$ longis, bracteis bracteolisque lanceolatis ovatisve. Flores $1^{1 / 4}-1^{1 / 2} \mathrm{~cm}$ diametro. Sepals lanceolato-ovata glandulas 8 ovales s. oblongas $1^{1 / 2}-2^{1 / 2} \mathrm{~mm}$ longas $2-3^{1 / 2} \mathrm{~mm}$ superantia. Petalorum limbus crenulatus orbiculari-obovatus $4-6 \mathrm{~mm}$, quinti $3 \mathrm{~mm}$, unguis $3-5 \mathrm{~mm}$, quinti $2-3 \mathrm{~mm}$ longus. Antherae connectivum glaberrinum. Samarae rufo-sericeae: nux ovoidea $3 \times 4 \times 6 \mathrm{~mm}$ diametro, endocarpii processu nullo; ala usque $1^{1 / 2}-2{ }^{1 / 2} \mathrm{~cm}$ longa et 8-11 $\mathrm{mm}$ lata, nune oblique semiobovata margine inferiore directo, nune falciformis margine inferiore subsemicirculari et superiore $\zeta$-tormi, appendicula basali $2 \mathrm{~mm}$ alta obtusa s. rotundata. - Goyaz; Minas. 62. H. procoriacea Ndz. n. sp. ${ }^{34}$ ) f. 1. hispida Ndz.: Inflorescentiis hispidis, bracteis bracteolisque lanceolatis usque 6 resp. $2^{1 / 2} \mathrm{~mm}$ longis; foliis ovato-oblongis usque $15 \mathrm{~cm}$ longis et $7 \mathrm{~cm}$ latis utrinque glabratis siccis supra fusco-rubiginosis et subtus auratis, nervis rubellis. - Goyaz (Pohl 1994 (,H. n. sp. juxta $H$. coriaceam e Griseb. in herb. Vindob.]: Arrayal Trahiras).

f. 2. typica Ndz.: Inflorescentiis velutinis, bracteis bracteolisque ovatis obovatisve usque 3 resp. $上 1^{1 / 2} \mathrm{~mm}$ longis; foliis cordatis s. oblongo-cordatis usque $11 \mathrm{~cm}$ longis et $7 \mathrm{~cm}$ latis supra canescenti-, subtus aureo-prninosis. - Goyaz (Burchell 7639: Goyaz - Cavalcante, Goyaz bor. [H. grandiflora e Griseh. in sched.]; Glaziou 20760, 20763 a et 20764); Minas (Martius [H. coriacea $\beta$. Juss.: forma foliis subglabratis usque $7 \mathrm{~cm}$ tantum longis et $4 \mathrm{~cm}$ latis et cortice lenticellis crebris verrucoso]: in campis deserti Serro Frio ad S. Antonio; Regnell III. 325: Uberava; Burchell 6326. [H. Duarteana e Griseb.]).

i† Ramis teretibus glabratis fusco-rubiginosis s. canescentibus copiaque lenticellarum verrucosis usque tere $1 / 2 \mathrm{~cm}$ diametro, internodiis $3 / 4-2(--6) \mathrm{cm}$ longis. Folia cordata s. orbiculari-cordata apice obtusa s. rotundata s. brevissime acuminata, usque $6 \mathrm{~cm}$ longa et $4 \mathrm{~cm}$ lata, margine subplana, utrinque glaberrima et (praecipue supra) lucida necnon nervis (subtus magis) prominulis reticulata, subtus glandulis $4-8$ secundum marginem nervis inpressis, subsessilia petiolo erassissimo vix $1 \mathrm{~mm}$ longo. Paniculae axillares terminalesque (summae foliis fulcientibus ad bracteas reductis in paniculam ampliorem congestae) racemulis corymbiformibus paucifloris (plerisque vix ultra 6-floriferis) compositae, pedunculis floriferis $2-\tilde{\mathbf{b}}(-8) \mathrm{mm}$, pedicellis $5-8 \mathrm{~mm}$, bracteis bracteolisque ovatis obovatisve $1-2^{1 / 2} \mathrm{~mm}$

34) Forsan potius varietas tantum sequentis. 
longis. Flores $1^{1 / 2}-2 \mathrm{~cm}$ diametro. Sepala ovato-lanceolata glandulas 8 ovales s, oblongas $2-2^{1 / 2} \mathrm{~mm}$ longas $\pm 2^{1 / 2} \mathrm{~mm}$ superantia. Petalorum limbus e basi cordata suborbicularis crenulatus 4-6 mm, unguis 3-4 mm longus. Antherae connetirum apice piliferum. Pollen $\pm 36 \mu$ diametro. Samarae non suppetunt. - Goyaz (Pohl 3346 [d. 1503]: ante Faz. Mattinada prope Rio Abaite; Burchell 7749: Goyaz-Cavalcante, Goyaz bor.; Glaziou 20765); Minas (Martius: Minas Noras).

63. H. coriacea Juss.

II. Pedunculi cujusque ordinis vix crassiusculi s. subgraciles (floriferi $2 / 3$ - vix $1 / 2 \mathrm{~mm}$ diametro) et rufo- s. ferrugineo-velutini.

1. Liana (?) ramulis compressis rufo-s. aureo-sericeis, ramis teretibus glabratis canescentibus lenticellarum copia tuberculatis usque $1 / 3 \mathrm{~cm}$ diametro, internodiis $1 / 2-5 \mathrm{~cm}$ longis. Folia e basi acuta s. obtusa ovalia s. I oblonga s. obovata, apice obtusa s. brevissime et obtuse acuminata usque $12 \mathrm{~cm}$ longa et $6 \mathrm{~cm}$ lata, margine subplana, supra glabrata et (nervis tantum primaris paulo impresso-prominulis) laevia lucidaque, subtus pube appressa aurea s. argentea serisea et glandulis parvis secundum marginem nervis impositis instructa, petiolo vix crassiusculo $4-6 \mathrm{~mm}$ longo. Racemuli apice corymbiformes usque $5 \mathrm{~cm}$ longi 6.-12-flori nune simplices axillaresque, nunc dispositi in paniculas simpliciter s. duplo compositas \pm amplas axillares, pedunculis floriferis $1-3 \mathrm{~mm}$, pedicellis $2-4 \mathrm{~mm}$, bracteis ovatis $2--4 \mathrm{~mm}$, bracteolis ovatis $\mathrm{s}$. ovalibus obovatisre $1^{1 / 2}-2 \mathrm{~mm}$ longis. Flores $1^{1 / 3} \mathrm{~cm}$ diametro. Sepala ovato-lanceolata, nune eglandulosa $4 \mathrm{~mm}$ longa, nunc glandulas 8 ovales $2 \mathrm{~mm}$ longas 2--3 mm superantia. Petalorum limbus obovatus 4-5 mm, quinti cordatus $3 \mathrm{~mm}$, unguis 2-3 mm longus. Styli dorso apicis rotundati s. vix angulati. Samarae non suppetunt. Minas; Goyaz.

64. H. xanthophylla Juss. var. $\alpha$. typica Ndz. H. xanthophylla Juss. et H. byrsonimifolia Juss. : Foliis chartaceocoriaceis; calyce eglanduloso; antheris glaberrimis.

f. 1. Foliis oblongo-oralibus s. -obovatis. - Minas (Claussen $82 \mathrm{~A}$; Burche 116067 ; Warming 9. XI. 1863: Donna Theodora pasto, 14. IV. et 15. X. 1863); Goyaz (Glaziou 20762).

f. 2. Foliis suborbiculari-ovalibus s. -obovatis. - Minas (Claussen 400 [H. byrsonimifolia e Griseb.]).

var. $\beta$. Duarteana (Juss.) Ndz. - H. Duarteana Juss. (?) ${ }^{35}$ ): Foliis crassiusculis rigidocoriaceis; calyce 8-glandulifero; connectivi apice pilifero. -- Minas (Warming 3. X. 1863 et 4. I. 1864: Lagoa Santa!.

2. Folia supra nervis creberrimis (et primariis et secundariis) subaequaliter prominulis intricate reticulato-rugosa, subtus nunc (etiam adulta) I velutino-s. pruinoso-pubescentia, nunc pube \pm excussa tantum parce puberula.

† Frutex ,humilis (e Schwacke 8728) s. 2-metralis (e Löfgren 898) s. elongatus" (Warming), ramulis compressis pube rufa subscriceo-velutinis, ramis teretibus glabratis schistaceis lenticellisque \pm crebris tuberculatis usque $6 \mathrm{~mm}$ diametro, internodiis $1 / 3-5 \mathrm{~cm}$ longis. Folia e basi obtusa s. rotunda s. subcordata ovalia s. \pm oblonga, apice obtusa s. rotundata (s. raro emarginata aut brevissime et obtuse subacuminata), usque $13 \mathrm{~cm}$ longa et $8 \mathrm{~cm}$ lata, margine subplana, firmo-coriacea, supra adulta quoque \pm pube canescente adspersa s. vix plane glabrata et \pm lucida, subtus tomento rufo s. demum canescente (et \pm excusso) \pm subsericeo-velutina atque nervis medio primariisque valde prominentibus \pm parallelis, secundariis tantum prominulis reticulata et nunc eglandulosa

35) Nullum specimen originarium perspexi, sed specimina tantum quaedam a Grisebach defnita; qui quum saepius erraverit, hac de re vequeo certi quid affirmare. 
nune glandulis paucis obsoletis secundum marginem subplanum instructa, petiolo crasso 3-6 (raro tantum 1) $\mathrm{mm}$ longo. Racemi usque $6 \mathrm{~cm}$ (incl. peduneulo) longi 2- -12-flori fulti foliolis minutis $1-1 / 2 \mathrm{~cm}$ longis s. ad bracteas oblongas $4-2 \mathrm{~mm}$ longas reductis et dispositi in paniculas axillares, pedunculis floriferis $2 \neg 5 \mathrm{~mm}$, pedicellis $2-6 \mathrm{~mm}$, bracteis (floriferis) bracteolisque ovalibus s. ovatis s. obovatis s. oblongis $21 / 2-2 \mathrm{~mm}$ longis. Flores ultra $1^{1 / 2} \mathrm{~cm}$ diametro. Sepala ovato-lanceolata nune eglandulosa $4-4^{1 / 2} \mathrm{~mm}$ longa, nunc glandulas 8 ovales $2 \mathrm{~mm}$ longas $\pm 2^{1 / 2} \mathrm{~mm}$ superantia. Petalorum limbus orbiculari-obovatus (quinti basi cordatus) $4-5 \mathrm{~mm}$, unguis $3-4 \mathrm{~mm}$ longus. Samarae pallide rufo-subsericeae: nux horizontalis subcylindraceo-ovoidea (a lateribus parum compressa) $6 \mathrm{~mm}$ longa $3 \times 4 \mathrm{~mm}$ diametro, areola ventrali paulo cavata orbiculari $4 \mathrm{~mm}$ diametro, endocarpii processu vix $1 \mathrm{~mm}$ in loculi cavitatem prominente; ala apice rotundata oblique ovalis s. semiovalis, margine inferiore subdirecto (s. apice tantum curvato) oblique ascendente (et ita cum nuce angulum obtusum, cum margine alterius samarae inferiore subrectum efformante), superiore arcuato et basi appendicula $6 \mathrm{~mm}$ longa vix $2 \mathrm{~mm}$ alta rotunda instructo et ita 5 -formi; embryo loculo conformis, cotyledonibus crasso-carnosis ineaqualibas, radicula minima. - $H$. affinis e Griseb. p. p. (num etiam Juss.?). - Minas; Goyaz; S. Paulo. 65. H. byrsonimifolia Juss. (? ${ }^{36}$ ) var. a. eglandulosa Ndz.: Calyce eglanduloso; antheris glaberrimis.

f. 1. Stylis apicis dorso rotundatis s. rectangulis. - Minas (Regnell III. 324: Uberava); Goyaz (GIaziou 20763).

f. 2. Stylis apicis dorso acuminatis s. apiculatis. - Goyaz (?) (Pohl 5717 [H. affinis

e Griseb.]: Chapada inter Farado et Rib de Pratu).

var. $\beta$. glandulifera Ndz.: Calyce glandulifero; connectivi apice piloso.

f. 1. Stylis apicis dorso rotundatis s. angulosis. - Minas (Stephan: Congonhas do Campo; Warming: Lagoa Santa [H. affinis e Griseb.]: 22. X. 1863 [719: ad margines silvarum], 9. IX. 1864 et 5. VI. 1865); S. Paulo (Lund VllI. 1834: in campis prope Paracatu; Burchell 535̃1 [Het. pannosa e Griseb.]; Löfgren 898: Araraguara, Serrado); Glaziou 12488.

f. 2. Stylis apicis dorso apiculatis. - Minas (Schwacke 8728: Serra de Antonio Pereira); Goyaz (?) (Pohl 3601 [foliis obovatis s. obovato-oblongis]: inter Faz. Lopez et S. Cruz). i† Frutex "erectus" (e Schwacke 7433) ramulis compressis ferrugineo-velutinis, ramis teretibus cinerascentibus lenticellisque crebris tuberculatis usque $1 / 2 \mathrm{~cm}$ diametro, internodiis $1 / 2-5 \mathrm{~cm}$ longis. Folia e basi acuta (s. raro obtusa) oblonga s. oblongo-obovata apice obtusa s. brevissime et obtuse acuminata s. etiam emarginata, usque $8 \mathrm{~cm}$ (rarissime usque $14 \mathrm{~cm}$ ) longa et $3 \frac{1}{2} \mathrm{~cm}$ lata, tenui-coriacea, novella utrinque ferrugineo-velutina, adulta supra (si excipias pilos quosdam incanos praccipue secundum nervos persistentes) glabrata lucidaque, subtus quoque eodem modo quo supra intricate reticulatoverruculosa, costa media sola prominente, nervis primariis vix magis quam secundarii tertiariique prominulis, et nunc glabrata opacaque (sicca saepius ferruginea), nune \pm ferrugineo-sericea s. -velutina, omnia serie glandularum parvarum in nervis secundum marginem 士 rerolutum impressa, petiolo crassiusculo puberulo $2-6 \mathrm{~mm}$ longo; floralia usque $1^{1 / 2} \mathrm{C}^{1 / 3}$ $\mathrm{cm}$ minuta s. ad bracteas $4-2 \mathrm{~mm}$ longas reducta. Racemi vix ultra $4 \mathrm{~cm}$ longi $2--10$ flori ad foliola bracteasve axillares et dispositi in paniculas $1 / 3-1 \% \mathrm{dm}$ longas axillares terminalesque et saepius in paniculam ampliorem ramos terminantem congestas, pedunculis floriferis $6-1 \mathrm{~mm}$, pedicellis $6-3 \mathrm{~mm}$, bracteis floriferis ovatis s. ovalibus s. oblongis $2-3$ $\mathrm{mm}$, bracteolis ovalibus s. obovatis $\_11 / 2 \mathrm{~mm}$ longis. Flores ultra $1 \frac{1}{2} \mathrm{~cm}$ diame tro.

36) Qua de re - speciminibus originariis mibi non subjectis - nequeo certi quid affirmare. 
Sepala ovato-lanceolata nune eglandulosa $4 \mathrm{~mm}$ longa, nune glandulas 8 oblongas $1^{1 / 2}-2$ $\mathrm{mm}$ longas $2 \frac{1}{2}-3 \mathrm{~mm}$ superantia. Petalorum limbus denticulatus orbicularis (quinti basi cordatus) $5-6 \mathrm{~mm}$, unguis $\pm 3 \mathrm{~mm}$ longus. Antherae apice (praecipue connectivo) piliferae. Styli apicis dorso plerique rotundi, rarius (in iisdem inflorescentiis) angulati s. breviter apiculati. Samarae (in var. $\gamma$. saligna tantum adhuc suppetentes) samaris $H$. byrsonimifolice omnino simillimae, ferrugineae s. alutaceae, ala semi-obovata usque $3 \mathrm{~cm}$ longa et $1^{1 / 2} \mathrm{~cm}$ lata. - Minas; Goyaz; Bahia. 66. H. escalloniifolia Juss. sensu ampl.

a. Folia majoru usque $8(-14) \mathrm{cm}$ longa.

var. $\alpha$. Jussieuana Ndz. - H. escalloniofolia Juss.: Pedunculis floriferis $3-6$, pedicellis

$3-5(-10) \mathrm{mm}$ longis; calyce 8-glandulifero: stylis apicis dorso saepe rotundis, rarius acutis s. acuminatis.

f. 1. typica Ndz: Foliis subtus subglabratis. - Minas (Sello sine numero locove; A ckermann; Schüch; Pohl 245 [1504 d]: Barbacena, et 2324 [1506 d]: ad Cormo). 1. 2. elongata Ndz.: Pedicellis $\pm 1 \mathrm{~cm}$, foliis subtus glabratis lineari-oblongis usque $1^{1 / 3} \mathrm{dm}$ longis, his vix usque $3 \mathrm{~cm}$ latis. - Goyaz ( $\mathrm{P} \circ \mathrm{hl}$ 2150: Cavalcante [f. stylis acuminatis]).

f. 3. affinis (Juss.) Ndz. - H. affinis Juss.: Foliis adultis subtus pube diutius persistente velutinis s. sericeis. - Goyaz (Glaziou 2076la); Glaziou 10376 [stylis apicis dorso acutis s. subuncinatis]; Bahia (Martius observ. 1883 [IX. 1818]: in altis desertis ad oppidum Villa do Rio de Contas [stylis dorso apicis rectangulis]; Blanchet 2760: prope Utinga in desertis versus fl. S. Francisci).

var. $\beta$. ochnifolia (Juss.) Ndz. - H. ochnifolia Juss.: Pedunculis floriferis $1-3 \mathrm{~mm}$, pedicellis 4-6 mm longis; calyce eglanduloso; stylis apicis dorso saepius apiculatis. f. 1. Foliis oblongis subtus canescenti-puberulis. - Brasilia nediterranea (Herb. Zuccarini [in herb. Monacensi]; Pohl [ex herb. Martiano - herb. Bruxellens]). f. 2. Foliis oblongo-obovatis. - Minas (Claussen $81 \mathrm{~A}$ et 223); Glaziou 14570.

b. Folia etiam maxima vix usque $5(-6) \mathrm{cm}$ longa et $2^{1 / 2} \mathrm{~cm}$ lata, haud raro lanceolata, adulta utrinque glabrata (si pilos perpaucos sparsos excipias).

var. $\gamma$. saligna (Juss.) Ndz. - H. saligna Juss. - H. parvifolia Juss (?) ${ }^{3 i}$ ): Paniculis ramos terminantibus; floribus, sulfureis nitriodoris“ (e Schwacke 7433).

f. 1. Stylis apicis dorso rotundatis s. obtusis. - Minas (Widgren a. 1845; Regnell. III. 327: Caldas; Lindberg 235 a: ad ripam fl. Rio de Machado, Caldas; Warming II. 1866: Serra da Piedade; Glaziou 20229: Serra da Piedade).

f. 2. Stylis apicis dorso acutis s. apiculatis s. paulo pediformi-uncinatis. - Minas. (Sello 1II. it. [4. X. 1818]: B 1846-c 1317 [H. coerulea var. diversifolia Griseb. in Linn. XIII. 226]: Mo de Tapanhuacanga; Schwacke 7433: Ouro Preto); Bahia (Martius [bracteis bracteolisque oblongis $2 \mathrm{~mm}$, pedunculis floriferis $5-7 \mathrm{~mm}$, pedicellis $6-8 \mathrm{~mm}$ longis]: in campis ad Sincora).

B. Bracteae ovatae lanceolataeve cochleariformi- s. cymbiformi-cavae et pleraeque apice acutae: Pedunculi cujueque ordinis pilis appressis rufo-subsericei.

subsect. B. Coelolepis.

1. Samarae ala e nuce subhorizontali distincte arcuatim s. geniculatim ascendens.

1. „Arbor parva" (e Gardener) ramulis compressis rufo-subsericeis, ramis teretibus glabratis cinereis lenticeilisque crebris scabris usque $4 \mathrm{~mm}$ diametro, internodiis $1 / 3-4$ $\mathrm{cm}$ longis. Folia ovata s. ovalia s. obovata s. \pm oblonga, usque $11 \mathrm{~cm}$ longa et.

37) Qua de re - specime originario nullo mihi subjecto - nequeo certi quid affirmare: 
$5 \%$ cm lata, basi obtusa (s. quaedam rotunda so subcordata), novella utrinque rufosubsericea, adulta subglabrata supra nitida, subtus opaca, adulta coriacea, nervis majoribus subtus prominentibus, minoribus creberrimis supra parum, subtus magis prominulis subintricatis areolato-reticulata, subtus glandulis obsoletis nonnullis secundum marginem nervis impositis, petiolo crasso 2-5 mm longo; floralia \pm sensim minuta usque ad bracteas $1 / 4 \mathrm{~cm}$ longas. Racemi 2--i 0 -flori $1^{1 / 2}-7 \mathrm{~cm}$ (pedunculo incl.) longi dispositi in paniculas folioliferas $\mathrm{s}$. bracteiferas axillares terminalesque et in paniculam + amplam terminalem congestas, bracteis bracteolisque ovatis $1^{3 / 4}-2^{1 / 2} \mathrm{~mm}$ longis. Flores $1^{1 / 4} \mathrm{1}^{3 / 4} \mathrm{~cm}$ diametro. Sepala ovatolanceolata raro eglandulosa $5 \mathrm{~mm}$ longa, pleraque glandulas 8 oblongas $2^{1 / 2}-3 \mathrm{~mm}$ longas $2^{1 / 2}-3 \mathrm{~mm}$ superantia. Petalorum limbus denticulatus (anticorum e basi rotunda, posticorum e sagittato-ccrdata) orbicularis nune \pm 4 , nune $5-7 \mathrm{~mm}$, unguis nune 2 , nunc 3 , quinti $4 \mathrm{~mm}$ longus. Antherae ovales, connectivi parte inferiore atropurpurea glabra, superiore flavida pilifera. Pollen 27-36 $\mu$ diametro. Styli dorso apicis plerique acutanguli, rari rotundi s. breviter uncinati. Samarae ferrugineae puberulae paulo ascendentes: nux cx areola ventrali orato-suborbiculari $\left(4^{1 / 3} \times 3 \frac{2}{3} \mathrm{~mm}\right.$ diametro) semiovoidea $6-7 \mathrm{~mm}$ longa, ala paulo ascendens semi-obovata ultra $2 \frac{1}{2} \mathrm{~cm}$ longa et ultra $1 \mathrm{~cm}$ lata, margine inferiore subdirecto, superiore $\zeta$-formi-curvato i. e. basi inappendiculam rotundam $6 \mathrm{~mm}$ longam et $2 \mathrm{~mm}$ altam accrescente. - Brasilia: a S. Paulo usque Piauhy. 67. H. grandiffora Juss. var. $\alpha$. glandulifera Ndz.: Calyce 8-glanduloso; stylis dorso apicis rotundis s. angulatis.

subvar. I. pachypus Ndz.: Peduncnlis floriferis usque $5 \mathrm{~mm}$, pedicellis usque $7 \mathrm{~mm}$ longis, his illisque divaricatis crassiusculis compressis $1 / 2$ resp. $1 \mathrm{~mm}$ diametro, bracteis bracteolisque ovatis; floribus $1^{3 / 4} \mathrm{~cm}$ diametro.

f. 1. typica Ndz.: Foliis ovatis s. oblongo-ovatis utrinque obtusis s. raro apice breviter obtuseque acuminatis, nunc margine planis (Gardener 2500 et 2501), nune revolutis; stylis dorso apicis acutangulis. - Piauhy (Gardener 2500 et 2501: vulgaris in locis elevatis [Chapadas] siccioribus); Minas (Pizarro 107); Glaziou 20230.

f. 2. anqustifolia $\mathrm{Ndz}{ }^{38}$ ): Foliis plerisque lanceolatis oblanceolatisve (lat.: long. $=1: 3-4$ ); stylis dorso apicis rotundis s. obtusis. - Minas (Bunbury: Gongo Loco).

subvar. II. stencpus Ndz.: Pedunculis floriferis $2-3 \mathrm{~mm}$, pedicellis $3-5 \mathrm{~mm}$ longis, his illisque oblique ascendentibus compressis vix $1 / 2$ resp. $2 / 3 \mathrm{~mm}$ diametro; floribus $1 \frac{1}{4} \mathrm{~cm}$ diametro; foliis obovatis s. ovalibus s. \pm oblongis obtusis s. breviter et obtuse acuminatis, margine revolutis, usque $9 \mathrm{~cm}$ longis et ultra $5 \mathrm{~cm}$ latis; stylis dorso apicis rectangulis. - Goyaz (Burchell 7443 [H. suberosa var. Lessertiana e Griseb.]: Goyaz bor:: Goyaz - Cavalcante; Glaziou 20761); Minas (Regnell III. 326 ${ }^{\text {39}}$ ): Uberava).

rar. $\beta$. eglandulosa Ndz.: Calyce eglanduloso; stylis dorso apicis breviter uncinatis; foliis oblongis s. oblongo-ovatis, usque $11 \mathrm{~cm}$ longis et $5 \mathrm{~cm}$ latis, margine revolutis. - Rio de Janeiro et Bahia (?) (Sello II. it. 277 et 437: inter Campos et Vittoria, et 696 et $10 \check{9}$ : inter Vittoria et Bahia).

2. Hoc loco inserenda et forsan varietas tantum praecedentis s. n. 66, sed e Grisebach ,foliis petiolo vero destitutis, eorum nervatura et inflorescentia simpliciori“ distineta esse videtur species quaedam Grisebachiana, cujus haec est descriptio:

„Frutex metralis (e Gardener) ramis rufo-puberulis, junioribus compressiusculis, internodiis $5-8 \mathrm{~cm}$ longis, nodis partialibus prominulis et folii basin rotundatam complicatamque

38) Forma transitum in $H$. acutifoliam adhibens.

39) Cujus speciminis flores omnes antheris destituti fuerunt. 
immediatim excipientibus, stipulis inconspicuis. Folia elliptico-oblonga 5-14 cm longa $2^{1 / z}-5^{1 / 2} \mathrm{~cm}$ lata, aequaliter acutata, rigido-coriacea marginata, sicca supra nitida pallide rufescentia, subtus opaca discolora luteo-cinerea, utrinque pube minutissima (lentis ope tantum conspicua) obducta, arcunervia, mediano subtus crassiuscule prominulo, venis copiosis venularumque reti intricato utrinque arcte prominulis, glandulis subtus minutissimis suprabasilaribus $v$. sparsis aut nullis. Racemi laxiflori e summis axillis simplices (in specimine, quod exstat, unico) $2 \frac{1}{2}-5 \frac{1}{2} \mathrm{~cm}$ longi et stipitati, axi pedicellisque rufo-pubescentibus, his oppositis, utrinque $4-12 \mathrm{~mm}$ longis, laxe patentibus modice crassiusculis v. superne tenuibus, $4 \mathrm{~mm}$ supra basin articulatis, bracteolis $2 \mathrm{~mm}$ longis ovalibus patulis subtus rufo-pubescentibus bracteae conformibus. Calyx $4 \mathrm{~mm}$ fere altus extus ruto-pubescens intus glaber, segmentis ovato-oblongis obtusis apice revolutis glandulas 8 oblongas duplo superantibus. Petala calyeem duplo superantia, lamina subrotunda inciso-denticulata. Staminum antherae glabrae, connectivo oblique incumbente pallido et ad punctum insertionis atro-maculato loculos arcuatos aequante. Styli glabri, stigmate compresso truncato uncinato. Samarae . . . H. reticulata Griseb. ${ }^{40}$ ) -- Pernambuco (Gardener 2795: in convalli Sa. Rosa).“

65 (?). H. Grisebachiana $N d z,{ }^{40}$,

3. Antherae subsphaeroideae s. quidem (a fronte aspectae) \pm orbiculares, connectivo toto aequaliter atropurpureo glaberrimo.

$\dagger$ FFrutex usque $8 \mathrm{~m}$ (ex Hassler) scandens ${ }^{*}$ (e Gardener atque e Schwacke 10096) s. "erectus" (e Schwacke 10095) s. ,sub-3-metralis" (e Wullschlägel 56) ramulis cornpressis rufo-subsericeis, ramis teretibus glabratis rubiginosis s. schistaceis sublaevibus (lenticellis paucis) usque $2 / 3 \mathrm{~cm}$ diametro, internodiis $2 / 3-10 \mathrm{~cm}$ longis. Folia majora ovata, minora (s. in subvar. II. omnia) ovato-lanceolata lanceolatave, usque $11 \mathrm{resp} .15 \mathrm{~cm}$ longa et usque 7 resp. $6 \mathrm{~cm}$ lata, basi obtusa, apice pleraque £ obtuse acuminata, coriacea, utrinque jam novella vix puberula, adulta glaberrima et (subtus minus) lucida, utrinque areolato-reticulata nervis intricatis s. reticulatis (medio primariisque subtus prominentibus, ceteris subtus et omnibus supra prominulis), petiolo crasso obscuro glabro 4-8 $\mathrm{mm}$ longo; floralia abruptiun minuta $1^{1 / 2}-^{1 / 3} \mathrm{~cm}$ longa. Racemi breves (pedunculo incl. 1 $1 / 2$ - vix ultra $3 \mathrm{~cm}$ longi) corymbiformes flores perfectos $2-8$ et sursum complures gemmas abortivas gerentes et dispositi in paniculas axillares saepe geminatas terminalesque et in paniculam superioris ordinis terminalem folioliferam congestas, pedunculis floriferis pedicellisque $3-4 \mathrm{~mm}$ longis. Flores $1^{1 / 4} \mathrm{~cm}$ diametro. Sepala lanceolata nune eglandulosa nunc glandulas 8 ovales $1^{1 / 4}-1^{1 / 2} \mathrm{~mm}$ longas $1^{1 / 2}-2^{1 / 2} \mathrm{~mm}$ superantia. Petalorum limbus \pm suborbicularis paulo crenulatus $3-4 \mathrm{~mm}$, unguis $2-3 \mathrm{~mm}$ longus. Styli aequilongi apicis dorso rotundis. angulatis. raro brevissime uncinati. Samarae "Pisi mediocris magnitudine, facie interna subconcava, lateralibus convexae et reticulato-venosae, supra extensae in alam fere pollicarem et semipollicem latam sursum et extrorsum vergentem basi subangustatam margine postico subrectilineam, curvilineam untico, extus (basi excepta) fere glabratam, intus medulla faretam." - Paraguaria; Brasilia media et septentrionalis; Guiana batava.

69. H. anoptera Juss. var. $\alpha$. glandulifera Ndz.: Calyce 8-gìnduloso; foliis intricato-nervosis.

subvar. I. ovata Ndz: Foliis ovatis brevissime (vix usque $4 \mathrm{~mm}$ ) acuminatis usque $11 \mathrm{~cm}$, bracteis bracteolisque orato-rotundatis $\pm 2 \mathrm{~mm}$ longis.

40, Qurm nomen specificum Poiretianum (Malpighia reticulata) pro $H$. platyptera p. p. restituendum sit, nominesupra adhibito pro specie incerta Grisebacbiana utar. 
f. 1. Stylis dorso apicis rotundatis s. vix rectangulis. - Minas (Schwacke 10095 et 10096: Serra do Lenheiro); Goyaz (Gardener 3063: in fruticetis humidis prope Missionem de Duro).

1. 2. Stylis dorso apicis breviter uncinatis. - Paraguaria (Hassler 4688 et 4840: in dumetis prope V. Igatini, 5043 et 5302: Sierra Maracayu, in dumeto prope Ipelui); Pernambuco (Gardener 2798: in ripa fl. Rio Preto prope Santa Maria); Guiana batava (Wullschlägel 56: Paramaribo et Monica (?). Bai).

subvar. II. elongata Ndz.41): Et foliis et bracteis bracteolisque lanceolato-ovatis lanceolatisve, foliis longius $\left(1-2 \mathrm{~cm}\right.$ ) acuminatis usque $1^{1 / 2} \mathrm{dm}$, bracteis $2^{1 / 2}-3^{1 / 2} \mathrm{~mm}$, bracteolis $2-2^{1 / 2} \mathrm{~mm}$ longis; stylis dorso apicis acutangulis $\mathrm{s}$. breviter acuminatis. - Goyaz (?) (Pohl ว็ว [1508 d]: S. João Baptista); .... . herb. Zuccarini.

subvar. III. micrantha Ndz: Floribus vix $1 \mathrm{~cm}$ diametro, ceteris notis intermedia inter

I. et II. - Pará (Spruce VIII. 185ั0 [an n. 766?]: in vicinibus Santarem).

var. $\beta$. eglandulosa (aut.) Ndz. - H. eglandulosa aut. p. p.: Calyce eglanduloso; foliis reticulato-nervosis.

subvar. I. latifolia Ndz.: Foliis bracteis bracteolis ovatis; stylis brevissine uncinatis. Minas (Regnell III. 329).

subvar. II. lancifolia Ndz.: Foliis bracteis bracteolis + Ianceolatis; stylis dorso apicis acutis s. breviter acuminatis. - Glaziou 18941; Bahia (Blanchet 3514 [f. foliis minusculis: H. eglandulose aut.]: Jacobine Moritiba); Venezuela (Funck et Schlim 703: Cumana prope Caripe, 3000').

t† Racemi \pm elongati (pedunculo incl. usque $1 \mathrm{dm}$ longi). Styli dorso apicis uncinati, anticus posticis \pm distincte brevior graciliorque.

* Frutex ,scandens“ (e Gardener) s. „erectus" (e Martius) ramulis compressis rufo. subsericeis, ramis teretibus glabratis cinereis lenticellisque magnis grosse tuberculatis usque $3 / 4 \mathrm{~cm}$ diametro, internodiis $1 / 4-5 \mathrm{~cm}$ longis. Folia e basi acuta s. obtusa (s. rotunda s. subcordata) lanceolata s. lanceolato-oblonga, pleraque longe (usque $3 \mathrm{~cm}$ vel ultra) acuminata, usque $1^{2} / 3 \mathrm{dm}$ longa et $6 \mathrm{~cm}$ lata, rigido-coriacea, novella utrinque rufo-subsericea, mox glabrata, supra laevissima (exc. var. $\gamma_{\text {. }}$ ) lucidaque, subtus nervis majoribus prominentibus minoribusque creberrimis prominulis intricate reticulata sublucida glandulisque nonnullis secundum marginem nervis jmpositis notata, petiolo \pm crasso glabro 4-6 mm longo; floralia abrupte minuta ad foliola $1 \frac{1}{2}-1 / 3 \mathrm{~cm}$ longa s. bracteas. Racemi usque, 16-flori, pedunculis floriferis pedicellisque subgracilibus $3-6 \mathrm{~mm}$, bracteis bracteolisque ovatis vel lanceolatis usque $2 / 3$ resp. $1 / 3 \mathrm{~cm}$ longis. Flores $1 \frac{1}{3}-1 \frac{3}{4} \mathrm{~cm}$ diametro. Sepala lanceolata nunc eglandulosa, nunc glandulas 8 orales oblongasve $1^{1 / 2}-2^{1 / 2} \mathrm{~mm}$ longas $2-3 \mathrm{~mm}$ superantia. Petalorum limbus ovato-s. obovato-suborbicularis crispulus crenulatus $4-6 \mathrm{~mm}$, unguis $2-4 \mathrm{~mm}$ longus. Styli apicis dorso breviter uncinati. Samarae (in var. $\beta$. tantum notae) alutaceae, nuce magis opaca puberulae, ceterum glabratae, oblique ascendentes: nux subhorizontalis ovoidea a lateribus valde compressa usque $3 / 4 \mathrm{~cm}$ longa $1 / 2 \mathrm{~cm}$ alta et parum ultra $1 / 4 \mathrm{~cm}$ lata, loculo endocarpii processu destituto; ala a nuce geniculatim oblique ascendens oblique obovata usque $3^{1 / 2} \mathrm{~cm}$ longa et $1^{3 / 4} \mathrm{~cm}$ lata, margine inferiore minus, superiore magis curvato et hoc basi in appendiculam rotundam usque $3 / 4 \mathrm{~cm}$ longam et vix $2 \mathrm{~mm}$ altam ascendente. - A S. Paulo usque ad Columbiam.

70. H. acutifolia Juss.

41) $\mathrm{Tr}$ ansitum exhibens in 70. H. acutifoliam. 
var. a. typica Ndz. - H. acutifolia Juss. ${ }^{42}$ ): Calyce 8-glandulifero.

f. 1. Bracteis bracteolisque ovatis $2-4$ resp. $2 \mathrm{~mm}$ longis; floribus $1^{1 / 3}-\mathbf{1}^{1 / 2} \mathrm{~cm}$ diametro. - Brasilia (Sello III. it. B. 1834-c 1295: Corregos [16. VIII. 1818] et Comargos $[H$. coerulea e Griseb. in Linn. XllI. $226-H$. anoptera e Griseb. in Fl. bras. XU. 1. 70]; Weddell 953; Glaziou 10377 [glandulis calycinis 士 obsoletis]).

f. 2. Bracteis bracteolisque ovato-lanceolatis s. lanceolatis usque $2 / 3 \mathrm{resp} .1 / 3 \mathrm{~cm}$ longis; floribus usque $1^{3} / \mathrm{cm}$ diametro. - Columbia (Schlim 286: Ocaña 4000'). var. $\beta$. eglandulosa (Juss.) Ndz. - H. eglandulosa Juss. ${ }^{42}$ ): Bracteis lanceolato-ovatis lanceolatisve acutiusculis usque $2 / 3 \mathrm{~cm}$ longis; calyce eglanduloso. - Peruvia (Ruiz: ad Vitoc); Goyaz (Gardener 3061: in silvis prope Missionem de Duro); Minas (Glaziou 13590, 13613 et 15866; Warming 9 [17. et 26. X, 1863 et 30. 1X. 1864]: ad Lagoa Santa); S. Paulo (Comm. geogr. e geol. de S. Paulo 356 [leg. Löfgren]: Itapetininga, in silva, 958 [leg. Löfgren]: Araraguara, Cerrado, 1419 [leg. Löfgren]: S. José do Rio Pardo, capoeira, et s. n. [leg. Padre Russel 29: 20. X, 1897]: Ytu); Brasilia (. . . herb. Lin k).

** Liana ramulis compressis rufo-subsericeis, ramis (junioribus angulatis, deinde) teretibus glabratis cinereis s. schistaceis lenticellisque \pm crebris magnitudine mediocribus tuberculatis, vetustioribus cortice suberoso usque $1 / 2 \mathrm{~cm}$ diametro, internodiis $1 / 2-10 \mathrm{~cm}$ longis. Folia e basi obtusa s. rotundata (s. raro acuta) obovata (s. raro ovata) s. \pm oblonga lanceolatare acuminata usque $16 \mathrm{~cm}$ longa et $8 \mathrm{~cm}$ lata, margine vix revoluta, chartaceos. raro firmo-coriacea, novella utrinque \pm rufo-subsericea, supra mox glabrata lucidaque. subtus pube minutissima et vix lente conspicua pulverulento-sericea, nervis utrinque prominulis (resp. majoribus subtus valde et acute prominentibus) intricata et subtus glandulis paucis secundum marginem nervis impositis impressa, petiolo \pm crasso $1 / 3-2 / 3 \mathrm{~cm}$ longo; floralia abruptim in foliola $1^{1 / 2}-1 / 2 \mathrm{~cm}$ longa minuta $\mathrm{s}$. in bracteolas lanceolatas $2 / 3 \ldots 1 / 3 \mathrm{~cm}$ longas reducta. Racemi dispositi in paniculas axillares (s. etiam terminales), pedunculis floriferis pedicellisque crassiusculis $1-2 \mathrm{~mm}$ resp. $2-4 \mathrm{~mm}$, bracteis bracteolisque ovatis $\mathrm{s}$. \pm lanceolatis acutis $\mathrm{s}$. acuminatis $3--5$ resp. $2^{1 / 2}-3 \mathrm{~mm}$ longis. Flores $1^{1 / 2} \mathrm{~cm}$ diametro. Sepala ovata $\mathrm{s}$. \pm lanceolata nunc eglandulosa ultra $4 \mathrm{~mm}$ longa, nune glandulas 8 ovales s. oblongas $1-3 \mathrm{~mm}$ longas $2-2 \frac{1}{2} \mathrm{~mm}$ superantia. Petalorum limbus obovatus s. oralis s. ovatus (quinti basi sagittatus) $4-6 \mathrm{~mm}$, unguis $2-3^{1 / 2} \mathrm{~mm}$ longus. Stýli dorso apicis longe $\left( \pm^{1 / 2} \mathrm{~mm}\right)$ uncinati. Samarae rufo-subsericeae: nux horizontalis a lateribus valde compressa $2 / 3 \mathrm{~cm}$ longa $4 \mathrm{~mm}$ alta vix ultra $2 \mathrm{~mm}$ lata; ala subsemiobovata fere $4 \mathrm{~cm}$ longa et $1^{1 / 2} \mathrm{~cm}$ lata, margine inferiore parum arcuato et angulo obtuso a nuce oblique ascendente, superiore $\zeta$-formi, appendicula basali rotunda $2 / 3 \mathrm{~cm}$ longa et $2 \mathrm{~mm}$ alta nucem superante. - Brasilia septentrionalis; Guiana; Antillae minores meridionales. \%1. H. suberosa Griseb. var. ${ }$. Lessertiana (Juss.) Griseb. - H. Lessertiana Juss.: Calyce glandulifero. Amazonas (Pöppig 2892: Ega, in silvarum marginibus); Maranhao (G. Don 84); Guiana gallica (Poiteau: Cayenne); Guiana batava (Lindley: Gujava; Hostmann 224: Surinam, et 1107 p. p.; Kappler 1710: in regionibus interioribus ad fl. Surinam, et 2122: ad fl. Lara; Wullschlägel 858: e regione Surinam. super., 
et 1323: e regione Pará); Guiana anglica (Rob. Schomburgk 1.729: Pirara, et II. 726); ins. S. Trinitatis (Sieber 322); ins. S. Vincentii (Gould [H. Lindeniana e Griseb.].

var. $\beta$. Candolleana (Juss.) Ndz. - H. Candolleana Juss. et H. nervosa Juss.: Calyce eglanduloso. - Pernvia (Spruce 185\% : prope Tarapoto, Per. or. $\lceil$ H. eglandulosa]); Amazonas (Spruce 1940 [H. platyptera e Griseb.]: inter Barcellos et San Isabel); Matto Grosso (Manso et Lhotzky 48: Cujabá [H. nervosa Juss.]); bahia Martius: in silvis Catingas ad Sincora et Haracas [H. nervosa Juss.]); Guiana gallica (Martin; Sagot 1220: Mana); Guiana batava (Hostmann 1107 p. p.); Guiana anglica (Rob. Schomburgk IJ. 295: Pirara; Rich. Schomburgk 360: Essequibo, 500: Taito, et 1039).

II. Liana "usque $20 \mathrm{~m}$ scandens" (ex Eggers 2407) ramulis compressis rufo-velutinis, ramis teretibus glabratis incanis lenticellisque scabris usque $3 / 4 \mathrm{~cm}$ diametro, internodiis $1 / 2-5 \mathrm{~cm}$ longis. Folia e basi acuta s. obtusa oblonga s. 土 lanceolata s. ovata obovatave, apice pleraqre acuminata, usque $16 \mathrm{~cm}$ longa et $7 \mathrm{~cm}$ lata, margine subplana, utrinque novella rufo-velutina, adulta glabrata et paulo (supra magis) lucida, nervis utrinque - praecipue subtus - prominulis (resp. primariis subtus prominentibus) intricata, eglandulosa s. raro subtus glandulis pancis obsoletis instructa, petiolo crassiusculo s. crasso usque $1 \mathrm{~cm}$ vel ultra longo; floralia abruptim value minuta conformia petiolata $1^{1 / 2}-1 / 2 \mathrm{~cm}$ longa s. in bracteas reducta. Racemi plerique vix ultra 10-, rami usque 20-flori rufo-velutini dispositi in paniculas folioliferas s. bracteiferas axillares terminalesve raro ultra $1^{1 / 4} \mathrm{dm}$ longas, pedunculis floriferis $1-2^{1 / 2} \mathrm{~mm}$, pedicellis $3-5 \mathrm{~mm}$, bracteis lanceolatis $\mathrm{s}$. ovato-lanceolatis s. ovato-acutis $3-5 \mathrm{~mm}$, bracteolis ovatis $2-2^{1 / 2} \mathrm{~mm}$ longis. Flores $1-1^{1 / 2} \mathrm{~cm}$ diametro. Sepala lanceolata nune eglandulosa $3-3^{1 / 2} \mathrm{~mm}$ longa, nune glandulas 8 oblongas $1^{1 / 4}-2 \mathrm{~mm}$ longas $2 \mathrm{~mm}$ superantia. Petalorum limbus ovatus s. cordatus s. \pm orbicularis paulo crenulatus $3-4 \mathrm{~mm}$, unguis $2-3(-4) \mathrm{mm}$ longus. $\mathrm{S}$ tamina antheris glaberrimis, connectivo atropurpureo, stylo antico (resp. sepalo eglanduloso) oppositum omnium \pm longissimum, praesertim distincte longius quam 2 stylis lateralibus opposita. Styli nune inter se aequales, nunc anticus posticis longius uncinatus neenon paulo longior. Samarae dense velutinae rufae (resp. siccae alutaccae): nux a lateribus lentiformicompressa $6-8 \mathrm{~mm}$ longa, areola ventrali ovata usque $7 \mathrm{~mm}$ alta et $5 \mathrm{~mm}$ lata; ala horizontalis s. paulo a scendens $2^{1 / 2}-4 \mathrm{~cm}$ longa et $1-1^{3 / 4} \mathrm{~cm}$ lata, supra basim constricta et inde oblique ovata s. obovata s. semiobovata, margine interiore \pm directo s. paulo curvato, nune \pm horizontali, nune paulo ascendente, superiore $\zeta$-formi et basi in appendiculam nune triangulari-acutam, nune rotundatam $\mathrm{s}$. obtuse rostratam $1-2^{1 / 2} \mathrm{~mm}$ altam producto; semina saepius 2- s.3- embryonifera. - Banisteria laurifolia L. - H. floribunda et $H$. longifolia H. B. K. - H. coerulea Juss. - America centralis; Mexicum; Antillae majores; ins. S. Crucis.

\section{H. laurifolia (L.) Juss.}

var. $\alpha$. mexicana Ndz:: Foliis chartaceis $\mathrm{s}$. tenui-coriaceis oblongis usque $16 \mathrm{~cm}$ longis et vix $6 \mathrm{~cm}$ latis, utrinque acutis s. apice acute et longiuscule acuminatis, margine 士 undulatis; bracteis lanceolatis usque ${ }^{1} / 2 \mathrm{~cm}$ longis; adelphiarum lateralium stamine medio duobus ceteris breviore ac rix crassiore; stylis plerisque distincte uncinatis. - America centralis; Mexicum.

subvar. I. floribunda (H. B. K.) Ndz. - H. floribunda H. B. K.: Calyce eglanduloso.

f. 1. Stylis dorso apicis tantum acutis s. breviter meinatis. - Guatemala (Smith 1995: Escuintla, 1100' alt.); Mesicum (Bourgeau 2282 et 2322: prope Cordova). 
f. 2. Stylis (praecipue antico) dorso apicis \pm longe uncinatis. - Nicaragua (Oersted: 11I. 1847: inter Sapoa et Tortuga; Wright 6 [H. Lindeniana e Griseb.]); Honduras (Smith 5169: San Pedro Sula, dep. Santa Barbara, 800' alt.); Mexicum (Humboldt: Venta del Exidu, $400 \mathrm{~m}$ alt.; Karwinski [Brysonima stigmatophorus Schlchtd.]: Tehuantepec, Oaxaca; Galeotti: Juchatengo et Tututepeque; Seler 2022: in silvis secundum fluvios inter Tapana et La Junta, distr. Tonala, Chiapas).

subvar. Il. longifolia (H. B. K.) Ndz. - H. longifolia H. B. K.: Calyce 8-glanduloso; stylis distincte et fere semper \pm longe uncinatis. - Nicargui (Guter (?): prope Granada); Guatemala (Smith 3268 [leg. Heyde et Lux]: San Miguel Uspantam, dep. Quiché, $6000^{\circ}$ alt., et 3269: Jojabaj, dep. Quiché, 4500 alt.); Mexicum (Humboldt: prope urbem Mexici, $2200 \mathrm{~m}$ alt.; Alleman a. 1833; Mairet a. 1833; Hänke: Acapulco; Seler 3432: Barranca de Beltran, ad declivit. montis ignivomi Colima, Jalisco.)

var. $\beta$. antillana Ndz.: Foliis firmo-coriaceis ovatis s. obovatis s. orato-lanceolatis s. \pm oblongis, usque $22 \mathrm{~cm}$ longis et $10 \mathrm{~cm}$ latis, basi nune acutis, nunc obtusis, apice obtusiusculis s. obtuse et plerumque breviter acuminatis; bracteis \pm late ovatis, apice acutiusculis s. acuminatis usque $4 \mathrm{~mm}$ longis; calyce 8-glanduloso; adelphiarum lateralium stamine medio duobus ceteris distincte crassiore ac subaequilongo; stylis 2 posticis dorso apicis obtusis, medio distincte acuminato s. \pm unciuato. - H. laurifolia aut. - Antillae majores: Cuba (.... herb. Jamain; Poeppig a. 1822; Santos-Burat et Bordier a. 1825: Haranna; Ramon de la Sagra a. 1825̌, 31 [a. 1829], 283 et 285: Havanna; G. Don: Havanna; . . . . herb. Zuccarin'i; Rugel 400: ad fl. S. Juan; Wrihgt 92: prope villam Monte Verde dictam, Cuba or.; Com bs 113: Cieneguita, distr. Cienfuegos, prov. Santa Clara); Jamaica (Berter o V.-VI. 1821; .... herb. Jussieu [H. coerulea Juss.]; .... [herk. Portenschlag]: in fruticetis; A lexander a. 1850; March; herb. bot. dep. 5740 [leg. Harris]: Mt. Mansfield, 800', 5819 [leg. Harris]: Belle Vew, in collibus scopulosis, 1000', 5820 [leg. Harris]: Bardowie, 1800', et 6738 [leg. Thompson]: Providence Road); Hispaniola (Bertero 286; Poiteau; Schomburgk a. 1837; Mayerhoff 89 [a. 1856] et a. 1859; Ritter: herb. Portenschlag, herb. Endlicher et 820 [Malpighia coriacea]; Prenleloup 66: ad Boca de Quiabon; Eggers 2407: inter Santiago et Punto Plata ad Palmarejo, $200 \mathrm{~m}, 2407$ b: prope Bajabonico ad Llano de Perez, $100 \mathrm{~m}, 2407$ c: prope Puerto Plata in silvis juxta fl. Mamayes, $2407 \mathrm{~d}$ : in silvis montis Isabel de la torre, $300 \mathrm{~m}$, et 2453b: in silvis ad Rio Muñoz); Portorico (Bertero [?] 93 [Balbis mis. a. 1822: Banisteria Leona?]; Schwanecke; Krug 149: prope Mayaguez, et 169: prope Añasco; Eggers 646 [Stigmatophyllon diversifolium]: ad Rio Grande, et a. 1881: Rio Blanco prope Naguabo; Stahl 160 et 574: prope Bayamon in ruderatis et fruticetis; Sintenis 101: Mayaguez in silvis, $101 \mathrm{~b}$ : prope Mayaguez ad rivulum Quebrada de Oro, 459: prope Maricao in convalli fluminis superioris, $1318 \mathrm{~b}$ : prope Fajardo in silvis montanis, 1558 [ "Bejucode buey ${ }^{*}$ ] et 1559: Sierra de Luquillo ultra montem ${ }$ Maoi $^{*}$ ad monten „Jimenes" versus, 1693: prope Fajardo ad pedem montis Mulla, $2454 \mathrm{~b}$ : prope Utuado in scopulosis calcareis ad Cayuca, 3286: prope Coamo, in monte Calabaza, ad Aybonito versus, 3809: prope Guanica in fruticetis litoralibus ad Laguna, 4722: prope Ponce in silvis juxta flumen ad Coral viejo, 4802: prope Penuelas in fruticetis ad ripam fluminis circa oppidum, 4902: prope Guayanilla in fruticetis litoralibus ad Peñon, 5006: prope Peñuelas, 5068: prope Maunabo ad Punta de la Tuna, 5548: Aguado in silvis ad Rio grande, et 6818: [rope Mororis, in fruticetis ad Frances; Heller 4406: prope Mayaguez, 100'); ins. S. Crucis (Moll [comm. Rohr: H. cosrulea in herb. Bruxell.]); India occid. loco non 
ind. (Rohr 56 et s. n.; Ryan; West; herb. Pollart de Canidri; herb. Jacquin fil.).

- Culta in horto Carlsruh. et Paris.

2. Folia oblonga s. ovato-oblonga s. lanceolata \pm longe et acute acuminata ${ }^{43}$ ) coriacea, supra glabrata \pm lucida nervis creberrimis prominulis intricata, subtus etiam adulta pube minima appressa incano-sericante adspersa opaca nervis primariis acute et valde prominentibus, ceteris prominulis intricato-reticulata. Racemi plerique elongati (usque 1-2 dm longi) et multi(usque 20--4C-)flori, pedunculis pedicellisque brevibus s. brevissimis, bracteis bracteolisque \pm cavis cochleari- s. cymbiformibus. Calyx 8 -glandulosus. Stamina externa ( oppositipetala“) internis ( ceteris „oppositipetalis" longiora). Styli dorso apicis \pm pediformes atque vertice ipso plani et paulisper (sicut in Stigmatophylli subgenere Baeopteryge) dilatati. Samarae ala tota crasso- et firmo-coriacea \pm horizontalis, margine superiore plerumque basi exappendiculato et ita simpliciter areuato.

Sect. 4. Pachypterys.

I. Liana $\perp$ ampla, ramulis compressis s. angulosis rufo-subsericeis, ramis teretibus glabratis lenticellisque tuberculatis usque $2 / 3 \mathrm{~cm}$ diametro, internodiis $3 / \mathrm{dm}$ longis. Folia oblonga pro genere maxima usque $4 \mathrm{dm}$ longa usque $1 \frac{2}{3} \mathrm{dm}$ lata, acumine usque $4 \mathrm{~cm}$ longo ${ }^{43}$ ), margine revoluta, nervis primariis utrinque $6-9$, petiolo crasso usque $1^{1 / 2} \mathrm{~cm}$ longo; floralia usque $1 / 2 \mathrm{~cm}$ minuta. Racemi usque $2^{1 / 2} \mathrm{dm}$ (incl. pedunculo) longi usque 40 -flori, rhachide alte canaliculata, pedunculis floriferis crassiusculis $\mathrm{s}$. crassis $\left(2 / 3-1^{1 / 3} \mathrm{~mm}\right.$ diametro) striatis $2-3 \mathrm{~mm}$, pedicellis $2-5 \mathrm{~mm}$, bracteis lanceolatis s. ovato-lanceolatis \pm acuminatis $4-5 \mathrm{~mm} \mathrm{~s}$. quidem ovato-acutis $3-4 \mathrm{~mm}$, bracteolis ovato-obtusis s. -rotundatis $2-4 \mathrm{~mm}$ longis. Flores $1-1^{1 / 4} \mathrm{~cm}$ diametro. Sepala ovatolanceolata s. lanceolata glandulas 8 ovales s. oblongas $1-2^{1 / 2} \mathrm{~mm}$ longas $2^{1 / 4}-1 \mathrm{~mm}$ superantia. Petala valde reflexa, ungui semiorbiculari redunco $2-3^{1 / 2} \mathrm{~mm}$, quinti \pm directo usque $4 \mathrm{~mm}$, limbo cordato-ovato crenulato 3-4 mm longo. Samarae t cultriformes. Banisteria longifolia Sw. - H. platyptera D. C. - Juss. p. p. ${ }^{44}$ - Antillae minores.

73. H. Iongifolia (Sw.) $\left.\mathrm{Ndz} .^{45}\right)$

var. a. borealis Ndz.: Styli dorso apicis paulo ac vix in uncum s. potius in angulum acutum producti ac fere inclusi, sicut stamina. Samarae ala cultriformis oblique arcuatim adsurgens usque $4^{1} / 2 \mathrm{~cm}$ longa et $1^{1} / 2 \mathrm{~cm}$ lata, margine superiore rotundato-appendiculato, inferiore ascendente. - Dominica (Imray; Eggers 730 et 1062: in silvis umbrosis ad Sugar loaf prope Prince Ruperts; Ramage; Nicholls 60); Guadalupa (Isert a. 1787; Bertero 34 s. 834 [?]; Nyst 296; Duchassaing; Duss 3377 [„Liane Caco* inc.]: prope Pigeon); S. Lucia (Ramage: 10. IV. 1888); Martinica (Plée; Hahn 71); India occidentalis loco speciali non ind. (Pursh [in herb. Krug et Urban: ex herb. Ac. N. Sc. Philad. a. 1891 n. 80]).

43) De Candolle errore quodam folia $H$. platypterae obtusa dicit.

44) Jam Jussieu in "Monographia" sub "H.platyptera D. C." dixit: „An igitur duplex species, altera Guianensis (Malp. reticulata, Banisteria multiflora, B. magnoliaefolia, Hiraea candicans), altera Antillana (Heteropterys platyptera; Banisteria longifolia, macroptera et rufa). Sed in herbariis characteres, quibus distinguantur, non suppetunt". Re vera - optimo jure 2 speceis habeas, speciminibus praecipue martinicensibus transitum gradatim progredientem ab altera in alteram praebentibus.

45) Jam Jussieu in "Monographia" sub „H. platyptera D. C.“ dixit: „Species Swartziana, typo non viso, cum descriptio perfecte plantae nostrae conveniat cumque exstent specimina (v. s. mus. Paris.) a Plée in ins. S. Luciae, unde et Swartzio suppetehant, lecta, huc absque ullo fere dubio refertur". In herb. quoque Hauniensi exstant 2 specimina (alterum ex herb. Hornemanniano) anno 1787 ab Ise rt in insula Martinica lecta et huc pertinentia, quorum schedulis "Banisteria longifolia" inscripta est. Qua de causa nomen Swartzianum pro Candolleano ("H. platyptera") restituend um censeo ceterum multo prius nomine Kuntbiano H. longifolia (i, e. var. H. laurifoliae). 
var. B. martinicensis $\mathrm{Ndz}_{0^{4}}{ }^{4}$ ): Styli dorso apicis distincte \pm pediformi-uncinati et paulo. exserti sicut stamina interna - praecipue 3 antica. Samarae ala ( \pm in eodem specimine) a var. $\alpha$. boreali in speciem sequentem transiens. - Martinica (Isert a, 1787 [Banisteria longifolia, specimen originarium, ut videtur]; Terrasson; . . [?]: herb. Reichenbach fil. [herb. Vindob.]); ins. S. Vincentii (Smith 1549).

iI. Stamina interna (,oppositisepala“) gracilia et \pm exserta, sicut styli $\varsigma$-formi-curvati et apice late uncinati unco magis dilatato. Samarae ala semiorbicularis horizontalis s. reclinata, margine superiore semiorbiculari et fere semper basi exappendiculato, inferiore horizontali \pm directo s. versus apicem recurvo.

1. Bracteae bracteolaeque eglandulosae. Petala reflexa, ungui \pm redunco. Stamina 3 anticointerna (,oppositisepala") paulo tantum 2 posticis longiora panloque exserta. Samarae ala usque $3^{1 / 2} \mathrm{~cm}$ longa et $2-2^{1 / 2} \mathrm{~cm}$ lata.

$\dagger$,Arbor vel frutex humilis" (e Sonntag 38) s. liana, ceterum eodem habitu, quo H. longifolia. Folia basi obtusa s. rotundata. Bracteae lanceolatae saepe longe et acute acuminatae usque $3-4 \mathrm{~cm}$ longae s. ovato-acutae usque $1^{1 / 4} \mathrm{~cm}$, bracteolac ovatae $2-6 \mathrm{~mm}$ longae. Flores $1 \frac{1}{4}-1^{3 / 4} \mathrm{~cm}$ diametro. Sepala lanceolata glandulas oblongas $1^{1} / 2-3 \mathrm{~mm}$ longas $1^{1 / 2}-3 \mathrm{~mm}$ superantia. Petalorum limbus late ovalis usque. $5-6$ (quinti saepins basi glanduloso-fimbriatus $3-4$ ) $\mathrm{mm}$, unguis $2-3 \mathrm{~mm}$ longus. Styli modice curvati. Samarae ala $3 \frac{1}{2} \mathrm{~cm}$ longa et $2 \frac{\mathrm{cm}}{\mathrm{c}}$ lata, uux usque $2 \mathrm{~cm}$ longa, $1 \mathrm{~cm}$ alta et $2 / 3 \mathrm{~cm}$ lata. - Malpighia reticulata Poir. - Columbia (Triana: Isthm. de San Pablo, prov. Choco, $100 \mathrm{~m}$; Sonntag 38: Castañal); Guiana anglica (Rich. Schomburgk 82 et 15̆17: ad ripam fl. Barama; Jenman ว244: Mayaruni); Guiana batava (. . . : herb. Vahl in herb. Hauniensi; Hostmann 531 et s. n. [in herb. Berol.]; Wullschlägel 916: e regione Saramana); Guiana gallica (... [herb. Jussieu]: Cayenne; Martin; Sagot 93: Karouany; Leprieur 306; Mélinon a. 1863 et 1864; Jelski: Cayenne); Amazonas (Poeppig 2645 [Banisteria grandis]: in cultorum versuris prope Ega).

74. H. reticulata (Poir.) Ndz.

†† Frutex scandens, ramulis 上 compressis rufo-subsericeis, ramis teretibus glabratis rufocinereis lenticellisque magnis grosse tuberculatis usque $4-5 \mathrm{~mm}$ diametro, internodiis 2-6 cm longis. Folia e basi rotunda s. \pm cordata ovato- s. ovali- s. obovato-oblonga usque $2^{1 / 4} \mathrm{dm}$ longa et $1 \mathrm{dm}$ lata, margine revoluta, nervis primariis utrinque $6-10$, acumine $1 / 4-1^{1 / 2} \mathrm{~cm}$, petiolo $1 / 2-1$ cm longo. Racemi usque $2 \mathrm{dm}$ (pedunculo incl.) longi usque 30-flori axillares terminalesque, plerique solitarii, rarius pauci in panicnlas bracteiferas dispositi, pedunculis cujusque ordinis canaliculatis, floriferis $3-5$, pedicellis $5-8$ $\mathrm{mm}$, bracteis bracteolisque ovato-obtusis $4-7$ resp. 3-5 mm s. raro pro bracteis infimis foliolis usque $2 \mathrm{~cm}$ longis. Flores $1^{1 / 2} \mathrm{~cm}$ diametro. Sepala ovata s. lanceolata glandulas ovales oblongasve $1^{1 / 4}-3 \mathrm{~mm}$ longas $1-3 \mathrm{~mm}$ superantia. Petalorum limbus orbicularis (quinti basi cordatus) creuulatus $\pm 4 \mathrm{~mm}$, unguis $3 \mathrm{~mm}$ longus. Styli praecipue 2 laterales - valde $s$-formi-curvati. Samarae viridi-purpureae: nux valde a lateribus compressa usque $1 \mathrm{~cm}$ longa altaque et vix $4 \mathrm{~mm}$ lata; ala usque $3^{1 / 2} \mathrm{~cm}$ longa et $2 \mathrm{~cm}$ lata nucis marginem dorsalem paulo amplectens, margine inferiore valde redunco. - H. Jussieui Hook. f. - Africa occidentalis secundum litus maritimum a Senegambia usque ad H. Congo.

75. H. afiricana Juss. ${ }^{46}$.

46) Bunisterine Leonae Cav. figura hanc speciem non quadrat. 
var. $\alpha$. borealis Ndz.: Pedunculis cujusque ordinis magis canaliculatis; sepalis ovatis s. lanceolato-ovatis glandulas ovales $1-2^{1 / 2} \mathrm{~mm}$ longas $1-2 \mathrm{~mm}$ superantibus; petalis magis recurris; staminibus vix exsertis; stylis $2-3 \mathrm{~mm}$ longis.

f. 1. senegalensis Ndz.: Sepalis ovatis glandulas $1-2 \mathrm{~mm}$ longas $1-2 \mathrm{~mm}$ superantibus; stylis $2 \mathrm{~mm}$ longis. - Senegambia (Heudelot: Rio Nunez).

f. 2. nigritiana Ndz.: Sepalis ovatis s. lanceolato - ovatis glandulas $1^{1 / 2}-2^{1 / 2} \mathrm{~mm}$ longas 1-2 mm superantibus; stylis $3 \mathrm{~mm}$ longis. - Nigritia (Man $\mathrm{n} \mathrm{462).}$

var. $\beta$. australis Ndz.: Pedunculis cujusque ordinis paulo tantum canaliculatis; sepalis lanceolatis glandulas oblongas $2-3 \mathrm{~mm}$ longas $2^{1 / 2}-3^{1 / 2} \mathrm{~mm}$ superantibus; petalis minus recurvis; staminibus longius exsertis; stylis 4-5 mm longis. - Kamerun (Preusis 282: Barombi s. ripa borealis fl. Kribi; Zenker 1107: Bipinde; Holland 147: Bonny); Monrovia (Naumann 49' [5. VHI. 1874]: in nemoribus); Congo (Büttner 181: ad ripam sinistram fl. Congo infra insulam Lone; Buchholz X. 1874 et VI. 1875: in nemoribus regionis siccae).

2. Liana (?) ramulis compressis rubiginoso- s. ferrugineo-subsericeis, ramis teretibus glabratis schistaceis lenticellisque tuberculatis usque $2 / 3 \mathrm{~cm}$ diametro, internodiis $2-4(1-7) \mathrm{cm}$ longis. Folia e basi obtusa s. rotundata s. subcordata lanceolata \pm longius acuminata, 4-14 cm longa, $1^{1 / 2}-5^{1 / 2} \mathrm{~cm}$ lata, margine revoluta, petiolo $1 / 2-1 \mathrm{~cm}$ longo; floralia bracteiformia. Racemi usque $1 \mathrm{dm}$ (incl. pedunculo) longi usque 20-flori dispositi in paniculas, pedunculis floriferis $上$ divaricatis $1-4 \mathrm{~mm}$, pedicellis $3-5 \mathrm{~mm}$, bracteis bracteolisque ovatis plerisque subtus 1 - $\mathrm{s}$. 2 -glanduliferis $2^{1 / 2}-5$ resp. $2-3 \mathrm{~mm}$ longis. Flores $1^{3 / 4} \mathrm{~cm}$ diametro. Sepala lanceolata glandulas 8 ovales s. ovali-oblongas $2-21 / 2 \mathrm{~mm}$ longas $\pm 2 \mathrm{~mm}$ superantia. Petala \pm erecta, limbo suberenulato late ovali s. suborbiculari $5-7$ (quinti basi cordato 4) $\mathrm{mm}$, ungui \pm directo $2-4 \mathrm{~mm}$ longo. Stamina omnia - praecipue 3 antica interna (,oppositisepala“) - gracilia longeque exserta, sicut styli valde $\varsigma$-formi-curvati et dorso apicis breviter tantum uncinati, gynixo ipso breviter rostratim producto. Samarae rufo-pubescentes flabellato-venosae: nux horizontalis $1 \mathrm{~cm}$ longa $6 \mathrm{~mm}$ alta $4 \mathrm{~mm}$ lata, arecla ventrali obtusato-subtriangulari $5 \mathrm{~mm}$ alta; al a semicirculum superans paulo ultra $2 \mathrm{~cm}$ longa et fere $1 \frac{1}{1 / 2} \mathrm{~cm}$ lata nueis dorsum longe a mplectens, margine inferiore valde redunco. - Amazonas (Poeppig s. n.: Ega; Spruce 1092 [XU. 1850-III. 1851]: in vicinibus Barra; . . . . herb. Schwaegrichen [ded Hiendlmayr]); Pará (Spruce 247: in ricinibus Santarem). 76. H. helicina Griseb.

\section{Addenda.}

1. pag. 5. post lineam 9. adde:

var. $\gamma$. andina Ndz.: Formae 1. tomentosae varietatis $\alpha$. typicae similis, attamen foliis \pm oblongis nsque $7^{1 / 2} \mathrm{~cm}$ longis et $3^{1 / 2} \mathrm{~cm}$ latis, petiolo usque $1-1^{1 / 4} \mathrm{~cm}$ longo infra apicem glandula 1 sessili s. rarissime breviter stipitata instructo. - Peruvia (Ruiz a. $179 \pm$ [Banisteria glandulosa resp. H. rubiginosa in sched. herb. Berol.]: ad Pulca); Bolivia (Bang 219? [15. V. 1894]: Coripati, Yungas).

2. pg. 5. post speciem H. Beecheyanam inserenda esse videtur speeies quaedam, cujus specimen unicum tantum idque valde mancum atque gemmiferum mihi suppetit:

Ramuli rufo-subsericei, internodiis $1-4 \mathrm{~cm}$ longis. Folia ovalia („oblongo-ovata") apice obtuso s. rotundo vix mucronulata usque $5^{1 / 2} \mathrm{~cm}$ longa et $3 \mathrm{~cm}$ lata, margine subplana, novella utrinque rufo-subsericea, adulta supra glabrata, subtus puberula et serie glandularum obsoletarum margini \pm parallela notata, petiolo puberulo usque $2 / 3 \mathrm{~cm}$ longo. „Paniculae in ramis ramulis- 
que terminales maxima parte umbellis quadrifloris compositae, pedunculi diversorum ordinum fer rugineo-rufescentes, floriferi subnulli, pedicelli semipollicares. Calyx ferrugineus 8-glandulosus." Petalorum limbus e basi sagittata suborbicularis, nervo extrorsum prominente. ${ }^{*}$ Styli breves apice triangulari-obtusi. Samara ...-Banisteria Quapara $\beta$. mucronulata D. C. - Soledad (Bertero).

1a. (\%\%.) H. Berteroana Juss. 3. pg. 8. lin. 6. post , $14568^{*}$ adde: et $18943 \mathrm{~b}$ [foliis etiam subtus subglabratis].

\section{Species incertae sedis. ${ }^{47}$}

1. (78.) H. biglandulosa Juss. l. c. ๖. 30.- Guiana gallica.

2. (79.) H. Brasiliensis Rgi. et Koern. in Ind. sem. h. Petr. 1858 p. 47. - Brasilia.

3. (80.) H. Ioniceraefolia Pl. et Fr. in Ann. sc. nat. 1V. sér. t. XVIII. pg. 324. - Columbia.

4. (81.) H. Mathewsiana Juss. in Arch. du Mus. III. p. 4う்4. n. 29. - Peruvia.

5. (82.) H. orinocensis (H. B. K.) Juss. 1. c. p. 462. 11. 43. - Banisteria? orinocensis H. B. K. Nov, gen. V. 162 (resp. 125). - Venezuela.

6. (S3.) H. scandens Rgl. et Koern. l. c. p. 46.

7. (84.) H. undulata Ten. in hort. bot. Neap. 1840 (Koch bot. W. Schrift 1860 p. 111.)

\section{Species (s. varietates) e genere Heteropteryge excludendae.}

1. H. aceroides var. angustata Griseb. (Glaziou 1590) in Vid. Medd. 1875 pg. 137 est Tetrapterys.

2. H. aceroides var. pachyphylla Griseb. (Glaziou 6105) 1. c. est Tetrapterys.

3. H. anoptera e Griseb. (Spruce 768: in vicinibus Santarem) est Tetrapterys.

4. H. bicolor Juss. in Fl. Bras. mer. III. pg. 23 est Tetrapterys; ef. supra pg. 24. not. 21.

5. H. ? cinerascens Bth. in London journ. bot. VII. pg. 131 est Banisteria.

6. H. ? cornifolia (Sprg.) H. B. K. in Nov. gen. V. p. 165 (resp. 127) (cf. n. 81. in Arch. du Mus. III. pg. 481) re vera Banisteria est.

7. H. ilicifolia Griseb. in Linn. XII. p. 220 (cf. n. 12 in Arch. du Mus. III. p. 443) est Tetrapterys.

8. H. Leschenaultiana var. Barboziann Griseb. in Fl. bras. XII. I. pg. 61 e specimine authentico hertarii Bruxellensis est Tetrapterys; cf. supra pg. 38. not. 31.

9. H. oleifolia (Bth.) Griseb. in Linn. XXII.pg. 19 (= Hiraea oleifolia Bth. in Lond. journ. bot. VI. pg. 136) est Mascagnia.

10. H. (?) parvifolia (Vent.) D. C. in Prodr. I. pg. 591. n. 2. = H. parviflora e Griseb. in Fl. of Brit. W. I. Isl. p. 119. n. 34. est Stigmatophyllon emarginatum f. 2. parvifolium.

11. H. racemosa Juss. in Arch. du Mus. IlI. pg. 445. n. 15. est Mascagnia.

12. H. stannea Griseb. in Vid. Medd. 1852 pg. 46. n. 17. est Hiraea.

13. H. ternstroemiifolia Juss. in Arch. du Mus. III. pg. 444. n. 14. est Banisteria Fischeriana Rgl. et Körn.

14. H. Warmingiana Griseb, in Vid, Medd. 1875 pg. 135 est Mascagnia.

47) Speciminibus originariis mihi non suppetentibus et descriptione imperfecta nil certi affirmari licet. 

